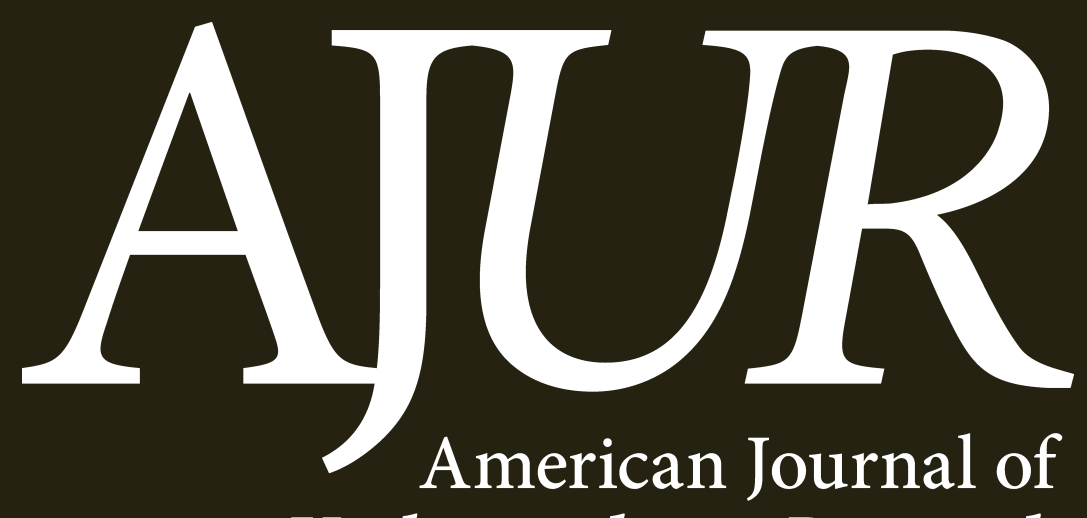
Undergraduate Research

Volume 14 | Issue 1 | April 2017

www.ajuronline.org 


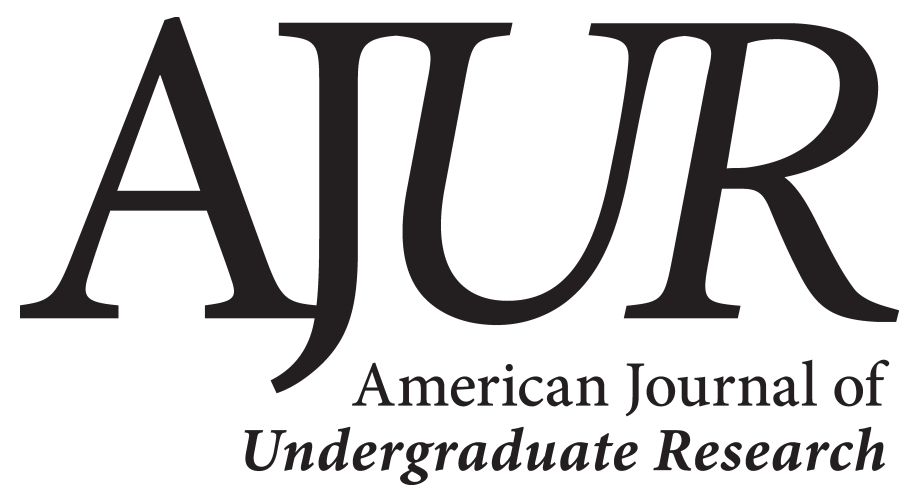

Volume 14 | Issue 1 | April 2017

www.ajuronline.org

2

3

5

11

17

25

35

49

61

AJUR History and Editorial Board

Special Thanks to AJUR's Sponsors

Identifying Issues Surrounding First Generation Students

Lena Rubio, Candi Mireles, Quinlan Jones, \& Melody Mayse

A Comparative Analysis of the Fitness of Collegiate Dancers as compared to Collegiate Volleyball and Softball Players Leanna Miller \& Fred L. Miller III

Adaptation of Esherichia coli to Antiobiotic Cycling via Single Nucleotide Polymorphisms

Samuel E. Hager, Ellen Jensen, Timothy J. Johnson, \& David Mitchell

Constructing the Imaginative Bridge: Third-Generation Holocaust

Narratives

Megan Reynolds

Mathematical Modeling Analysis to Simulate the Dynamics of Immune Cells, HIV, and Tuberculosis

Rumana Abmed \& Mabbubur Rabman

Gender and Sexuality in Medieval Islamic Mysticism: A

Comparative Study of Ibn 'Arabi and al-Ghazali

Emily Dovel

Breaking the Chain of Silence: Political Activism and Social Justice in Omar Offendum's Syrian-American Hip-Hop

Harry Olafsen, Mohammed Ali, Mikayla McCord, \& Dr. Roxana Cazan 
American Journal of Undergraduate Research (AJUR) is a national, peer-reviewed, open-source, quarterly, multidisciplinary student research journal. It is indexed internationally by EBSCO, and is listed via the Library of Congress under ISSNs of 1536-4585 (for print) and 2375-8732 (for web). The journal was established in 2002.

EDITORIAL TEAM Volume 14 / Issue 1 / April 2017

Dr. Kestutis G. Bendinskas, Editor, editor@ajuronline.org

Dr. Anthony Contento, Technical Editor

Rose Throop, Print Shop Liason

Daniel Laird, Web Master

Dr. Bonita Graham, LaTex and Copy Editor

EDITORIAL BOARD by subject area

ACCOUNTING

Dr. Dean Crawford,

dean.crawford@oswego.edu

\section{ART HISTORY}

Dr. Lisa Seppi,

lisa.seppi@oswego.edu

ASTROPHYSICS

Dr. Shashi Kanbur,

shashi.kanbur@oswego.edu

BEHAVIORAL NEUROSCIENCE

Dr. Aileen M. Bailey,

ambailey@smom.edu

BIOCHEMISTRY

Dr. Pamela K. Kerrigan,

pamela.kerrigan@mountsaintvincent.edu

BIOENGINEERING

Dr. Jorge I. Rodriguez,

jorger@clemson.edu

BIOINFORMATICS

Dr. Kevin Daimi,

daimikj@udmercy.edu

Dr. John R. Jungck,

jungck@udel.edu

Dr. Isabelle Bichindaritz,

ibicbind@oswego.edu

BIOLOGY, PHYSIOLOGY

Dr. David Dunn,

david.dunn@oswego.edu

BIOLOGY, DEVELOPMENTAL

Dr. Poongodi Geetha-Loganathan,

p.geethaloganathan@oswego.edu

\section{BIOLOGY, MICROBIOLOGY}

Dr. Peter Newell,

peter.newell@oswego.edu

\section{BOTANY}

Dr. William R. Bromer,

wbromer@stfrancis.edu

Dr. Julien Bachelier,

julien.bachelier@oswego.edu

\begin{abstract}
CHEMISTRY
Dr. Alfredo Castro,

castroa@felician.edu

Dr. Charles Kriley,

cekriley@gcc.edu

Dr. Douglas Mulford,

douglas.mulford@emory.edu

Dr. Mark A. Benvenuto,

benvenma@udmercy.edu
\end{abstract}

COMMUNICATION DISORDERS

AND SCIENCES

Dr. Kim Tillery,

Kim.Tillery@fredonia.edu

COMMUNICATION STUDIES

Dr. Jennifer Gerometta,

jgerometta@iona.edu

COMPUTER SCIENCES

Dr. Dele Oluwade,

deleoluwade@yahoo.com

Dr. Kevin Daimi,

daimikj@udmercy.edu

Dr. Levent Ertaul,

levent.ertaul@csueastbay.edu

Dr. Mais W Nijim,

Mais.Nijim@tamuk.edu

COMPUTATIONAL CHEMISTRY

Dr. Alexander Soudackov

asouda@illinois.edu

ECOLOGY

Dr. William R. Bromer,

wbromer@stfrancis.edu

ECONOMICS

Dr. Elizabeth Schmitt,

elizabeth.schmitt@oswego.edu

EDUCATION

Dr. Marcia Burrell,

marcia.burrell@oswego.edu

EDUCATION, PHYSICS

Dr. Andrew D. Gavrin,

agavrin@iupui.edu

ENGINEERING, ELECTRICAL

Dr. Michael Omidiora,

michael.omidiora@nyu.edu
ENGINEERING, ENVIRONMENTAL

Dr. Eileen M. Cashman,

eileen.cashman@bumboldt.edu

ENGINEERING, MANUFACTURING AND CONSTRUCTION, ROBOTICS

Dr. Haoyu Wang,

wanghao@mail.ccsu.edu

ENGINEERING, SOFTWARE

Dr. Kevin Daimi,

daimik.j@udmercy.edu

ENVIRONMENTAL SCIENCE

Dr. Eileen M. Cashman,

eileen.cashman@bumboldt.edu

\section{GEOLOGY}

Dr. Larry Davis,

ldavis@csbsju.edu

HISTORY

Dr. Richard Weyhing,

richard.weybing@oswego.edu

Dr. Murat Yasar,

murat.yasar@oswego.edu

HONORARY EDITORIAL BOARD MEMBER

Dr. Lorrie Clemo,

lorrie.a.clemo@gmail.com

KINESIOLOGY / EXERCISE SCIENCE

Dr. David Senchina,

david.senchina@drake.edu

LITERARY STUDIES

Dr. Douglas Guerra,

douglas.guerra@oswego.edu

\section{MATHEMATICS \\ Dr. John Emert, \\ emert@bsu.edu}

Dr. Jeffrey J. Boats,

boatsjj@udmercy.edu

Dr. J.D. Phillips,

jophilli@nmu.edu

Dr. Dele Oluwade,

deleoluwade@yahoo.com
Dr. Christopher Baltus, christopher.baltus@oswego.edu

Dr. Mark Baker,

mark.baker@oswego.edu

MEDICAL SCIENCES

Joan Newell, MD

joannewellmd@gmail.com

METEOROLOGY

Dr. Steven Skubis, steven.skubis@oswego.edu

MUSIC

Dr. Juliet Forshaw,

juliet.forshaw@oswego.edu

NANOSCIENCE AND CHEMISTRY

Dr. Gary Baker,

bakergar@missouri.edu

NEUROSCIENCE

Dr. Pamela E. Scott-Johnson, pamela.scottjobnson@morgan.edu

Dr. Amy Overman,

aoverman@elon.edu

PHYSICS

Dr. Carolina Ilie, carolina.ilie@oswego.edu

Dr. Mohammad Islam,

mohammad.islam@oswego.edu

POLITICAL AND SOCIAL SCIENCES

Dr. Dean Dohrman,

dean.dobrman@csuglobal.edu

PSYCHOLOGY

Dr. Amy Overman,

aoverman@elon.edu

Dr. Pamela E. Scott-Johnson,

pamela.scottjobnson@morgan.edu

STATISTICS

Dr. Mark Ecker,

mark.ecker@uni.edu

TECHNOLOGY, ENGINEERING

Dr. Recayi Pecen,

regpecen@na.edu 


\section{SPECIAL THA N KS}

AJUR is made possible through the assistance of our sponsors.

Support for this issue has been provided by Wiley as well as the Office of the Provost at

the State University of New York at Oswego. Thank you!
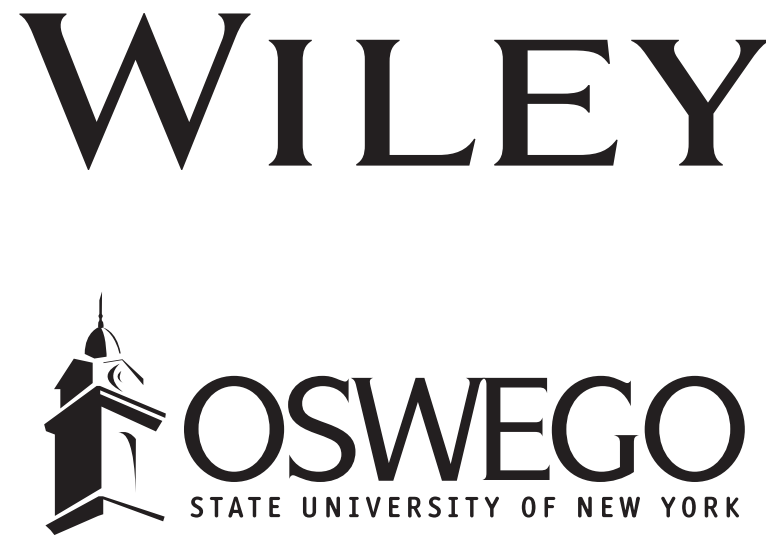

Interested in supporting quality undergraduate research?

Request sponsorship information at editor@ajuronline.org 


\title{
Identifying Issues Surrounding First Generation Students
}

\author{
Lena Rubio, Candi Mireles, Quinlan Jones, \& Melody Mayse \\ Social Work Department, Tarleton State University \\ Students:lena.rubio@go.tarleton.edu*,candi.mireles@go.tarleton.edu,quinlan.jones@go.tarleton.edu,melody.mayse@go.tarleton.edu \\ Mentor:ehall@tarleton.edu
}

\begin{abstract}
First-generation students compose a subpopulation within the institution of higher education, which exhibits its own set of resources in areas such as academic preparation, support systems, family background, and finances to apply to education. This quantitative study examined gaps and barriers to resources currently available to assist the population. The researchers utilized four pre-developed demographic questions along with a 34-item survey instrument assessing the experiences of first generation students, to gather the data presented in the study. The analysis involved coding and elementary data analysis of demographics and reporting frequencies. The 200 participants in the study identified as first-generation students at four-year universities within the United States. The majority of the participants surveyed were white $(69.5 \% ; \mathrm{n}=139),{ }^{1}$ between the ages of 17 and $26(94.5 \%$; $\mathrm{n}=189)$, and from families within the middle-class income bracket of $(39.5 \% ; \mathrm{n}=79)$. The results indicated that most common barrier to participants attending college was tuition-cost $(63 \% ; n=126)$, followed by a lack of information about a college, such as financial aid availability and required documents $(34.5 \% ; n=69)$. Over $64 \%(n=129)$ received support or guidance from support networks in the form of parents and/or guardians. The study provided information about the issues encountered by firstgeneration students, as well as the accessed support networks, and preferred resources.
\end{abstract}

\section{KEYWORDS}

First-Generation Student; College Retention; Academic Preparation; Financial Assistance; Support Systems

\section{INTRODUCTION}

Identifying Issues Surrounding First-Generation Students

First-generation students compose a distinct population within the higher education system with their own set of needs. They are "traditionally defined as students whose parents did not attend college and have a high school education or less."1 These students are without parents who are knowledgeable of the adjustment process and have very few role models to guide them through the process of achieving higher education. ${ }^{2}$ The needs and concerns expressed by first-generation students throughout their educational career reveal the additional barriers of being the first in their family to embark on the path towards higher education compared to generational college students.

The educational experience of first-generation students and the issues encountered are similar to their classmates, however, they "typically lack the traditional support networks available to their peers whose parents earned degrees." 3 The absence of this support network often leads first-generation students to navigate through the college system on their own and without the guidance needed. Their parents or guardians have limited knowledge about completing a college degree. Several community and academic institutions have developed various programs and services for students to assist in their degree completion. Resources such as college readiness sessions are made available to assist and guide students in overcoming the issues associated with not successfully completing college. However, first-generation students have continuously demonstrated low rates of degree completion compared to their non-first-generation peers. ${ }^{3}$

Appropriate intervention strategies to assist first-generation students with their degree completion can be developed by identifying issues they encounter during their college career. First-generation students are not accessing available resources compared to other students. ${ }^{2}$ The rate of resource utilization is influenced by issues they encounter during their college careers, such as having a limited support system, poor academic preparation, and little financial assistance. ${ }^{2}$

\section{Social Capital Theory}

Social support networks and relationships have been identified as common themes in the literature concerning first-generation students and degree completion. Social Capital Theory focuses on social relationships and networking within a social situation and it refers to "the value of a relationship with another person that provides support and assistance in a given social situation." 4

\footnotetext{
${ }^{1}$ Several participants identified by more than one race: Hispanic $(34.5 \% ; n=69)$, and African American $(15 \%$; $n=30)$.
} 
Furthermore, "the central premise of social capital is that social networks have value."5 This theory applies to first-generation students and provides a connection between social support and accessing resources.

First described by Pierre Bourdieu in 1980, Social Capital Theory provides an understanding of the importance of social support and its relationship to higher education. Social capital in the form of social support is a factor first-generation students lack, as they are without the support of parents who have completed higher education, while "non-first-generation college students arrive in college with social capital in the form of college knowledge derived from family members that aids them in navigating the institution and generating additional beneficial social capital." 4 First-generation students are without social capital in the form available to non-first-generation students and must gather it from alternative social support systems. They have a disadvantage compared to their peers, which leads to greater deficiencies in social capital and culminates in a generational stagnation. ${ }^{4}$ They must rely on support from others: alternative family members, peers, faculty, staff, and educators within the system of higher education. By creating these support systems, through social capital, they are provided with the guidance and assistance necessary to aid them in adjusting throughout the process of higher education.

Social support also facilitates social networking, which provides an opportunity for first-generation students to gain awareness of existing services and resources. According to Moschetti \& Hudley, through social networks students can attain information and guidance as well as "emotional support that encourages a perception that the social, physical, and academic environments are negotiable and enables students to cognitively manage their new surroundings." 4 In addition, Social Capital Theory highlights that through relationships social capital can provide "encouragement and information about personal or academic decisions."4 Assistance with academic decisions and coursework are among the needs of first-generation students during their degree completion.

Social Capital Theory emphasizes the need for social support in aiding first-generation students in higher education. Alternative social support systems are necessary to provide the guidance that first-generation students lack. Social capital increases the ability of students to access resources through social networking. Social networking can create additional awareness and provide the information needed to navigate and locate resources for all students.

\section{Literature Review}

Several studies reported an increased amount of first-generation students attending college within the past twenty years. First generation college students represented 20\% of first-year college students in 1992 compared to 30\% in 2001.3,6 Furthermore, within the last ten years, an average of one out of two students attending community college and one of every three students attending a four-year college were first-generation students. ${ }^{7}$ Despite these growing numbers, first-generation students are "nearly four times more likely to leave higher education after the first year than non-first-generation students." 8 In comparison to their non-first-generation counterparts in undergraduate studies, they are also more likely to have lower grade point averages and are less inclined to complete their degrees. ${ }^{9}$

\section{Academic Performance and Preparation}

Other studies reported issues for first-generation students in areas such as "educational persistence, precollege academic preparation, and financing their college education." In the area of academic performance and preparation, first generation students are entering the college atmosphere with a lack of academic preparation or educational resilience as they are realizing "their high school curriculum was less than rigorous and that the academic expectations inherent in baccalaureate programs can be somewhat overwhelming, resulting in self-doubt." 2 Through the use of regression analyses, systematic reviews, and demographic observations, studies conclude the transition from high school to college is an experience that leads to issues throughout their educational career.

\section{Financing Education}

First generation students also experience difficulties financing their education. Their families are more likely to be in the lowest income quartile and, as a result, are without the option of financial freedom, which contributes to the frequent need of loans to pay for college and other college-related expenses. ${ }^{10} \mathrm{~A}$ study by Coffman determined "low income levels strongly influence factors such as having a support network, college debt, and degree completion."10 This study highlights the impact and influence financial difficulties have on degree completion for this group. Financial difficulty is one of the issues first generation students encounter as a "lack of financial support and subsequent loan indebtedness may affect chances of college success."11

\section{Support Systems and Family Background}

Support systems and family background dictate the guidance first generation students receive. Coffman reports one issue encountered in achieving higher education, while being the first to attend college in one's family, is that family background can exert influence over educational decisions related to academic preparation, time management, and performing the student role. ${ }^{\mathbf{1 0}}$ 
First-generation students do not have family members who have attended college and enter the college atmosphere with little knowledge on how to navigate the higher education system. ${ }^{1}$

The barriers first-generation students encounter must be addressed by higher education institutions. From the reported lack of traditional support from families and school systems,${ }^{3}$ to the lack of ability and motivation to utilize available campus resources, first-generation students enter the college system in an imbalanced state. Studies indicate the current barriers for first-generation students can be observed in a variety of forms such as limited support, resource utilization, role models, academic preparation, and financial knowledge.,2,10 Although many schools have implemented programs to address the academic gap between firstgeneration students and generational college students, increased efforts are beneficial to the well-being of first-generation students during their educational career. The aforementioned studies provide institutions of higher education with additional data to assist in the modification of existing programs or in the development or implementation of further strategies to encourage academic success by first-generation students.

Expanding on previous studies, we sought to obtain additional data describing students' awareness and utilization of available resources and information about resources being utilized by first-generation students. More specifically, we inquired about specific experiences and the impact of support systems on first-generation students. We posed the question, "What are the gaps and barriers in resources currently available to first generation students?" The objectives of the research include

$\mathrm{O}_{1}$ : identifying the areas in which first-generation students are exhibiting issues,

$\mathrm{O}_{2}$ : identifying whether first-generation students are utilizing available resources, and

$\mathrm{O}_{3}$ : identifying the presence or absence of a family, peer, or academic support system.

The following hypotheses were based on the identified barriers from previous studies.

$\mathrm{H}_{1}$ : First-generation students exhibit deficiencies in the areas of financial assistance, academic preparation, and support networks.

$\mathrm{H}_{2}$ : First-generation students are not utilizing resources.

$\mathrm{H}_{3}$ : First-generation students with less support from family, peers, etc. experience more difficulties in the areas of financial assistance, and academic preparation.

\section{METHODS AND PROCEDURES}

This research study identifies issues experienced by first-generation students and provides an increased understanding of the factors hindering program completion.

\section{Study Setting}

We identified participants at a four-year higher educational institution. The individuals surveyed were provided the option of completing the survey in one sitting or completing the survey later and returning it to the designated drop-off area.

\section{Participants and Sampling}

Participants were identified using a convenience sampling approach. The methods of recruitment included the locating potential participants across the university in common social areas and various college courses. Participants were 18 years of age or older and were currently enrolled as undergraduate or graduate students.

\section{Survey Instrument}

The research method utilized in the study consisted of 4 pre-developed demographic questions with a 34-item survey instrument assessing the experiences of first-generation students. The estimated period for completing the survey was between 15 and 45 minutes. Each individual surveyed met the requirements of the study: being 18 years of age or older, self-identification as a firstgeneration student, and enrollment at the university in which the study was being conducted. Individuals were provided a thorough explanation of the research topic, the qualifications for taking the survey, and the consent form before being allowed to participate. The research study utilized a quantitative approach with a sample size of 200 students, as is necessary for generalization and reliability. The utilization of a quantitative study minimized bias and maximized objectivity.

\section{Procedure}

The study received formal IRB permission prior to beginning the research.

We easily located first-generation students based on first-hand knowledge of programs and college courses they are associated with and involved in as students. This availability contributed to the convenience of sampling. The researchers were also able to modify and combine two surveys to meet the needs of the research study. 


\section{Ethical Considerations}

The ethical considerations involved in the research study included anonymity, voluntary participation, and informed consent. The study referred to the ethical considerations outlined in the core values of the National Association of Social Workers Code of Ethics. We utilized three values: integrity, competence, and dignity and worth of a person.

We upheld the value of integrity as they acted according to the ethics surrounding procedures of research. Integrity requires social workers to be “continually aware of the profession's mission, values, ethical principles, and ethical standards and practice in a manner consistent with them." 12 In addition, it requires social workers to act "honestly and responsibly and promote ethical practices on the part of the organizations with which they are affiliated."12

The social work value of competence requires social workers to "continually strive to increase their professional knowledge and skills and to apply them in practice." 12 Social workers are expected to contribute to the knowledge base by participating in activities that will enhance their skill set. We engaged in efforts contributing to the knowledge base surrounding the target population.

Valuing the dignity and worth of a person requires "social workers treat each person in a caring and respectful fashion, mindful of individual differences and cultural and ethnic diversity." 12 The researchers were deliberate and ethical in the way they treated the participants of the study, and they were respectful and mindful of the individuality of the participants.

We followed the ethical guidelines of informed consent by providing a consent form to the participants and verbally explaining the purpose of the research and the commitment entailed in participation. The ethical guideline of voluntary participation was followed by allowing the participants the option to withdraw from the study at any time. During the study, anonymity was observed because participants self-identified.

We took into consideration the concept of fairness in the distribution of surveys. Some participants questioned the reasoning for the researchers approaching him/her, which required an explanation of the importance of equal distribution when conducting research. We took efforts to ensure every potential participant received respect regardless of their participation in the research study. All participants were informed of minimal risks associated with the study: time and answering questions about the educational status of family members.

\section{RESULTS}

\section{Demographics}

A total of 200 total participants were surveyed. The majority of the participants were between the ages of 17 and $26(94.5 \%$; $\mathrm{n}=189)$. The identified races of participants were White $(69.5 \% ; \mathrm{n}=139)$; followed by Hispanic $(34.5 \% ; \mathrm{n}=69)$ and African American $(15 \% ; n=30)$. The most commonly indicated college class was freshman $(29 \% ; n=59)$, followed by senior $(23 \%$; $n=46)$, junior $(23 \% ; n=46)$, sophomore $(22.5 \% ; n=45)$, and graduate level $(2 \% ; n=4)$. Participants reported their perception of their family's economic status as middle class $(39.5 \% ; \mathrm{n}=79)$, lower middle class $(22.5 \% ; \mathrm{n}=45)$, working class $(15.5 \%$; $\mathrm{n}=31)$, uppermiddle class $(11.5 \% ; n=23)$, and long term poverty $(6 \% ; n=12)$. Parents' highest education level was most often reported as high school (9th through 12th grade) $(51.5 \% ; n=103)$ followed by some college attendance $(31 \% ; n=62)$, middle school $(5$ th through 8th grade) $(13.5 \% ; n=27)$, and elementary school (kindergarten through 4 th grade) $(4 \% ; n=8)$.

\section{Analysis and Results}

The data supported two of the hypotheses.

$\mathrm{H}_{1}$ was supported and indicated that first-generation students experience difficulties in the areas of financial assistance, academic preparation, and support networks. Close to $70 \%(n=137)$ of participants reported financial barriers, and $40 \%(n=81)$ reported limited academic preparation. More specifically, participants reported obstacles of tuition cost $(63 \% ; n=126)$, and a lack of information about financial aid availability and required documents $(34.5 \% ; n=69)$.

The first hypothesis also stated that first-generation students would have difficulty with support networks. Although the calculation of the results revealed that participants received encouragement and support, it primarily came from parents $(64.5 \%$; $\mathrm{n}=129)$, friends $(22.5 \% ; \mathrm{n}=45)$, other relatives $(19 \% ; \mathrm{n}=38)$, and siblings $(16.5 \% ; \mathrm{n}=33)$, with limited support from those with access to higher education resources such as high school teachers/counselors $(25 \% ; n=50)$. Some participants reported that their college did not provide support to them as first-generation students $(44.5 \% ; n=89)$, with the remaining participants reporting yes $(28 \% ; n=56)$, or unsure $(27.5 \% ; n=55)$. 
$\mathrm{H}_{2}$ stated that first generation students were not utilizing resources and this was confirmed in the results. They reported their school was not providing support to first generation students $(44.5 \%$; $=89)$, despite the availability of resources on campus. To close the gaps, participants could identify services that would have been most helpful to them during their freshman year. All of those mentioned were available at the institution. They were not aware of the resources, explaining the lack of resource utilization on college campuses.

$\mathrm{H}_{3}$ was inconclusive: first-generation students with less support from family, peers, etc. experience more difficulties in the areas of financial assistance, and academic preparation compared to first-generation students who indicated more support from family. The data revealed that despite the amount of support from a support system, participants were still experiencing issues with financial assistance and academic preparation. Participants have received support or guidance from support networks in the forms of parents/guardians $(64.5 \% ; n=129)$ followed by high school teachers/counselor $(25 \% ; n=50)$, friends $(22.5 \% ; n=45)$, other relatives $(19 \% ; n=38)$, siblings $(16.5 \% ; n=33)$, while only $5.5 \%(n=11)$ reported receiving support from no one. Due to the limited amount of participants who indicated not having support $(n=11)$, researchers could not support, nor reject the hypothesis.

Participants reported that they would have found support, information, or other services most helpful during their freshman year. The preferred form of this support would be financial guidance $(47.5 \% ; n=95)$, peer mentors $(40.5 \% ; n=81)$, faculty $/$ staff mentors $(39.5 \% ; \mathrm{n}=79)$, and tutoring $(36.5 \% ; \mathrm{n}=73)$. The data also revealed that most participants somewhat agreed $(41.5 \%$, $\mathrm{n}=83)$ that they were satisfied with their performance in their course work; followed by agreed $(40.5 \% ; \mathrm{n}=81)$, neutral $(9.5 \%$; $\mathrm{n}=19)$, somewhat disagree $(7 \% ; \mathrm{n}=14)$, and disagree $(1.5 \% ; \mathrm{n}=3)$.

The overall results identify resources, programs, and intervention strategies necessary to link first-generation students with the appropriate services. The findings support the researcher's predictions that first-generation students exhibiting issues in the areas of financial assistance, academic preparation, and support networks are not utilizing available resources.

\section{DISCUSSION}

The results indicated that most participants encountered various barriers during their college experience. This study provides valuable information about the issues encountered by first-generation students, as well as the importance of accessing support networks and resources. Overall, first-generation students exhibiting issues in the areas of financial assistance, academic preparation, and support networks are not utilizing available resources. They continue to experience difficulties in the areas of financial assistance, academic preparation, and academic support systems. These findings support previous studies and lend additional information specifically related to types of resources that would be helpful for students entering college. They also provide information to higher education institutions about the importance of transitioning first-generation students.

\section{Novelty of work}

The work provided novel information about the group as it highlighted the relationship between the issues experienced and access to available resources. The information collected also provided further insight into the issues encountered and the support utilized by first-generation students during their academic endeavors. In addition, the work in this study is directly related to the profession of social work and offers implications on the three levels of practice to assist professionals when working with firstgeneration students.

\section{CONCLUSION}

Social workers can provide resources, education, and guidance needed to incoming or current first-generation students, as well as the individuals, or institutions affiliated with them. The profession of social work has an obligation and responsibility to assist marginalized populations, such as first-generation students. Social workers can use this data to inform the common levels of social work practice (micro, mezzo, and macro).

On the micro level, social workers can directly assist first-generation students prior to their enrollment in higher education or while they are working towards their degree. The micro area of practice can be directed by the data analysis as the results indicate an unawareness of the available resources and services provided. The unawareness of on-campus services can also translate into an unawareness of similar resources possibly provided within the student's community or high school. By obtaining competence in common problem areas, social workers can be informed and prepared to identify areas requiring assistance. Social workers can interact with first-generation students to identify the areas they are exhibiting issues in and provide information about the resources and services available to assist them.

Social workers can provide assistance at the mezzo level by working with first-generation students and their families. The study identified commons issues experienced by first-generation students. This information can aid social workers in assisting families to develop a plan of action. The social worker can work with students and their families by assessing and planning various 
strategies to overcome issues that may affect graduation. They can also help involve the student's family, especially parents, in enhancing and building a supportive network for the student throughout their educational career. In addition, they can provide education to family members about the process of achieving higher education and the role parents can have in supporting, encouraging or empowering to the student.

Social workers can help at the macro level by becoming involved with programs, policies, or legislation surrounding firstgeneration students and the issues they encounter. They can advocate for or help develop new programs and policies within universities, high schools, or communities that aim to provide resources or services that may not be currently available. Social workers can advocate on behalf of the first-generation student population on a legislative level to provide additional funding to public institutions or communities for the creation of new programs, resources, or services. Furthermore, social workers can engage in further research to contribute to the expansion of the knowledge base and to provide the evidence needed to help develop and implement interventions within the system of higher education for first-generation students.

\section{POSSIBLE LIMITATIONS}

One limitation of this study was the participants' self-identification as first-generation students. Several participants were confused by the definition of "the first-generation student" and self-identified despite having college graduates as parents. This confusion was not calculated in the study as it led to the dismissal of several completed surveys and the need to locate additional participants that fit the correct definition of a first-generation student. The study did not contain a control group of generational college students making comparisons impossible. Although the sample size was 200 participants, the researchers did utilize a convenience sampling technique which affected the type of students who could participate based on time frames and areas in which researchers recruited.

Additional limitations of the study pertained to the length of the survey and the completion of surveys in a timely manner. Firstgeneration students are not required to self-identify as such while enrolling in college, which created a limitation in that we had to locate the participants by verbally asking a student to self-identify. The continuous recruitment of participants provided a limitation to timely data collection. The length of the survey provided another limitation to the study as many participants were reluctant or refused to complete the survey due to a number of pages and the corresponding time commitment. This contributed to the participant's unwillingness to complete the surveys in the time allotted by the researchers and the preference toward taking and completing the surveys later. The researchers were unable to find and gather the completed surveys from the participants who chose to leave and had to engage in recruitment efforts of additional participants through snowball sampling techniques.

\section{ACKNOWLEDGMENTS}

The authors thank the Social Work Department of Tarleton State University and the faculty mentors involved in facilitating this undergraduate research project. The authors also thank the voluntary participants of the study, as well as the community partner who also assisted with the process of the research study.

\section{REFERENCES}

1. Shelton, C. (2011) Helping first-generation college students succeed, Journal of Psychological Issues in Organizational Culture 1, 63. doi:10.1002/jpoc.20041.

2. Woosley, S. A., \& Shepler, D. K. (2011) Understanding the early integration experiences of first-generation college students, College Student Journal 45, 700-714.

3. Swecker, H. K., Fifolt, M., \& Searby, L. (2013) Academic advising and first-generation college students: A quantitative study on student retention, NACADA Journal 33, 46-53. doi:10.12930/NACADA-13-192.

4. Moschetti, R. V., \& Hudley, C. (2015) Social capital and academic motivation among first-generation community college students, Community College Journal of Research and Practice 39, 235-251.

5. Harvard University's Kennedy School of Government. (n.d.). Better together. Connect with others. Build trust. Get involved. Retrieved from www. bettertogether.org: http:/ / www.bettertogether.org/socialcapital.htm

6. Blackwell, E., \& Pinder, P. J. (2014) What are the motivational factors of first-generation minority college students who overcome their family histories to pursue higher education?, College Student Journal 45, 1.

7. McMurray, A. J., \& Sorrells, D. (2009) Bridging the gap: Reaching first-generation students in the classroom, Journal of Instructional Psychology, 3, 210.

8. Stebleton, M. J., \& Soria, K. M. (2012) Breaking down barriers: Academic obstacles of first-generation students at research universities, Learning Assistance Review 17, 7-20.

9. Olson, J. S. (2014), Opportunities, obstacles, and options: First-generation college graduates and social cognitive career theory, Journal of Career Development 41, 199-217.

10. Coffman, S. (2011) A social constructionist view of issues confronting first-generation college students, New Directions for Teaching \& Learning, 2011 127, 81-90. doi: 10.1002/tl.459 


\title{
A Comparative Analysis of the Fitness of Collegiate Dancers as compared to Collegiate Volleyball and Softball Players
}

\author{
Leanna Miller* \& Fred L. Miller III \\ Department of Kinesiology, Anderson University, Anderson, IN \\ Student: Imiller@anderson.edu* \\ Mentor:fmiller@huntington.edu
}

\begin{abstract}
Few studies directly compare the various fitness components of collegiate dancers and athletes in acknowledged sports. The limited studies that do exist fail to consider certain variables or to assess multiple fitness components. The purpose of this study was to provide a more comprehensive comparison of collegiate dancers and collegiate volleyball and softball players. We used multiple fitness components as an indicator of the comparative physical demands of these activities, to assess whether the physical demands of collegiate dance may warrant a comparable level of medical support as afforded to the volleyball and softball players. Thirty dancers and thirty volleyball and softball players were tested using six different measurements of physical fitness commonly used in athletic assessments at universities. A two-tailed independent $t$-test was performed to determine differences between dancers and athletes in each fitness component. Three tests revealed significant differences between the groups, with the dancers having a lower percent body fat and greater flexibility, and the athletes having greater relative upper body strength. No significant differences were found in relative leg strength, core strength, or estimated $\mathrm{VO}_{2 \max }$. The results of the current study suggest that dance provides training adaptations equivalent to traditional intermittent sports and thus support the use of similar levels of medical care for collegiate dancers to that afforded to collegiate volleyball and softball players.
\end{abstract}

\section{KEYWORDS}

Physical Fitness; Dance; Dance Medicine; Athletics; Dance Health Benefits

\section{INTRODUCTION}

According to statistics provided by the National Dance Education Organization, there are approximately 665 postsecondary institutions offering dance major and minor programs in the United States. There is a recent trend to use dance to achieve fitness. Dance causes training adaptations, but to what extent does a collegiate level, semi-professional dancer experience training adaptations in comparison to a collegiate athlete? There are numerous studies that show dance to be an effective fitness modality, as it improves muscular strength and endurance, cardiorespiratory health, flexibility, and body composition in an enjoyable and creative manner. 1, 2, 3,4 These studies focus on the fitness benefits of dance training among at-risk adolescents and previously sedentary women, and they do not provide meaningful insight into the benefits and demands of collegiate level dance. Other studies have focused on a demographic and activity level more appropriate for analyzing collegiate dance, but are incomplete or limited in many aspects.

Several previous studies contrasted the fitness gains between genres of dance, suggesting that the athletic demands of dance can differ, but participation in many styles of dance can result in good aerobic fitness. ${ }^{1,2}$ Other studies confirmed that fitness levels vary amongst dancers of different styles. Studies that tested the aerobic fitness of professional contemporary and modern dancers compared to that of professional ballet dancers showed the contemporary and modern dancers to have higher maximal oxygen uptake, lower blood pressure, resting heart rates, and peak heart rate than ballet dancers. ${ }^{2,5}$ The researchers hypothesized that the difference between genres is largely due to the tendency for modern dance numbers to be lengthier than ballet numbers, as well as to the decreased stigma against cross-training for modern dancers in comparison to ballet dancers. ${ }^{5,6}$ Other studies examined muscular strength differences between dancers of different genres. Ballet dancers did not show muscular strength significantly above average fit individuals, but modern dancers had muscular strength similar to that of other traditional athletes. The ballet dancers had lower BMIs than many traditional athletes however, and showed greater flexibility. ${ }^{7}$ Similar studies found that some muscle groups display similar levels of strength in dancers as in athletes, but other muscular strength measurements can be more comparable to those of sedentary individuals, despite the dancers participating in more than five times the amount of physical activity as the non-dancer sample group. 8,9 This may be related to the common practice of dancers to avoid cross-training for fear that cross-training would limit dance ability. 5,8 This lack of comprehensive exercise prompted some professional dancers to have similar results on certain fitness components to sedentary individuals. With proper cross-training, not only did overall fitness of the participating dancers improve, but also the number of injuries was reduced. ${ }^{7}$ These results suggest that the most physically fit dancers are trained in several styles, as well as cross-train to correct muscle imbalances. ${ }^{7,8}$ 
Other discussions addressed the limitations of muscular performance due to the aesthetic nature of dance. One such study suggested the variability in muscle strength was partially due to the importance of aesthetic in dance. The focus of the dancer is not maximal force production, but rather on controlling the force to obtain a certain aesthetic. ${ }^{2,8}$ Researchers suggested that improved muscular strength and endurance also improve coordination, which will yield aesthetic performance improvements. However, there is little research investigating the correlation between increased fitness parameters and aesthetic performance. ${ }^{10}$ Measurements of aesthetic competence are less clearly defined as measurements of fitness, confounding research in aesthetic improvements associated with athletic gain. Further research is needed to find relationships between fitness components and aesthetic performance. If a correlation between a specific fitness component and improved aesthetic performance could be found, dancers could undergo supplementary conditioning focused on that particular fitness component. The same principles used by sports scientists to identify the component of fitness that best improves athletes of a specific sport can be applied to analyze dance performance, with slight modifications to the scales used to analyze performance.

The purpose of this study was to provide a direct comparison of collegiate dancers to traditional collegiate athletes to identify the similarities and differences in the athletic demand of their sports. This was accomplished by comparing the five health-related fitness components of female collegiate dancers and conventional female collegiate athletes, utilizing standard tests commonly used in fitness assessments for collegiate athletes. The direct comparison of body composition, muscular endurance, muscular strength, flexibility, and cardiorespiratory endurance provides insight into the physical demands of dance compared to the physical demands of traditional sports.

\section{METHOD}

\section{Participants}

The participants were college-age females $(\mathrm{n}=60)$ selected from a Midwestern university. Thirty dance majors and thirty traditional athletes in softball or volleyball were tested. The dancers trained for a minimum of five hours a week. They trained in three primary dance techniques - modern, ballet, and jazz - regularly to ensure that they exhibited the fitness gains from multiple styles. The traditional athletes had an active status on either the varsity volleyball or the varsity softball team. At the time of testing, the volleyball players were in-season, and the softball players were nearing the end of preseason training.

\section{Procedures and Instruments of Analysis}

The study compared the fitness of 30 female collegiate dancers to that of 30 traditional collegiate female athletes involved in softball or volleyball. The study included measurements of body composition, cardiovascular endurance, flexibility, muscular endurance, and muscular strength.

By using athletes whose sports have similar aerobic demands to those of dance, it was hoped that the variability of aerobic capacity would be reduced. Muscle strength tests encompassed several muscle groups to provide a more accurate overall assessment of strength. It was hypothesized that the sample group of dancers would display similar fitness levels to the sample group of traditional athletes, supporting the argument for dance to be considered as a sport.

The study was approved by the Human Research Participants Committee at Anderson University. All participants completed a health history form, completed a PAR-Q, and signed an informed consent form prior to testing. Each participant's height and weight was measured prior to testing.

The first measurement was body composition, utilizing a bioelectrical impedance analysis (BIA). The machine was tared, then the participant's sex, weight, and height were entered. Using both hands, the participant held the device fully extended in front of her body. The results of the test were recorded in a table. Each participant was measured with the same device, and the device was calibrated after each use.

The second portion of the test measured flexibility using a standard sit and reach test. The participant removed her shoes and sat on the floor with her legs stretched out in front of her. The sit and reach box was placed so that the participant's feet are at the 26 $\mathrm{cm}$ mark. Keeping knees straight and feet flat against the front end of the test box, the participant leaned forward and pushed her hand up the ruler as far as possible. The test was performed three times. The results were averaged and recorded.

Next the participant performed two tests of muscular strength and one of muscular endurance. Each muscular strength test assessed a different area of the body.

Lower body muscular strength was measured by means of a maximal leg press using the leg press machine. The leg press machine was chosen to provide a more accurate test of actual strength and not training level. To use free weights would have favored any 
participant who was familiar with weight lifting techniques. To utilize the leg press machine, the participant sat with her knees bent and both feet flat against the base panel. The participant straightened her knees against the resistance weight until legs were fully extended, then slowly bent her knees to return to the starting position. The initial weight for leg press was set at the closest machine setting to half of the participant's body weight. Weight was added until the participant had reached the maximum resistance that she could press. To account for differences in body size, the maximal weight pressed was divided by the participant's body weight, and the results were recorded.

Upper body strength was measured by performing an inclined chest press on the hammer press machine. The participant began seated at the machine, using proper form and posture. The participant grasped the handles and extended her arms forward and up. The initial weight for the chest press was set at the closest machine setting to one fifth of the participant's body weight. Weight was added until the participant could not lift the load. Like the first test of muscular strength, the maximal weight was divided by the participant's body weight to obtain a measurement of relative strength. Results were recorded.

The participant performed a test of core endurance by performing a standard curl up test. The participant lay in a supine position on a mat, with her feet flat on the floor and her knees bent at a 90-degree angle. The arms were extended to sides with fingers touching a piece of masking tape. A metronome was set at 40 beats per minute. At the first sound, the participant lifted her torso off the floor until her fingertips reach a second piece of tape placed $12 \mathrm{~cm}$ past the first piece of tape. At the second sound, the participant lowered back to starting position. This was repeated in time until the participant felt she could not continue or broke pace with the metronome. The number of completed curl ups was recorded. The maximum number of curl ups allowed was one hundred curl ups.

Finally, cardiorespiratory endurance was measured by a one-mile jog test. The participant completed one warm up lap at a moderate walk. Then the participant completed a mile at a comfortable steady jogging pace, with a total time greater than nine minutes. According to the testing protocol, heart rate at the end of the mile should not exceed 180 bpm. The participant's mile time was recorded. Heart rate was measured and recorded. An estimate of $\mathrm{VO}_{2 \max }$ was calculated using the following equation:

$$
\mathrm{VO}_{2 \max }(\mathrm{ml} / \mathrm{kg} / \mathrm{min}) \approx 100.5-(0.1636 \times w)-(1.438 \times t)-(0.1928 \times H R), \quad \text { Equation } 1
$$

where $w$ denotes body weight in $\mathrm{kg}, t$ is time in minutes and $H R$ is post-exercise heart rate in bpm. Every participant was tested on the same indoor track.

\section{Data Analysis}

Results from each test were entered into Microsoft Excel. The mean, range, and standard deviation for each test were calculated for the dancer sample and for the traditional athlete sample. The results for each sample group were compared using a two-tailed independent $t$-test to determine if there was a significant difference $(\alpha=0.05)$ between the means of the two sample groups.

\section{RESULTS}

The sample group of dancers $(\mathrm{N}=30)$ and the sample group of traditional athletes $(\mathrm{N}=30)$ completed six different fitness tests.

\begin{tabular}{|c|c|c|c|c|}
\hline Variable & $\begin{array}{c}\text { Dancer Mean } \pm \text { Standard } \\
\text { Deviation } \\
\text { (Range) }\end{array}$ & $\begin{array}{c}\text { Athlete Mean } \pm \text { Standard } \\
\text { Deviation } \\
\text { (Range) }\end{array}$ & $\begin{array}{c}t \text {-test } \\
\text { value } \\
t(58)=\end{array}$ & $P$ value \\
\hline Height (in) & $65.33 \pm 2.63(10.00)$ & $64.39 \pm 8.99(11.00)$ & -0.88 & 0.38 \\
\hline Weight (kg) & $62.09 \pm 7.46(31.82)$ & $70.39 \pm 11.23(40.68)$ & -3.37 & $<0.01$ \\
\hline$\%$ Body Fat & $22.48 \pm 3.80(15.60)$ & $25.51 \pm 5.31(30.67)$ & -2.55 & 0.01 \\
\hline Age (years) & $19.60 \pm 1.45(6.00)$ & $19.30 \pm 1.02(3.00)$ & 0.93 & 0.36 \\
\hline Sit and Reach Test $(\mathrm{cm})$ & $63.06 \pm 5.64(24.00)$ & $51.70 \pm 8.41(30.67)$ & 6.14 & $<0.01$ \\
\hline $\begin{array}{l}\text { Curl Up Test (number } \\
\text { completed) }\end{array}$ & $77.97 \pm 26.21(69.00)$ & $68.57 \pm 31.08(88.00)$ & 1.27 & 0.21 \\
\hline $\begin{array}{l}\text { Relative Chest Press (lbs. } \\
\text { lifted/ body weight in lbs.) }\end{array}$ & $0.56 \pm 0.11(0.43)$ & $0.64 \pm 0.11(0.49)$ & -2.62 & 0.01 \\
\hline $\begin{array}{l}\text { Relative Leg Press (lbs. } \\
\text { lifted/ body weight in lbs.) }\end{array}$ & $2.22 \pm 0.43(1.68)$ & $2.21 \pm 0.26(1.02)$ & 0.13 & 0.90 \\
\hline $\begin{array}{l}\text { Estimated } \mathrm{VO}_{2 \max } \\
(\mathrm{ml} / \mathrm{kg} / \mathrm{min})\end{array}$ & $43.41 \pm 4.97(28.59)$ & $42.09 \pm 2.98(10.33)$ & 1.25 & 0.22 \\
\hline
\end{tabular}

Table 1. Physical fitness means, standard deviation, ranges, and independent two-tailed $t$-test results for each variable. Bold $p$-values values indicate statistical significance. 
The groups displayed statistically significant differences in three of the six fitness tests. There was a significant difference between groups in body fat percentage measurement, the sit and reach test, and the relative chest press. There was no significant difference between groups in the measurement of relative leg press, $\mathrm{VO}_{2 \max }$ estimate, or the curl up test. The alpha value was set at 0.05 for every test. The mean age for dancer sample was 19.6 years; the average age of the traditional athletes was 19.3 years. The means, variances, and two-tailed independent $t$-test results for each test for the respective groups are displayed in Table 1.

The dancers had a lower percent body fat measurement $(M=22.48 \%, S D=3.8)$ than the traditional athletes $(M=25.51 \%, S D$ $=5.31)$. The difference was significant $t(58)=-2.55, p=.01$.

The mean scores of the sit and reach test were also significantly different between the groups, with a mean for the dancers of $63.06 \mathrm{~cm}(S D=5.64 \mathrm{~cm})$ and a mean for the traditional athletes of $51.70 \mathrm{~cm}(S D=8.41 \mathrm{~cm}), t(58)=6.14, p<.001$.

The relative chest press was the third test in which a $t$-test revealed a significant difference between the two samples $(t(58)=-2.62$, $p=.01)$. The dancers had a mean relative chest press of $0.56(S D= \pm 0.11)$. The traditional athletes had a higher average relative chest press of $0.64(S D= \pm 0.11)$.

\section{DISCUSSION}

The current study compared the physical demands of collegiate dance to traditional intermittent collegiate sports. It was hypothesized that dancers trained in several styles would display similar fitness to traditional athletes. This was found to be correct for three of the six physical fitness components. Not surprisingly, the dancers showed significantly greater flexibility and lower percent body fat, and the volleyball and softball players displayed greater relative upper body strength. The core strength, relative lower body strength, and estimated aerobic capacity were similar between the softball and volleyball group and the dancer group. Given the physical demands of dance, the core and lower body strength is not unexpected. However, the estimated aerobic fitness of dancers, despite the intermittent style of dance classes, was surprisingly equivalent to that of traditional athletes.

Of the three fitness components showing significant differences, the sit and reach test showed the greatest disparity between groups. This was expected due to the emphasis in dance on extension and flexibility. The dancers also had a significantly lower percent body fat than the athletes; this is likely a reflection of the aesthetic nature of dance and the emphasis on thinness in professional dance. Dancers who continue on a collegiate level tend to fit this body type and have a very low percent body fat. The relatively small variability in height and weight shown by the sample of dancers supports the notion that it is difficult for individuals outside of this aesthetic to continue in dance beyond a certain level.

The traditional athletes had significantly greater relative upper body strength, which suggests that dancers might benefit from more upper body strength training, especially given the contemporary dance trend towards more acrobatic movements heavily influenced by martial arts. Choreography includes more lifts for females to perform, instead of the traditional male and female partnering of classical ballet. Increased upper body strength of dancers would aid the dancer in performing new, more daring dance movements and partnering skills.

There was, no significant difference in lower body or core strength between the two groups. The study utilized relative strength for each muscular strength comparison. When comparing relative strength, differences in body size between participants did not impact the comparison. The leg press test that was used did not mimic the movements of dance, volleyball, or softball. The leg press test did not assess muscular power. The study was limited by available equipment; future studies are needed to evaluate muscular power utilizing movements more specific to dancers and volleyball and softball players. In addition, many participants exceeded the one hundred curl up maximum that was set prior to beginning testing. Continuing the curl up test to exhaustion would provide a more accurate comparison of core strength between testing groups.

The measurement of estimated $\mathrm{VO}_{2 \max }$ was also not significantly different between groups. Previous studies had shown disparities in aerobic gains between styles of dance, so this study tested dancers who are trained in a variety of styles..$^{1,2,5}$ The mean estimated $\mathrm{VO}_{2 \max }$ of the dancers was higher than that of the athletes but the set of dancers had nearly three times the variance, which may reflect the wide variability in aerobic nature between different styles of dance. The mean estimated $\mathrm{VO}_{2 \max }$ of both dancers and traditional athletes was in the $70^{\text {th }}$ percentile for women as determined by the Aerobics Center Longitudinal Study (1970-2002).

Previous studies did not distinguish between types of sport when comparing the aerobic fitness of athletes to dancers. Certain sports require sustained performance while others require short bursts of high intensity effort; dance is more like the latter. By finding similar aerobic fitness in dancers and in softball and volleyball players, it can be suggested that collegiate level dance induces fitness gains comparable to traditional collegiate athletics. 
There were several limitations. All testing was done at a small Midwestern University, so the sample groups were relatively small. Future studies will ideally utilize larger sample groups. In addition, future studies should test dancers in a variety of programs to provide a more comprehensive assessment of dancer fitness, as well as to compare dancers and other traditional sports. Given previous research on the variability of fitness gains between dance genres, the sample of dancers tested may not be representative of dancers at other universities.

Dancers who focus solely on one style of dance would not experience the fitness gains provided by other styles. However, most modern dancers must be well rounded in order to be employable. Dance companies perform a more varied repertoire and require the dancers to be capable of performing a wide variety of styles.

Another limitation of the current study was the use of an estimated $\mathrm{VO}_{2 \max }$; a metabolic cart could be used to provide a more accurate assessment of aerobic capacity. In addition, body composition could be assessed using more accurate techniques than a BIA. Future research that expands upon these results is necessary to better understand the athletic nature of dance.

In conclusion, there appear to be similar fitness levels between collegiate dancers and traditional athletes, supporting the view of the dancer as a collegiate athlete. This conclusion has several practical implications. One practical result would be inclusion of recreational dance classes as physical education credits. Given that the fitness gains of dance are comparable to those of traditional intermittent sports, it is logical that dance classes would be sufficient to meet physical education requirements, in the same way that schools offer recreational classes in traditional sports.

Another would be an increased number of physicians and trainers on staff with collegiate dance programs and companies. The collegiate sports teams have medical personnel who travel with the team and work with the athletes on a regular basis, yet there are few medical personnel on staff with dance programs at the same universities. Many times dancers are either not treated or must visit an outside physician who is unfamiliar with the dancer and the physical demands of dance. Athletic training education could be expanded to provide greater understanding of the injuries common to dancers.

Despite the aesthetic nature of dance, the current study suggests that collegiate dance provides training adaptations equivalent to traditional intermittent collegiate sports and that dancers ought to be considered college athletes.

\section{REFERENCES}

1. Fromel, K., Vasendova, J., Stratton, G., and Pangrazi, R. P. (2002). Dance as a Fitness Activity: The Impact of Teaching Style and Dance Form. Journal of Physical Education, Recreation \& Dance, 73(5), 26-30, 54.

2. Angioi M., Metsios, G., Koutedakis, V., and Wyon, M. A. (2009). Fitness in Contemporary Dance: A Systematic Review. International Journal of Sports Medicine, 30(7), 475-484. doi:10.1055/s-0029-1202821

3. Flores, R. (1995). Dance for Health: Improving Fitness in African American and Hispanic Adolescents. Public Health Reports (Washington, D.C.: 1974), 110(2), 189-93.

4. Leelarungrayub, D., Saidee, K., Pothongsunun, P., Pratanaphon, S., YanKai, A., and Bloomer, R.J. (2011). Six Weeks of Aerobic Dance Exercise Improves Blood Oxidative Stress Status and Increases Interleukin-2 in Previously Sedentary Women. Journal of Bodywork and Therapies, 15(3), 355-62.

5. Bronner, S., Ojofeitimi, S., Lora, J. B., Southwick, H., Kulak, M. C., Ganboa, J., Rooney, M., Gilman, G., and Gibbs, R. (2014). A Preseason Cardiorespiratory Profile of Dancers in Nine Professional Ballet and Modern Companies. Journal of Dance Medicine and Science, 18(2), 74-85.

6. Grove, J. R., Main, L.C., and Sharp, L. (2013). Stressors, Recovery Processes and Manifestation of Training Distress in Dance. Journal of Dance Medicine and Science, 17(2), 70-78.

7. Koutedakis, Y., and Jamurtas, A. (2004). The Dancer as a Performing Athlete: Physiological Considerations. Sports Medicine, 34(10), 651-661. Retrieved from http://core.ac.uk/ download/pdf/1931746.pdf

8. Ambegaonkar, J. P., Caswell, S. V., Winchester, J. B., Caswell, A. A., and Andre, M.J. (2012). Upper-body Muscular Endurance in Female University-level Modern Dancer: A Pilot Study. Journal of Dance Medicine and Science, 16(1), 3-7.

9. Rafferty, S. (2010). Considerations for Integrating Fitness into Dance Training. Journal of Dance Medicine and Science, 14(2), 45-49.

10. Angioi, M., Metsios, G., Twitchett, E., Koutedakis, Y., and Wyon, M. (2009). Association Between Selected Physical Fitness

Parameters and Aesthetic Competence in Contemporary Dancers. Journal of Dance Medicine and Science, 13(4), 115-123. 


\section{ABOUT THE STUDENT AUTHOR}

Leanna Miller graduated from Anderson University, Indiana in Spring 2016 with Bachelor's Degrees in Exercise Science and Psychology and a minor in Dance Performance. Leanna was an honors student, as well as a member of the Center for Public Service, Psi Chi, Alpha Chi, and Phi Epsilon Kappa. Leanna is interested in health and in the use of non-traditional therapeutic modalities in rehabilitation, as well as treatment of and injury prevention for dancers. Leanna plans to pursue a career in geriatric rehabilitation, using her dance background in conjunction with her exercise science and psychology education to best serve the aging population.

\section{PRESS SUMMARY}

Research indicates that dance can provide many benefits in physical fitness, yet the social and medical treatment of dancers differs vastly from that of athletes. This study tested six different physical fitness components of dancers and traditional athletes to provide a direct comparison of the gains in fitness from dance and traditional sports (softball and volleyball). This study found that although there was some variability, overall fitness of dancers seems to be equivalent to that of athletes, supporting the application of sports medicine to the field of dance. 


\title{
Adaptation of Esherichia coli to Antiobiotic Cycling via Single Nucleotide Polymorphisms
}

\author{
Samuel E. Hager , Ellen Jensen ${ }^{a}$, Timothy J. Johnson ${ }^{b}$, David Mitchell*a \\ ${ }^{a}$ Department of Biology, College of Saint Benedict/Saint John's University, Collegeville, $M N$ \\ ${ }^{b}$ Department of Veterinary and Biomedical Sciences, University of Minnesota, St. Paul, MN \\ Student: samuelhager1@gmail.com \\ Mentor:dmitchell@,csbsju.edu*
}

\begin{abstract}
Bacteria are quick to adapt and evolve, especially under the effects of selective pressures from chemical antibiotics. In addition, bacteria may develop resistance to antibiotics from multiple classes simultaneously, making their eradication from the human body particularly challenging. This study aims to demonstrate that bacterial multiple-drug resistance can be developed and retained in a laboratory setting. Escherichia coli $\mathrm{B}$ was grown in tryptic soy broth in the presence of a small, increasing concentration of streptomycin. This exposure resulted in a strain of E. coli, which had an increased minimum inhibitory concentration (MIC) towards streptomycin, or "resistance." This resistant strain was then grown in like manner in nalidixic acid and then penicillin G. The result was a strain that became resistant to streptomycin and nalidixic acid, and increasingly resistant to nalidixic acid after penicillin G exposure. Additionally, the bacteria retained resistance to streptomycin and nalidixic acid even after exposure to those chemicals ceased. Genome sequencing and comparison to E. coli B reference strain REL606 revealed the emergence of point mutations with each exposure to an antibiotic. Of particular interest is a mutation associated with the appearance of nalidixic acid resistance. Base pair 4,553,488 was changed from adenine to guanine, resulting in a change from aspartate to glycine in the protein helicase. Previous studies have not indicated mutations to this locus as nalidixic acid resistance conferring. Thus, this mutation may be a novel mutation conferring E. coli B nalidixic acid resistance. Since the region of the mutated helicase is functionally undefined, a mechanism is not apparent. Further research needs to be done to confirm this hypothesis and illuminate a mechanism.
\end{abstract}

\section{KEYWORDS}

Bacteria; Escherichia coli; Evolution; Antibiotic Resistance; Nalidixic Acid; Streptomycin; Point Mutation; Single-nucleotide Polymorphism; Helicase; Minimum Inhibitory Concentration

\section{INTRODUCTION}

Competing microbes have been producing and reacting to antibiotics for thousands of years, and humans have also been exposed to these naturally occurring compounds for millennia. ${ }^{1}$ Even at the production of mass antibiotic synthesis in the $1940 \mathrm{~s}$, some microbiologists have suspected that bacteria might be able to inhibit antibiotics such as penicillin; today, multiple-drug resistant (MDR) strains pose a real and enduring threat to human health. ${ }^{1}$ The presence of these strains in hospitals and human waste watersheds, where antibiotic compounds abound, suggests that humans are responsible for pushing antibiotic-resistance alleles to fixation in certain microbial populations..$^{2-4}$ In the former, bacterial populations are exposed to a finite number of chemicals, providing a limited variety of sustained selective pressures. In the latter, bacteria are exposed to the same antibiotics being used in healthcare, as well as those being used for agriculture. In either scenario, these prolonged, varied selective pressures provide an environment where bacteria that adapt by developing resistance will out-compete other organisms. When a strain does this repeatedly in response to our most effective drugs, we are faced with a troubling situation, where a strain is resistant to many of our treatment options. Multiple drug resistant bacteria (for example, Carbapenem-resistant Enterobacteriaceae (CRE)) are a real and present threat to healthcare. ${ }^{5}$

Resistance to antibiotics is either innate or acquired. For example, bacteria such as E. coli are generally intrinsically resistant to vancomycin not because of any adaptation, but because of pre-existing traits that thwart vancomycin activity. ${ }^{6}$ Bacteria that do not possess intrinsic resistance to a given chemical may acquire resistance, either through de novo genetic mutations such as point mutations and chromosomal rearrangement (i.e., fluoroquinolone resistance through gyr $A$ mutations in E. coli), or through lateral gene transfer (i.e., acquisition of plasmids conferring resistance through possession of specific sets of genes). ${ }^{7}$ This study is concerned with the evolution of resistance to antibiotics via de novo genetic mutations.

This evolution may actually be expedited by human activity. Previous research demonstrated that baseline mutation rates are not constant, and may in fact be increased through exposure to antibiotics. ${ }^{8}$ In addition, numerous studies have begun to illuminate 
the importance of sub-lethal concentrations of antibiotics in the adaptation process, particularly in how they elicit the SOS response in bacteria. DNA damage, caused by antibiotics, radiation, or reactive oxygen species can activate the SOS response, which repairs damaged DNA. However, SOS is also associated with higher rates of polymerase errors, lateral gene transfer, and recombination, increasing the rate of resistance evolution. ${ }^{2,4,8}$ In addition, not only do sub-lethal concentrations encourage mutation and genetic variation, but they may also select for resistant bacteria.., 10 Thus, mutation and selection for resistance alleles may occur at sub-lethal concentrations of antibiotics. Stated simply, human use of antibiotics may actually contribute to the evolution of drug-resistant organisms, causing said drugs to become less effective.

A number of previous studies demonstrated that in vivo evolution occurs in response to antibiotic selective pressure via point mutations, ${ }^{11-14}$ however, fewer studies examined the sequential accumulation of resistance phenotypes. In this study, cultures were introduced sequentially to three different antibiotics at sub-lethal concentration in order to encourage high mutation rates. Mutation rates were not measured in this study, but by exposing a culture to an initial concentration below the lethal level, we hoped to decrease the time required for a resistance mutation to appear. Then, the antibiotic concentration was gradually increased until well over the wild-type minimum inhibitory concentration (MIC, the minimum concentration of antibiotic required to inhibit bacterial growth), in order to ensure resistance mutations were driven to fixation in the population. The process was repeated with each antibiotic, all from different classes, to investigate the possibility of the addition of new mutations and the retention of mutations no longer under selection pressure. This was a question worth investigation, since resistance mutations often confer a cost to the organism's fitness. ${ }^{13}$ In this study we show that mutations to bacterial genomes can confer resistance to antibiotics (i.e. an inheritable rise in the MIC) ${ }^{15}$ and remain in the genome, even in the absence of the mutation's particular selection pressure.

\section{MATERIALS AND METHODS}

\section{Cultures and materials}

All flasks were grown for about 24 hours at $30^{\circ} \mathrm{C}$ and $200 \mathrm{rpm}$ (New Brunswick Scientific C25 Incubator Shaker). Culture density was measured with the optical density at $600 \mathrm{~nm}\left(\mathrm{OD}_{600}\right.$; Beckman DU640 spectrophotometer). Streptomycin sulfate salt (Sigma Chemical Co., CAS 3810-74-0), nalidixic acid sodium salt (Sigma Aldrich, CAS 3374-05-8), and penicillin G potassium salt (Nutritional Biochemicals Corp. CAS 113-98-4) were used to make stock solutions ( $4 \mathrm{mg} / \mathrm{mL}$ of the active compound) in sterile water. Tryptic soy agar (TSA) and tryptic soy broth (TSB) were used as media for growing plate and liquid cultures (BD Co.).

\section{Sequential exposure}

A pure culture of Escherichia coli B was streaked for isolation on TSA. A colony was selected for inoculation in $50 \mathrm{~mL}$ TSB and grown overnight, resulting in flask 0 . Then, $0.5 \mathrm{~mL}$ of flask 0 culture was transferred to $50 \mathrm{~mL}$ fresh TSB, which was prepared with streptomycin stock solution to yield a final streptomycin concentration of $0.53 \mu \mathrm{g} / \mathrm{mL}$ : flask 1 . After 24 hours, the $\mathrm{OD}_{600}$ was read and the next flask was prepared with the same 1:100 culture to TSB ratio, but with an increased concentration of streptomycin (Table 1). This was repeated seven times until a streptomycin concentration above the MIC $(0.8 \mu \mathrm{g} / \mathrm{mL}$, see Fig. 1) was reached.

\begin{tabular}{|c|c|c|c|c|c|c|c|c|}
\hline Flask & $\begin{array}{c}\text { Streptomycin } \\
\text { concentration } \\
(\boldsymbol{\mu g} / \mathbf{m L})\end{array}$ & $\mathbf{O D}_{\mathbf{6 0 0}}$ & Flask & $\begin{array}{c}\text { Nalidixic acid } \\
\text { concentration } \\
(\boldsymbol{\mu g} / \mathbf{m L})\end{array}$ & $\mathbf{O D}_{600}$ & Flask & $\begin{array}{c}\text { Penicillin G } \\
\text { concentration } \\
(\boldsymbol{\mu g} / \mathbf{m L})\end{array}$ & $\mathbf{O D}_{\mathbf{6 0 0}}$ \\
\hline $\mathbf{1}$ & 0.53 & 1.60 & $\mathbf{7 . 1}$ & 0.01 & 1.69 & $\mathbf{7 . 5 . 1}$ & 1.60 & 1.06 \\
\hline $\mathbf{2}$ & 1.71 & 1.70 & $\mathbf{7 . 2}$ & 0.20 & 1.65 & $\mathbf{7 . 5 . 2}$ & 3.20 & 1.65 \\
\hline $\mathbf{3}$ & 7.11 & 1.48 & $\mathbf{7 . 3}$ & 0.79 & 1.49 & $\mathbf{7 . 5 . 3}$ & 9.90 & 1.91 \\
\hline $\mathbf{4}$ & 31.43 & 1.69 & $\mathbf{7 . 4}$ & 1.58 & 1.74 & & & \\
\hline $\mathbf{5}$ & 31.43 & 1.69 & $\mathbf{7 . 5}$ & 3.17 & 1.56 & & & \\
\hline $\mathbf{6}$ & 62.38 & 1.67 & & & & & & \\
\hline $\mathbf{7}$ & 122.84 & 1.68 & & & & & & \\
\hline
\end{tabular}

Table 1. E. coli B growth flasks with growth conditions and $\mathrm{OD}_{600}$ readings after approx. 24 hours. Note that the contents of flask 7 were used to "seed" flask 7.1 , which contained nalidixic acid. Thus the bacteria in 7.1 had been exposed to streptomycin, but were then removed from streptomycin to be exposed to nalidixic acid.

To prepare the next antibiotic treatment, a flask was set up with a 1:100 ratio of liquid culture from flask 7 to fresh TSB, as well as enough nalidixic acid stock solution to yield a sub-lethal concentration, resulting in flask 7.1. The process followed that of the streptomycin treatment, varying only in antibiotic concentrations and number of repeats. For the final treatment, two small well 
isolated colonies on a TSA streak plate of flask 7.5 were used as the inoculum and were placed into $100 \mathrm{~mL}$ TSB prepared with penicillin $\mathrm{G}$ stock solution, flask 7.5.1. The remainder of the procedure follows the aforementioned. Concentrations for all flasks and their $\mathrm{OD}_{600}$ readings after 24 hours are found in Table 1. Culture identity was confirmed through colony morphology and Gram staining.

\section{Resistance metric: $M I C$}

To measure the MICs of each antibiotic, 96-well plate 12 2-fold serial dilutions of antibiotics were made from TSB and antibiotic stock solutions. A sample from each selected liquid culture, an aliquot taken directly from the growth flasks of the evolution experiments, was diluted with water to a concentration of $1.66 \times 10^{8}$ colony forming units $(\mathrm{CFU}) / \mathrm{mL}$. Each well was filled with $300 \mu \mathrm{L}$ of a TSB-antibiotic dilution, and $3 \mu \mathrm{L}$ of the diluted liquid culture. Thus, the initial number of cells in each well was approximately $5 \times 10^{5} \mathrm{CFU}$. After incubating at room temperature for 20 hours, plates were stirred via brief shaking, and then read for $\mathrm{OD}_{600}$ values (Molecular Devices VersaMax microplate reader). Averaged raw absorbance values at $600 \mathrm{~nm}$ along with standard deviations from at least three replicates were graphed against antibiotic concentration.

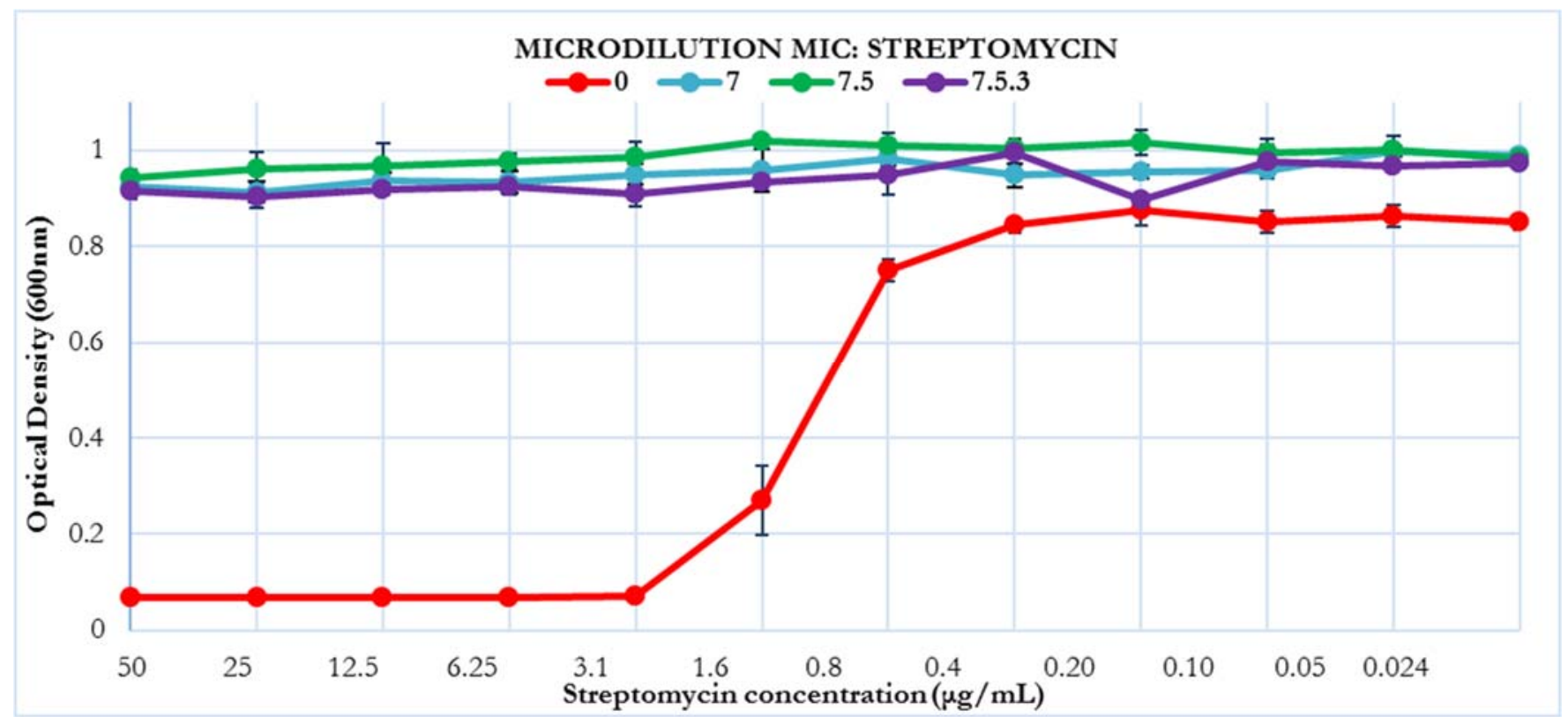

Figure 1. MIC for streptomycin, Series dilution in TSB, starting at $50 \mu \mathrm{g} / \mathrm{mL}$. Notice that the original parent strain in flask 0 has an MIC of about $0.8 \mu \mathrm{g} / \mathrm{mL}$. After exposure to streptomycin, this rises to more than $50 \mu \mathrm{g} / \mathrm{mL}$ (7, blue). This phenotype is retained by the cultures derived from 7, but no longer exposed to streptomycin (7.5 and 7.5.3, green and purple, respectively).

\section{Genome Sequencing}

From the parent strain and each resistant strain, multiple isolated colonies were selected for genomic analyses via Illumina sequencing. Flask growths were grown overnight on MacConkey agar to check for visible contamination, then a streak of colonies from the plate was re-grown overnight in $2 \mathrm{~mL} \mathrm{LB}$ broth with shaking at $37^{\circ} \mathrm{C}$. DNA was extracted from overnight growths of each strain using the Qiagen DNEasy Kit. Library preparations were performed with Illumina reagents and DNA sequencing was performed at the University of Minnesota Genomics Center (Saint Paul, MN, USA). A minimum of 10 million high quality reads (Q30 average) was generated for each strain, corresponding to approximately 250-fold coverage or greater for each strain sequenced. Following quality filtering, reads were mapped to E. coli B strain REL606 (Genbank CP000819)15 using CLC Genomics Workbench version 9.0 (Qiagen) with a similarity fraction of 0.9 and minimum coverage of 100x for variant calling. Variants were called using CLC Genomics Workbench's Basic Variant Detection tool and outputted to tabular format. Variants were called at high minimum frequency $(>90 \%)$ to identify true variants relative to the reference genome and other sequenced strains in this study. Variants were also called at low minimum frequency $(<10 \%)$ to identify possible mixed populations within each growth containing a low-frequency mutation. Mutations unique to each strain sequenced, relative to the parent strain sequenced, were identified and annotated. The raw reads for this project are available in the NCBI BioProject PRJNA336011. 


\begin{tabular}{|c|c|c|c|c|c|c|c|}
\hline Sample & $\begin{array}{c}\text { Barcode } \\
\text { sequence }\end{array}$ & $\begin{array}{c}\text { \% Perfect } \\
\text { barcode }\end{array}$ & $\begin{array}{c}\text { \% One } \\
\text { mismatch } \\
\text { barcode }\end{array}$ & $\begin{array}{c}\text { Yield } \\
\text { (Mbases) }\end{array}$ & $\begin{array}{c}\text { \% clusters } \\
\text { passing filter }\end{array}$ & $\begin{array}{c}\text { \% } \geq \text { Q30 } \\
\text { bases }\end{array}$ & $\begin{array}{c}\text { Mean Quality } \\
\text { score }\end{array}$ \\
\hline Flask 0 & GATCAG & 98.66 & 1.34 & 16,264 & 95.44 & 92.74 & 36.17 \\
\hline Flask 7 & TAGCTT & 98.38 & 1.62 & 16,881 & 95.67 & 93.22 & 36.27 \\
\hline Flask 7.5 & GGCTAC & 98.17 & 1.83 & 16,672 & 95.11 & 92.13 & 36.04 \\
\hline Flask 7.5.3 & CTTGTA & 98.32 & 1.68 & 16,593 & 95.61 & 92.79 & 36.18 \\
\hline
\end{tabular}

Table 2. Illumina sequencing run statistics. Illumina defines their Quality Score $(\mathrm{Q})$ as $\mathrm{Q}=-10 \log _{10}(e)$.

\section{RESULTS AND DISCUSSION}

We found that the E. coli B liquid cultures consistently yielded OD readings above 1.5 in the presence of various antibiotics, even at levels far higher (>150-fold increase) than the initial, wild-type MIC (Table 1). This suggested that one or more mutations had in fact conferred antibiotic resistance to the surviving cells. There was a notable change in the MIC of a given antibiotic after exposure to that same antibiotic, displayed in Figures 1, 2 and 3, supporting the idea that there was some significant change in the bacteria after exposure to an antibiotic. In Figure 1, we noticed ancestral strain (flask 0) has an MIC of streptomycin of about $0.8 \mu \mathrm{g} / \mathrm{mL}$. After the stepwise streptomycin exposure, the resulting culture in flask 7 was able to grow in concentrations of streptomycin 150 times greater than the parent flask $0 \mathrm{MIC}$ of streptomycin. The E. coli cultures were found to grow to similar densities in high concentrations streptomycin, even after streptomycin exposure ceased (Fig. 1). This supports the idea that some resistance-associated mutations can occur during selection pressure and then be retained for many generations.

Likewise, in Figure 2, we noticed that cultures not treated with nalidixic acid have an MIC to nalidixic acid of about $0.2 \mu \mathrm{g} / \mathrm{mL}$. After exposure to nalidixic acid, the MIC rose to about $3.1 \mu \mathrm{g} / \mathrm{mL}$. This too was retained after exposure to nalidixic acid ceased (see Figure 2). Penicillin G exposure conferred a different result. In Figure $\mathbf{3}$ we see that all the flasks were resistant to penicillin at all levels. Since even the wild-type culture, flask 0, was unaffected, it is unclear whether exposure to penicillin $\mathrm{G}$ caused any change in the way the cell inhibits its function. However, in Figure 2 we observed that after being exposed to penicillin, the culture (7.5.3) seemed to have a higher MIC of nalidixic acid. Since MIC tests were performed using aliquots of the evolved cultures, it is possible that this is the result of an increased frequency of nalidixic acid-resistant mutants, and not a change in the DNA. Nevertheless, it plausible that exposure to one drug may give advantage against a completely different drug.

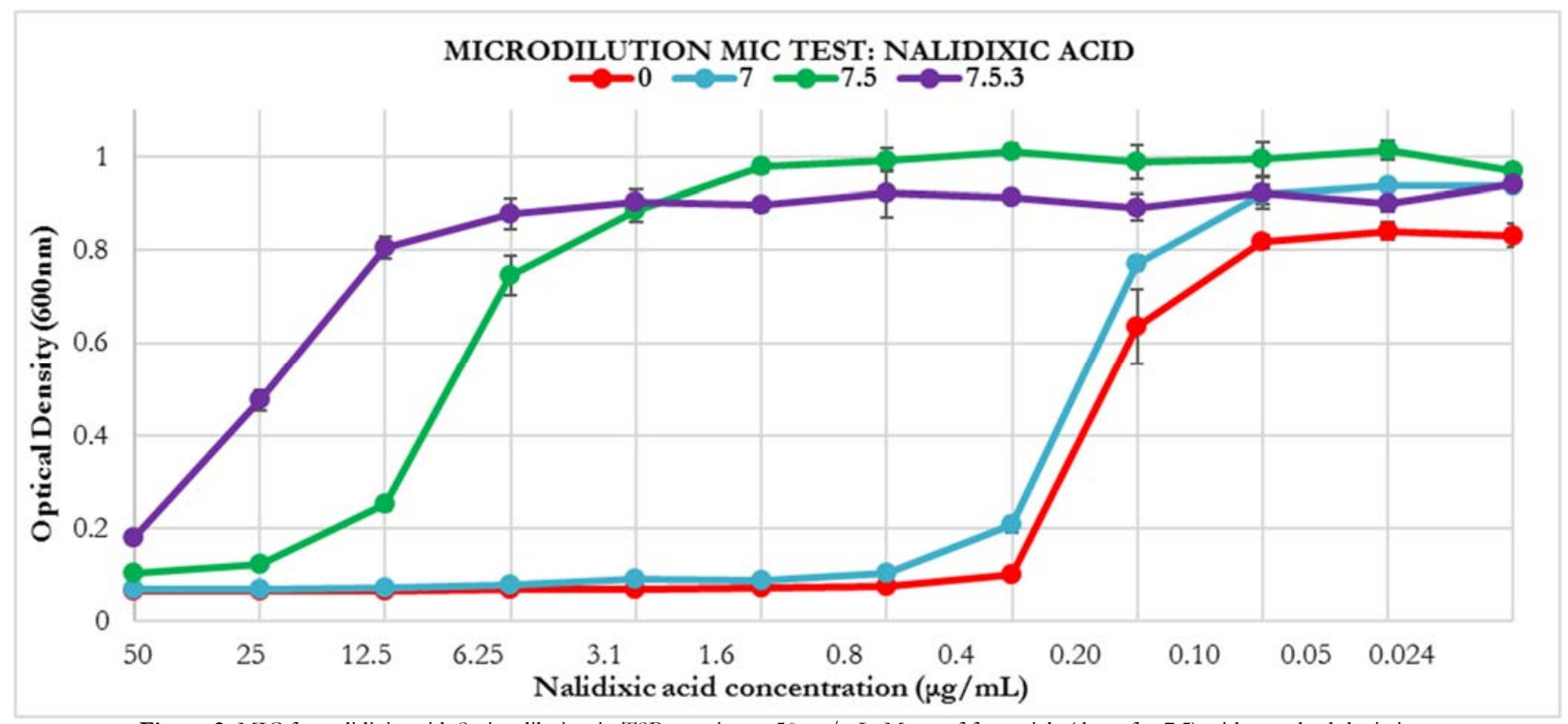

Figure 2. MIC for nalidixic acid. Series dilution in TSB, starting at $50 \mu \mathrm{g} / \mathrm{mL}$. Mean of four trials (three for 7.5) with standard deviation. 


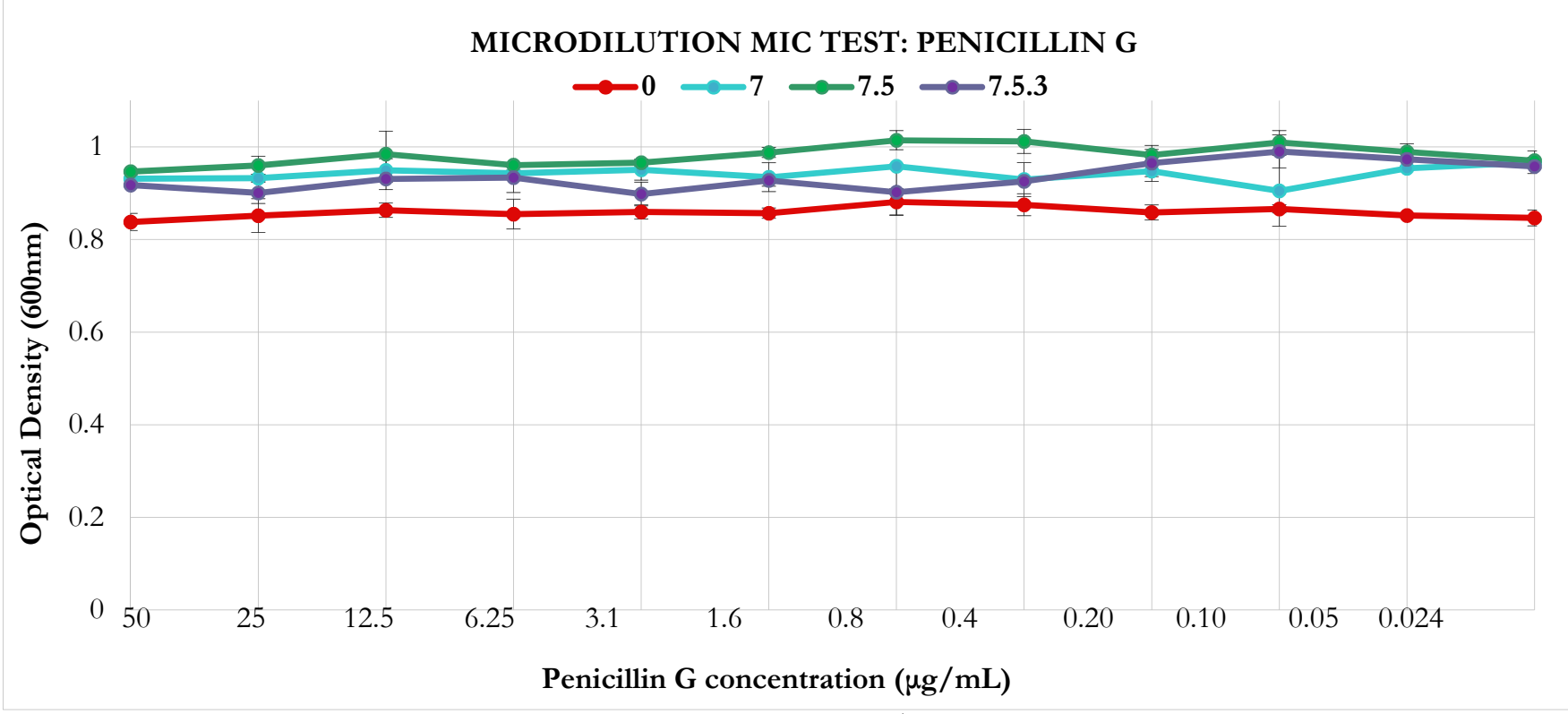

Figure 3. MIC for penicillin G. Series dilution in TSB, starting at $50 \mu \mathrm{g} / \mathrm{mL}$. Mean of four trials with standard deviation.

There existed the possibility that another species had contaminated and taken over the culture at some point, producing confounding results. However, this was put to rest with consistent Gram stain experiments indicating Gram-negative bacilli and colony morphology on EMB. The identity of all the samples as E. coli B was also confirmed with whole genome sequencing data, which provided details about how the bacteria adapted to this selection pressure.

Next-generation sequencing was performed for the four strains used for the MIC graphs. For all four cultures, SNP variants were called for strains with a minimum frequency of $90 \%$ with at least $100 \mathrm{x}$ mapping coverage. Table $\mathbf{3}$ contains a summary of the single-nucleotide polymorphisms among the samples meeting these criteria. Low-frequency SNP variants were also examined to determine if mutations existed in a potential mixed population within each strain examined. No evidence was found of low-level mutations or mixed populations via SNP analysis.

\begin{tabular}{|c|c|c|c|c|c|c|}
\hline \multirow{2}{*}{ Base pair } & \multicolumn{4}{|c|}{ Flask } & \multirow{2}{*}{ Mutation } & \multirow{2}{*}{ Gene } \\
\hline & $\mathbf{0}$ & 7 & 7.5 & 7.5.3 & & \\
\hline 77501 & $\Delta$ & & & & A to $G$ & Thiamine-binding periplasmic protein \\
\hline 456399 & $\Delta$ & $\Delta$ & & $\Delta$ & Deletion of C & Multidrug efflux RND transporter permease \\
\hline 3402195 & & $\Delta$ & $\Delta$ & $\Delta$ & T to $\mathrm{C}$ & 30 S ribosomal protein S12 (lysine 87 to glutamic acid) \\
\hline 4275010 & & & & $\Delta$ & $\mathrm{G}$ to $\mathrm{A}$ & Intergenic repeat region \\
\hline 4529779 & & & $\Delta$ & $\Delta$ & $\mathrm{T}$ to $\mathrm{A}$ & Fimbrial protein FimH \\
\hline 4553488 & & & $\Delta$ & $\Delta$ & A to $G$ & Helicase (aspartate to glycine) \\
\hline 4553606 & & & $\Delta$ & $\Delta$ & $\mathrm{C}$ to $\mathrm{T}$ & Helicase (silent) \\
\hline
\end{tabular}

Table 3. Summary of single-nucleotide polymorphisms. A " $\Delta$ " indicates a particular culture $(0$, the original; 7 , exposed to streptomycin; 7.5 . exposed to streptomycin and nalidixic acid; 7.5.3, exposed to streptomycin, naalidixic acid, and penicillin $G$ ) differed from the REL606 reference sequence at the numbered base. The mutation column indicates the nucleotide change occurring. The gene column indicates the potential gene impacted and any amino acid differences.

\section{After streptomycin treatment}

After streptomycin treatment, base pair 77501 matches the reference-type (Table 3). This may be a function of fitness, or it may be a sequencing error or mixed culture in the parent strain leading to this observation. Whatever the case, it is unlikely that the protein impacted by this mutation (thiamine-binding periplasmic protein) plays a role in streptomycin resistance.

Base pair 3402195 in the S12 portion of the 30s ribosomal subunit mutated from T to C, changing lysine 87 to glutamic acid. This is likely the mutation that confers resistance to streptomycin, since aminoglycosides are known to bind to the 30 s ribosomal subunit. ${ }^{16}$ Since the mutation remained in the following samples, this would be an example of resistance via target modification. 
Chumpolkulwong et al. working with E. coli strain BL also observed streptomycin resistance when the mutation of lysine 87 to arginine in the $\mathrm{S} 12$ protein subunit occurred. ${ }^{17}$

\section{After nalidixic acid treatment}

After nalidixic acid treatment, base pair 456399 matches the reference type. In all the other samples, $\mathrm{C}$ is deleted from this site in the multidrug efflux RND transporter permease gene. While reversion is a possibility, other explanations seem more likely. A subpopulation within flask 7 that lacked the mutation may have fixed the reference type in flask 7.5 after the change in antibiotics. Considering this mutation causes a frameshift mutation in the predicted protein sequence of the permease, this mutation may be quite costly to the organism's fitness. These predicted fitness costs would support the explanation that a subpopulation drove the reference allele to fixation when the mutation was not advantageous.

Despite the inclusive-sounding name of the gene, it is doubtful that this alone could have led to nalidixic acid resistance, considering the deletion was present in flask 7.5.3, but the resistance that it would have conferred remained. No other mutation showing up in 7.5.3 would be able to explain the sustained MIC.

Base pair 4529779 mutated from $\mathrm{T}$ to $\mathrm{A}$ in the fimbrial protein fimH gene. While this mutation does fit the profile needed to support the MIC change - it changed and was fixed — the protein being affected is not related to the target of nalidixic acid, nor does it seem that fimbriae would assist in the metabolism or transportation of nalidixic acid molecules. However, it is worth investigating as a possible explanation, or partial explanation, for nalidixic acid resistance. One might confer only this allele to an organism, and observe any change in MIC of nalidixic acid.

Base pair 4553606 changed from $\mathrm{C}$ to $\mathrm{T}$ in helicase. While there is no change in amino acid sequence, we cannot deem this mutation irrelevant. A recent study indicates that interactions between chromatin and proteins, which may contribute to organism fitness, can be altered by non-synonymous mutations. ${ }^{18}$

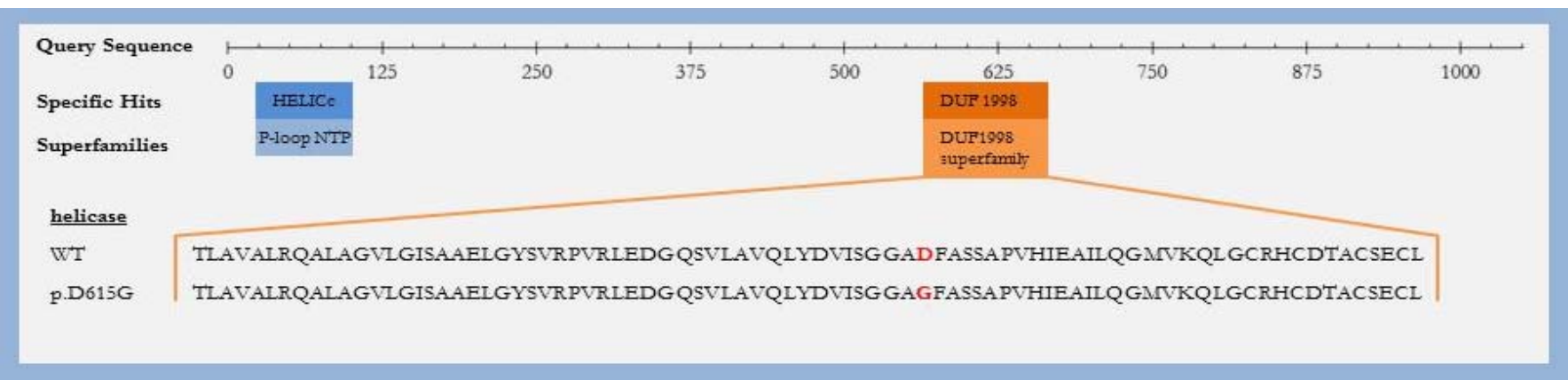

Figure 4. Conserved domains identified in the postulated helicase amino acid sequence (1051 amino acids). Multiple hits for "HELIc" occurred within the first 100 amino acid residues. DUF1998 spans residues 566 to 648 . The entire sequence of DUF is represented at the top and the mutation of interest is in yellow at 615. Figure created using data from BLAST and PSI-BLAST. ${ }^{19}$

Base pair 4553488 mutated from A to $G$ in helicase, resulting in a change from aspartate to glycine. As seen in Figure 4, the mutation occurs in the middle of an amino acid sequence identified as Domain of Unknown Function (DUF)1998. ${ }^{19-20}$ DUF1998 is functionally uncharacterized, so it is unclear what the change from aspartate to glycine is doing to the function of the protein. Nevertheless, the mutation occurs in a predicted helicase, known to be involved in DNA replication, similar to gyrase and topoisomerase, the primary targets of quinolone activity. ${ }^{21}$

It's tempting to presume that some significant change is occurring. Since aspartate and glycine differ significantly in both size and charge, the protein may bend more freely because of the reduced steric interactions, or perhaps an allosteric binding site was changed. Also possible is a loss of a nalidixic acid binding site. Whatever the mechanism, this mutation is the most parsimonious explanation for resistance to nalidixic acid: the occurrence in the samples offers an explanation for changes in the MIC towards nalidixic acid (i.e., in Figure 2 and Table 3 we notice that the flasks which have this mutation also have an increased MIC towards nalidixic acid). In addition, this is a non-synonymous amino acid mutation, and it occurs in the category of cell activity that nalidixic acid targets: DNA unwinding. Thus, experiments are being planned to construct this chromosomal mutation.

\section{After penicillin G treatment}

After penicillin G treatment, base pair 456399, C was deleted, as it was in flask 0 and flask 7. Again, it is unclear precisely what this deletion does to the protein product, but it is probable that it is a disadvantageous frameshift mutation. In this case, it would seem that this mutation is not conferring additional nalidixic acid resistance, but damaging part of the protein structure. The only 
other mutation associated with penicillin treatment is found at 4275010, in an intergenic repeat region, which does not seem to promise much in the way of metabolic changes. MIC tests on a culture with this mutation and the absence of mutations 4275010 and 4553488 would indicate how this mutation relates to nalidixic acid.

\section{CONCLUSIONS}

E. coli are fast-growing, adaptable organisms. Small changes, even to one base pair out of four and a half million, can make a significant difference in cell phenotype. Under the right pressure, these changes can be highly beneficial for the bacterium, but not for humans; resistance of bacteria to antibiotics is a dangerous phenomenon. It is important that we understand the causes and mechanisms of antibiotic resistance in order to devise better treatments to infections and infectious diseases. Understanding how a bacterium may become resistant to nalidixic acid, for example, may lead us to a better understanding of fluoroquinoloneresistant infections, and what drug or drug combination may be used to keep up with fast-growing, highly adaptable bacteria.

\section{ACKNOWLEDGMENTS}

The authors thank Dr. Demelza (Koehn) Larson for her participation on his Honors thesis defense committee. All authors thank the College of Saint Benedict/Saint John's University and the University of Minnesota for their support of this project. The authors acknowledge the Minnesota Supercomputing Institute (MSI) at the University of Minnesota for providing resources that facilitated the research reported within this paper.

\section{REFERENCES}

1. Aminov, R. I. (2010) A Brief History of the Antibiotic Era: Lessons Learned and Challenges for the Future. Front. Micro. 1, 134.

2. Chow, L., Waldron, L., and Gillings, M.R. (2015) Potential impacts of aquatic pollutants: sub-clinical antibiotic concentrations induce genome changes and promote antibiotic resistance. Front. Micro. 6, 1-10.

3. Bollin, M., Jensen, E., and Mitchell, D. (2015) Occurrence of Multiple Antibiotic Resistant Bacteria in Aquatic Environments in Central Minnesota. Am. J. Undergrad. Res. 12, 19-35.

4. Gillings, M.R. and Stokes, H.W. (2012) Are humans increasing bacterial evolvability? Trends Ecol. Evol. 27, 346-352.

5. Van Duin, D., Kaye, K.S., Neuner, E.A., and Bonomo, R.A. (2013) Carbapenem-resistant Enterobacteriaceae: a review of treatment and outcomes. Diagn. Microbiol. Infect. Dis. 75, 115-120.

6. Alekshun, M.N and Levy, S.B. (2007) Molecular Mechanisms of Antibacterial Multidrug Resistance. Cell 128, 1037-1050.

7. Martinez, J.L. and Baquero, F. (2000) Mutation Frequencies and Antibiotic Resistance. Antimicro. Agents and Chemotherapy 44, 1771-1777.

8. Beaber, J.W., Hochhut, B., and Waldor, M.K. (2004) SOS response promotes horizontal dissemination of antibiotic resistance genes. Nature 427, 72-74.

9. Kaufmann, B.B. and Hung, D.T. (2010) The Fast Track to Multidrug Resistance. Mol. Cell 37, $297-298$.

10. Gullberg, E., Cao, S., Berg, O.G., Ilback, C., Sandegren, L., Hughes, D., and Andersson, D.I. (2011) Selection of Resistant Bacteria at Very Low Antibiotic Concentrations. PLoS Pathogens 7, e1002158.

11. Linkevicius, M.Sandegren, L., and Andersson, D.I. (2013) Mechanisms and fitness costs of tigecycline resistance in Escherichia coli. J. Antimicrob. Chemother. 68, 2809-2819.

12. Adler, M., Anjum, M., Andersson, D.I., and Sandegren, L. (2013) Influence of acquired $\beta$-lactamases on the evolution of spontaneous carbapenem resistance in Escherichia coli. J. Antimicrob. Chemother. 68, 51-59.

13. Levin, B.R., Perrot, V., and Walker, N. (2000) Compensatory mutations, antibiotic resistance and the population genetics of adaptive evolution in bacteria. Genetics 154, 985-997.

14. Cirz, R.T. and Romesberg, F.E. (2006) Induction and inhibition of ciprofloxacin resistance-conferring mutations in hypermutator bacteria. Antimicrob. Agents Chemother. 50, 220-225.

15. Escherichia coli B str. REL606, complete genome. NCBI ref seq: NC_012967.1. Accessed April 4, 2016. http://www.ncbi.nlm.nih.gov/nuccore/NC_012967.1

16. Carter, A.P., Clemons, W.M., Brodersen, D.E., Morgan-Warren, R.J., Wimberly, B.T., and Ramakrishnan, V. (2000) Functional insights from the structure of the $30 \mathrm{~S}$ ribosomal subunit and its interactions with antibiotics. Nature 407, $340-348$.

17. Chumpolkulwong, N., Hori-Takemoto, C., Hosaka, T., Inaoka, T., Kigawa, T., Shirouzu, M., Ochi, K., and Yokoyama, S. (2004) Effects of Escherichia coli ribosomal protein S12 mutations on cell-free protein synthesis. Eur. J. Biochem. $271,1127-1134$.

18. Bailey, S.D., Zhang, X., Desai, K., Aid, M., Corradin, O., Cowper-Sal Lari, R. Akhter-Zaidi, B., Scacheri, P.C., Haibe-Kains, B., and Lupien, M. (2015) ZNF143 provides sequence specificity to secure chromatin interactions at gene promoters. Nat. Comm. 2, 6186.

19. Altschul, S. F., Madden, T. L., Schäffer, A. A., Zhang, J., Zhang, Z., Miller, W., and Lipman, D. J. (1997) Gapped BLAST and PSI-BLAST: a new generation of protein database search programs, Nucleic Acids Res. 25, 3389-3402.

20. Marchler-Bauer A et al. (2015) CDD: NCBI's conserved domain database. Nucleic Acids Res. 43(Database issue): D222-226.

21. Aldred, K.J., Kerns, R.J., and Osheroff, N. (2014) Mechanism of quinolone action and resistance. Biochem. 53, $1565-1574$. 


\section{ABOUT THE STUDENT AUTHOR}

Samuel Hager graduated Magna Cum Laude and with distinction in his major from St. John's University in Collegeville, MN in 2016. He received a Bachelor of Arts with a major in Biochemistry and a minor in Theology. He began laboratory research for this paper with a 2015 Summer Biology Research Fellowship at St. John's University and the College of Saint Benedict.

\section{PRESS SUMMARY}

Bacteria have demonstrated the ability to evolve quickly in response to challenges from other organisms such as the use of antibiotics for agricultural and human consumption. Many bacteria are capable of transferring pieces of DNA between organisms as a rapid means of gaining resistance to antibiotics or some other competitive advantage. In this study we were interested to see if E. coli could overcome the administration of antibiotics by means of a chromosomal mutation that could then be passed on to all future generations of the bacteria. In addition, we were interested to see if such a mutation would remain if an organism were exposed to an antibiotic from a different class of antibiotic drugs. Our results indicate that such a means of gaining antibiotic resistance is possible and confirms previous work demonstrating how bacteria can strive in the presence of multiple antibiotics. 


\title{
Constructing the Imaginative Bridge: Third-Generation Holocaust Narratives
}

\author{
Megan Reynolds* \\ Department of English, Trinity University, San Antonio, TX \\ Students:mreynold@trinity.edu* \\ Mentor:vaarons@trinity.edu*
}

\begin{abstract}
Reynolds's research examines the ways in which third-generation Holocaust writers, the grandchildren of Holocaust survivors, approach the subject of their own traumatic history and the intergenerational transmission of trauma and memory. Despite the two generational divide that separates the third generation from the preceding two generations of Holocaust writers, the transgenerational transmission of trauma continues to preoccupy contemporary narratives. This research examines the ways the grandchildren of survivors, represented in this paper by Margot Singer and Jonathan Safran Foer, confront and include lost worlds in their narratives as well as their attempts to resurrect these fractured pasts through innovative uses of imaginative leaps. The third generation continues to suffer from the intergenerational transmission of trauma and memory yet discovers innovative ways to share that trauma, evidence of evolving modes of bearing witness.
\end{abstract}

\section{KEYWORDS}

Holocaust Narratives; Third-Generation; Intergenerational Transmission of Trauma; Literature; Trauma; Memory Studies; Jewish Identity; Grandchildren of Survivors

\section{INTRODUCTION}

Holocaust memoirists like Primo Levi and Elie Wiesel (two of the most famous) struggle with trauma throughout their writing. Their writing includes certain distinctive characteristics like the hesitancy to speak at all, the "deep sense of moral urgency" to share the truth, and the utter sorrow of acknowledging Holocaust suffering. ${ }^{1}$ While some survivors wrote to preserve the truth about the Shoah, others believe that the "most appropriate response...is silence."1 Words fall short, inadequately describing the horrors survivors faced, and distorting the truth about the Holocaust itself. Survivor silence then translates to survivor's children. Many second-generation authors learned not to ask questions, to keep silent, but still experience a kind of reenacted past that is "not just remembered, it is re-lived."2

In the struggle to understand the horrors of the Holocaust, silence gave way to literary voice. The urge to share one's experiences and to document the horrors of the Shoah pushed many survivors and members of the second generation to create written testimonies. In these written accounts - from both survivors and the second-generation - fictional techniques, paradoxically, helped "make outrageous history more credible."1 These fictional techniques often eliminate "all references to past or future" to effectively "place the reader within the inferno." 1 The survivor and the second-generation writer struggle with problems of representation and how to articulate a past that feels beyond the scope of language, albeit for different reasons. For survivors, the atrocities they witnessed scarred them, leaving them to grapple with how to explain the seemingly unexplainable. Their writing depicts a "history [that] has permanently separated them from the human community" and a kind of arrested personal history. 1 Their children suffer from a different difficulty in articulating the past, namely that they did not witness it themselves but live in such close contact with those who testify to its horror. The second generation still expresses a profound connection to their parents' trauma, a concept Marianne Hirsch discusses in her theory of postmemory and one I will explore later in this paper. Both survivors and their children remain firmly trapped in past trauma.

The third generation of Holocaust writers - the grandchildren of Holocaust survivors - also demonstrates clear and persistent signs of the intergenerational transmission of trauma and memory throughout their writing. While the inheritance of trauma passed from the second to the third generation, the third generation distinguishes itself from its predecessors in its search to uncover and rebuild the past through innovative uses of imaginative leaps in their fictional stories. Without first-hand memories to rely on, the third generation transforms their inherited memories into imaginative leaps in ways that both embrace the holes they encounter and question how to fill them. Their approach to their inherited trauma expresses an inability to adequately name their own feelings of loss. While Margot Singer refers to nostalgia throughout her short stories, I refer to the phenomenon as an evolution of postmemory called post-postmemory. Despite the two-generation gap in historical distance from the Shoah, 
generationally transmitted Holocaust trauma still strongly affects these writers in visible ways as they approach their own traumatic familial histories in their writing.

The trans-generational transmission of trauma that continues to plague the third generation can be inherited via two main pathways: verbal and nonverbal. Verbal transmission, clearly the more direct channel from which to inherit trauma, includes storytelling and sharing memories. Some third-generation writers, like Julie Orringer, find themselves lucky enough to have grandparents that are not only alive, but also willing to share their experiences. "The novel," Orringer says in an interview with Sarah C. Lange, "was based in part on my grandfather's experiences during the war."3 Magdalen Ng discusses how Orriner's The Invisible Bridge "had some collaborative input from her family... Her grandmother read three drafts of the story." In this manner, stories about the Shoah can be mediated and passed down through the generations verbally. Through verbal transmission, the third generation can hear about their grandparents' experiences firsthand. Survivors pass on their memories directly to their grandchildren, a process that creates a strong empathetic bond to their now shared trauma. Although not explicitly verbal, the third generation also finds alternative means for learning about the Holocaust through museums or other cultural initiatives like books, memorials, and classes. In either directly verbal or still openly accessible pathways, the third generation can encounter Shoah history fairly easily.

The stories that museums and cultural initiatives tell do not answer many of the questions that haunt the third generation. Instead, grandchildren of survivors like Margot Singer and Jonathan Safran Foer search for their family's personal stories and experiences, the very stories that prove incredibly difficult to tell. While many members of the second generation had access to their parents and experienced their silences, the third generation runs into the silences of not only their grandparents (which could be due to their reluctance to discuss the Holocaust or their death) but their parents as well. Both generations, by "avoiding the trauma and by refraining from working it through...paradoxically recreated" a similar trauma in the third generation. ${ }^{5}$ The third generation, therefore, encounters an increased level of silence from the second generation due to the silence they face from both their grandparents and parents. While the second generation experienced silences surrounding the traumatic events of the Holocaust, they learned from their parents to keep aspects of Holocaust memory quiet. Simply put, for many second-generation writers, they learned that some elements of the Shoah remain unspoken. The second generation then passed the same kind of silence they experienced from their parents onto the third generation, which in turn created a Holocaust experience that "involved a lack of meaning, lack of words, feelings without content, horror without a story." 5 In order to tell their own story, the third generation must now overcome this doubling of silence due to not only their grandparents' reluctance to discuss Holocaust horrors, but their own parents' reticence.

\section{LOST WORLDS}

The majority of intergenerational trauma transference experienced by the third generation, therefore, falls under the non-verbal category. Marianne Hirsch created an integral theory connected to the inheritance of trauma that she refers to as postmemory. In suggesting that memory can occur after an event - even generations after - Hirsch argues that "experiences were transmitted to [the children and grandchildren of survivors] so deeply and affectively as to seem to constitute memories in their own right." 6 Postmemory affects both the second and the third generations because they feel so personally and emotionally affected by an event they never actually experienced that survivors' recollections permeate their own memories. Margot Singer, a thirdgeneration writer, accurately describes the complex phenomena of postmemory in her short story "Deir Yassin," in which one character Avraham, a member of the second generation, "knows these images may not really be memories at all, but just sediment of stories he's been told, or photographs he's seen." Avraham admits that his memories may not actually be bis memories at all, but he still cannot shake the hold they have over him or the feeling that these recollections somehow belong to him. Importantly, though, Avraham clearly pictures the memories he tentatively claims as his own; he can recall and name them.

Like the second generation, the third generation of Holocaust writers also expresses a strong historical and empathetic connection to the Holocaust even though they were not alive to witness it. Unlike the second generation, the third generation struggles to place these haunted "memories," passed on to them from parents and grandparents. Postmemory becomes post-postmemory for the third generation. Singer's "Deir Yassin," while demonstrating the postmemory of the second generation, also depicts the complicated idea of post-postmemory as something nagging but indefinable, a feeling that cannot quite be placed. Like postmemory, post-postmemory, similar to Singer's descriptions of nostalgia, indicates a longing for something but an inability to accurately locate or retrieve it. Nostalgia haunts Singer's characters. The key is the vagueness that troubles those searching for what might satisfy their longing. For Avraham and his niece Susan, nostalgia continues to plague them throughout the story, though in different ways. Susan comes back to Israel, a place she frequented as a child but has not visited in many years, to return her uncle Zalman's ashes to his childhood home. Even so, she cannot help questioning why she decided to take on such a task. At night, she thinks "Cremations are forbidden/...So what remains? Nothing./ She believes nothing, and yet here she is,/ carrying out a dead man's will. Maybe the word/ for it is just nostalgia."7 Something pulls Susan back to Israel, her family's homeland after the onset of World War II, but she cannot name what exactly draws her back. At the surface level, her uncle's dying wishes seem 
an appropriate reason to return, but even she remains unconvinced that the box labeled "CREMATED REMAINS" contains the sole reason for her homecoming. ${ }^{7}$

Her uncle Avraham who has lived in Israel almost all of his life experiences a similar tug of postmemory. In a section called "Nostalgia," he suddenly recalls "the Polish word for nostalgia... a word he didn't even know he knew, with overtones of sadness and longing the Hebrew did not have." Crucially, Avraham can articulate his postmemory whereas Susan cannot. Just as Susan returns to what she considers her ancestral home and experiences a nostalgia for a world she can never fully know, so too does Avraham suddenly yearn for his own ancestral home of Poland. Both characters long for a place they can never truly experience as a home because these worlds and memories remain obscured. Immediately after recalling the Polish word for nostalgia, Singer writes, "But whatever Avraham might be nostalgic for remains as deeply buried as the rest of his mother tongue he has forgotten or repressed." A Although unable to fully reconnect with their ancestral homes, Susan and Avraham still look towards the worlds they have each lost - and cannot adequately reclaim - with the hint of some forgotten remembrance. They experience small moments of recollection, such as Susan's memories of her childhood summers in Israel and Avraham's recall of his Polish roots, but instead of returning to that childhood world they see "nothing but [the] destruction" of their previous worlds. ${ }^{7}$ Their nostalgia, due to their respective postmemory and post-postmemory of past trauma, serves as a hope to reconnect with a world that is no longer there.

That nagging feeling postmemory and post-postmemory create drives both Avraham and Susan to try to uncover the past. Both characters' professions entail a form of digging, either physically or emotionally, to try to uncover the lost worlds they encounter. Avraham works as an archaeologist, an individual trained to uncover lost worlds and try to recreate them, to retell their story. In

"Deir Yassin" he tells his colleague, "Listen: don't you think we owe it to our children to go back and get the story straight? Don't you think they deserve to know the truth?"7 His sentiments reflect the drive for the truth and desire to uncover the past that the third generation continually pushes for. However, his colleague responds, "History schmistory...Just because they call it revisionist you think it has to be the truth?" "Even if these third generation authors (represented here by Avraham) could somehow exhume these lost worlds they may never know the story behind them. Avraham realizes that some worlds can never be uncovered, that some memories cannot be excavated, and that some recollections must invariably remain lost in the past.

In another of Singer's stories, "Hazor," revisionist claims call the biblical timeline into question; evidence once thought to support Joshua's defeat of the Canaanites, now undermines that very supposition by arguing that the Israelites never razed Hazor at all. Avraham's research, however, clings to the previously established explanation of the ancient archaeological site. He tries to remain unbiased though, and states that the "evidence was all that mattered." 8 Avraham relies on the physical evidence, "fragments of orange-brown, or grayish-yellow clay, incised or burnished, decorated or plain," he uncovers at the site..$^{8}$ But, just as his colleague in "Deir Yassin" explains, even the physical evidence may not expound the truth. Avraham arrives at no concrete answer by the end of the story; Singer never tells us which timeline archaeologists accept, leaving us exactly where we started: stuck in between two possible stories with no way to know the truth.

While Avraham struggles with the changing historical timeline, he also finds another "artifact" that might help him piece together a part of his own past: his sister Leah's diary. In reading it, he tries to recreate his own childhood through her eyes, to recover the lost world of his past. But his sister's diary disconcertingly sheds little light on his role in her past. His absence in her diary causes him to question whether "a diary contained any greater truth than any other artifact."8 Despite his attempts to learn from Leah's diary, Avraham acknowledges that his wife Eva "would have laughed at his attempts to piece together Leah's story, his fanciful theories based on the most tenuous of facts." 8 Once again, Avraham fails to answer any of the questions he has at the beginning of the short story. His inability to recreate his own sister's past proves all the more troubling for an individual trained to cogently reassemble the past from forgotten fragments.

His niece, Susan, attempts to surmount a similar challenge. As a reporter, she also relies on physical evidence to tell the story. But, unlike Avraham, who must overcome his temporal distance from the civilization he studies, Susan must also push through a physical distance. In "Body Count" Susan attempts to write about the fighting in the Balata and Jenin refugee camps in the West Bank of Israel. Unfortunately, from her office in New York, she must rely on Debbie, an American-born reporter living in Israel. Without direct access to the scene of the supposed massacre, Susan finds herself in a situation representative of the thirdgeneration writer who lacks access to survivors' memories and personal stories. Susan asks Debbie, "But did you see any bodies?"' Debbie's response, "I didn't, no," once again leaves Susan without any concrete answers; she can only rely on the fragmentary knowledge she has managed to gleam from Debbie and her own research. ${ }^{9}$ Like her uncle, Susan can only use what little she knows to create a record of the past, a record that, at the end of the Singer's short story, proves wildly inaccurate. Unlike her uncle, Susan never actually has the artifacts herself. She relies on second-hand accounts and second-hand information transmitted to her from others. Avraham's postmemory includes artifacts and memories of places he's actually been (the archaeological sites and memories from when he lived in Poland as a child). Susan's post-postmemory does not. By ending her short story with 
Susan's inaccuracies, Singer reflects third-generation anxieties about trying to tell a story with no artifacts of their own. If Susan cannot even tell recent history correctly, how can she possibly hope to tell her own familial story correctly?

Even the settings of Singer's stories reflect physically lost locations, particularly those lost to violence. Deir Yassin, once a small village that fell to violence, now houses the Kfar Shaul Mental Health Center, a hospital designed to "care for Holocaust survivors gone mad."7 Singer states, "Even now, Palestinians still call it Deir Yassin, although it isn't marked on any map," indicating that although this physical location has been destroyed, its legacy still captivates those who remember it themselves. ${ }^{7}$ Avraham can name the original location; Susan cannot. While the archaeological site Hazor has been lost to time, its legacy remains one of violence; the biblical description of it claims that Joshua razed the city when he arrived. Just like Deir Yassin, Hazor lives on only in shaky memory. The refugee camps mentioned in "Body Count" contain those lost to their homelands because of fighting. This is reminiscent of both Susan and Avraham who themselves feel dislocated. Even these refugees' makeshift homes have collapsed because of violence. Lastly, the title of her story "The Pale of Settlement," which I will examine further later in this paper, recalls the Russian partition of Poland and the regions for settlement allowed to the Jews, all of which belong to a period of history. With the dissolution of the Russian Empire, these traditionally Jewish sections also plummeted into the realm of history and memory.

Jonathan Safran Foer also includes examples of physically lost worlds in his novel, Everything Is Illuminated. Like the plethora of examples present in Singer's fiction, Foer's novel describes Trachimbrod, the fictional Jonathan's ancestral shtetl, as completely gone. These physical lost worlds signify that the third generation encounters what they perceive as unrecoverable memories and histories. The inclusion of these lost worlds capture the third generation's fear that they have lost access to history and that the only possibilities they may have to uncover the truth all lead disconcertingly to dead ends. Just as Singer's characters display a preoccupation with piecing together the past, Everything Is Illuminated also emerged from a deep-seated desire to uncover the truth behind Foer's family's experiences. His novel began as an investigation into his past, of which he had almost no knowledge. He states in an interview with Jane Zwart, "a lot of my writing has been born out of the inability to communicate things." 10 He goes on to say, "I encounter these holes in my life. The hole of my family's history in Eastern Europe. The hole of the silence about that history." 10 Foer reflects these holes and the difficulty of articulating the past in his novel, not only in the fictional Jonathan's quest to find the woman who saved his grandfather during the Holocaust, but also in the uncertainty he includes in the history of his family's supposed shtetl of origin, Trachimbrod. A plaque in Trachimbrod "marks the spot (or a spot close to the spot) where the wagon of one Trachim B (we think) went in."'11

Both Foer's and Singer's distance from their own familial past represent emotional lost worlds. Emotional lost worlds draw from fears of how to write about the Holocaust without a direct connection to the actual historical event; the third generation must determine how to discuss the Shoah even as survivors die. At a loss, they continually include imagery of lost worlds representing their longing to remember but their inability to access the past, their disconnect with the memories they feel commanded to remember. This tension proves characteristic of post-postmemory; it conveys a sense of loss as well as an inability to adequately name what exactly has been lost. It feels both personal and distant. Post-postmemory also reflects the difficulty of working with only transmitted memory instead of actual memory. Despite her family's Jewishness, "Susan herself is the kind of person to whom people sometimes say, But you don't look Jewish...The truth is...she doesn't exactly feel Jewish either. She feels hollow."' Susan must figure out how to reconnect with a heritage she feels no real relation to, an emotional past tortured by trauma that she knows only indirectly. To try to piece together her history, Susan, like her uncle who collects ancient artifacts, has her own closets "filled with artifacts from the past." 7 Yet these physical items cannot adequately retell the past or reshape the world she has lost. When, in "Body Count," Susan tries to tell the story of the supposed refugee-camp massacre she cannot help feeling "more than ever that she should be there instead of Debbie." Her family's history of trauma and their connection with the Middle East call to Susan, command her to witness the trauma firsthand. The physical distance, used here as a metaphor not only for Susan's emotional distance from her homeland, but also for the distance between survivors and the third generation, proves insurmountable. Susan remains in New York and, with "no evidence to support claims of massacre or deliberate slaughter of Palestinians by Israeli soldiers," gets the story wrong. ${ }^{9}$

Incorrect retelling of a story occurs in several of Singer's narratives, especially when her characters face issues of memory, and, more specifically, memory loss. Avraham clings to the previously established historical timeline in "Hazor" amidst abundant revisionist claims. Facing a complete rewrite of the historical and biblical timeline, Avraham must admit his own doubts about the accuracy of archaeological digs. "The problem was that the evidence could be read in so many ways. Any argument was just supposition piled on superposition, a house of sand." 8 History as he believes it could crumble at any time. This idea ultimately calls into question how we create a story using only the fragmented history which physical artifacts and inherited memory create. These incorrect stories speak to the insecurities of the third generation; they cannot possibly know the full extent of the truth, meaning that any story they may try to create themselves must inevitably fall to inconsistency. 
Singer's organization of "Hazor" casts doubt upon the reliability of a story sewn together from pieces. Singer intersperses the sections on Avraham attempting to uphold the traditional historical timescale and his musings on Leah's diary with sections dedicated to specific artifacts themselves. The juxtaposition between his studies in ancient archaeology, his interest in his sister's private life, and his descriptions and theories about certain artifacts reveal a similar inability to come to a firm conclusion about the past, even his own past. If Avraham cannot even truly understand his own sister from her diary then how can he hope to understand a culture that perished long ago and left behind similar everyday objects? Specifically, Singer includes a section on a Cuneiform tablet, a marker of human writing and, more importantly, the human desire to record life. The tablet, like his sister's diary, mentions few specifics about date and time, ultimately reminding Avraham that "Everything depended on a few lines etched in red-brown clay." B Both the tablet and the diary rely on a "scratch made by a human hand," but neither tell Avraham what he so desperately wants to know: the truth about the past. ${ }^{8}$

Susan, as a member of the third generation, faces a much more difficult path because unlike Avraham she does not have access to artifacts from her past that have any kind of coherent story. When she asks Avraham for her mother's diary, he lies and says that the he could not find the diary before throwing it away. He denies her attempt to recover her past. While Avraham can look to mementos from his past, Susan can only rely on the scant artifacts she can find, and then only on the emotional connection she has to them without ever really knowing the story behind them. Singer demonstrates this with uncle Zalman's death (Avraham's brother) in "Deir Yassin." After his death, Zalman, like the generations before him, leaves only "a fistful of facts both random and worn that hardly add up to an entire man/ the way eyes, a nose, ears, and teeth do not add up to a face" for Susan to fit together into a coherent narrative. ${ }^{7}$ Since much of the transference of memory occurs piecemeal, the third generation continually encounters half conversations about their past which can actually "drive the [third generation's] impulse to piece together" the full story about their own traumatic, familial past. ${ }^{12}$ While some narratives reflect a strong desire to tell their grandparents' stories in order to preserve their memories, more often than not Margot Singer's characters desperately want to fill the gaps in their own knowledge. Susan therefore collects trinkets of history from the older generations, items infused with other's memories that somehow become her own. This inheritance occurs without Avraham sharing one story during her visit in "Deir Yassin."

The lack of storytelling present in "Deir Yassin" leads ultimately to one horrifying question for third-generation writers: how do you recover lost worlds when survivor memory fades or grandparents die? Now that her grandparents are dead Susan ventures back to Israel to connect with her mother's side of the family. Unfortunately, she only uncovers silence. When Susan asks Avraham what the building that now stands atop the old site of Deir Yassin is, he responds that it is only a mental hospital. He does not attempt to tell her the history of Deir Yassin, effectively silencing the very past Susan expresses a desire to learn about and leaving that past unnamable. Yet Avraham, more than anyone else in the story, should understand "what happens... when memory fails" because his wife Eva suffers from severe Alzheimer's disease. ${ }^{7}$ He witnesses the aftermath of memory loss every time he visits his wife at the same mental hospital that rests atop the ashes of Deir Yassin. By positioning the mental hospital that serves both those suffering from "Jerusalem Syndrome" and those, like Eva, whose memories are "as blank as air" directly atop the site of a massacre, Singer indicates that trauma falls to silence, getting buried and forgotten as time progresses, unless someone continues to tell the story. ${ }^{7}$ Even Avraham cannot remember specific details of his life in Poland before his family moved to Israel: "Among the things Avraham cannot remember/ is what the leaving was like."7 The archaeologist cannot unearth his own past: only expose the holes.

For many third generation writers, issues of survivor memory, and specifically memory loss, correlate with the overwhelming fear of losing their connection with their past. Without access to these memories, the third generation once again encounters dead ends and silences. However, the imperative to remember and carry on Shoah legacy that follows Holocaust survivors and their families puts the third generation at odds with their realities. In stories that address issues of memory loss such as Singer's, how can the third generation remember when the only witnesses of the actual event who are present in the narratives do not remember? These lost worlds represent the fear of how to portray the Holocaust without direct access to memories or witnesses and the third generation's lack of knowledge. They also prove particularly troubling for the third generation trying to fill these gaps in their writing. The grandchildren of survivors, faced with trying to piece together fragments of transmitted memory, must figure out a way to recover these lost worlds not only in the knowledge they discover personally but in the articulation of that knowledge as well.

\section{RECONSTRUCTING LOST WORLDS}

Unfortunately, even if the third generation may be able to fill in some of the gaps they have, as seen in Singer's stories that include fragments and artifacts like "Hazor," they often encounter dead end after dead end. Without the full story about familial Holocaust trauma, the third generation often balances Holocaust trauma with other everyday aspects. Additionally, the subtlety with which third generation writers acknowledge the Holocaust in their characters' lives creates stories that rely on family relationships and everyday occurrences instead of Holocaust horrors. While direct references to Holocaust trauma convey "a sense of immediacy and impact" for the first and second generations, "the third generation writer views these events as an indirect 
part of the narrative, one balanced by other, also important, histories."13 Singer's "Deir Yassin," which tells three stories simultaneously (that of Susan, Avraham, and Zalman), exemplifies this balance. Even though Singer constantly shifts between these three distinct narratives, "one story doesn't overpower another; one character doesn't reside in the shadow of another."13 Similarly, Foer includes stories from the fictional Jonathan, Alexander, and Jonathan's ancestors. Most third generation writers do not create stories that begin and end with the Holocaust. Instead they balance this trauma with the mundane and allude to the Holocaust throughout.

For both Singer and Foer, balancing their familial Holocaust trauma with other aspects of daily life reflects a hesitancy to claim Shoah suffering as their own. Attempts to imagine the horrors their grandparents faced without appropriating them reflect a kind of empathetic understanding, something the third generation must struggle to uncover and to understand as well. Their hesitancy reflects the difference between actual memory and inherited memory: survivors claim their identity. They cannot help but claim it because it has literally been inscribed on their bodies. The third generation both respects and struggles to understand their role in that identity that shapes their family but can never truly be theirs. Third-generation writers, therefore, include subtle hints that conjure specific Holocaust memories in readers' minds; they constantly struggle with "how much of the past [they] can carry forward and how much [they] leave behind."14 Contemporary novelists are "preoccupied with the ways in which identity is affected by the ongoing presence of the past in the lives of those who did not experience it but are nonetheless profoundly affected" by inherited Holocaust trauma. ${ }^{15}$ They must determine how to create their own lives and memories without losing themselves in the past.

The subtlety of third-generational Holocaust imagery urges the reader to dig into the text, to uncover meaning, and to foster a dialogue between themselves and the text itself. Uncovering meaning with only miniscule hints to work with reflects the very situation the third generation faces. The subtlety they employ does not imply that the third generation feels less affected by the Holocaust, but rather that they simply approach the subject more cautiously because of their increased historical distance and their fundamental lack of knowledge of their familial histories (that is their personal histories), as well as their empathetic connection to the Shoah. In the face of so many lost worlds, the task of the third generation is to piece together these fragments of history, to "reconstruct and reassemble fragmented lives," and to create a cogent articulation of the past. ${ }^{16}$

To do this, they turn to innovative imaginative leaps. The third generation uses imaginative leaps in their fiction to reflect their fragmented identity and knowledge. Post-postmemory, in its inability to be pinned down, creates a space in which the third generation imaginatively constructs their own connection to their traumatic history. Due to grandchildren's increased emotional and historical distance the Holocaust is "increasingly a subject for the imagination." 13 As Holocaust survivors die, leaving an almost impenetrable silence, the third generation still finds ways to break through the quiet and connect to their familial past despite losing their direct link to Shoah trauma. The third generation, using transmitted trauma and memory, must make bigger leaps to compensate for the larger distances they must cover. While this does make discovering one's family history harder it also means "The third generation is much less restrained than its predecessors. They search for memory even while giving free rein to artistic imagination that informs a variety of innovative narrative techniques." 17 These "innovative narrative techniques" can be broken down into two categories: imaginative uses of form and imaginative uses of language and content.

Creative approaches of form include structural innovations in the story itself (chapter breaks and shifts between narrators) and the linear narrative (jumps throughout time taking the reader from past to present and back again). More often than not, imaginative leaps in form shape the ways in which third-generation authors break up their narratives. Breaking the narrative, shifting back and forth from one narrator to the next or from one protagonist to another, reflects not only the third generation's fragmentation, but also the ways in which they balance Holocaust trauma with other elements of the story and with a sense of life before and beyond the Holocaust. The third generation's use of innovative structural forms represents their "resistance to the use of a linear or neatly cohesive narrative."18 Writers like Jonathan Safran Foer and Margot Singer both experiment with form by pursuing multiple story lines throughout their narratives. Instead of transitioning smoothly from one storyline to the next, each author jumps, section to section, among different characters' perspectives. Foer's novel weaves the fictional Jonathan's distant past together with his contemporary search for that same past. Each chapter tells a different history, introduces new characters, and forces us to try and organize everything linearly ourselves.

This constant shifting gives the reader a kind of whiplash effect, especially in Foer's novel that jumps from past to present consistently throughout. The push and pull between the past and the present mimics the third generations' constant debate about how much of the past they can plausibly carry forward and still remain aware of their present lives and circumstances; thirdgeneration writers want to include the past, but must find ways to incorporate that past within the present they choose to write about. Experimenting with form in this manner also forces the reader in multiple directions, causing them to constantly remind themselves of what just happened in one story line and how that connects to the next storyline, which mirrors the fragmentation in the lives of grandchildren of survivors. 
While Foer shifts between storylines throughout a longer narrative, Singer does so in her short stories. Instead of fully explained stories, Singer includes vignettes, small instances of particularly strong imagery. The structure of Singer's stories reflects the way pieces do not always add up to a whole. Just as Susan knows only a few details about her uncle, "That he was seventy when he died of a heart attack/...That he never went to synagogue and had only disdain for God/...That he had a crooked eyetooth, hairy nostrils and ears," so too does Singer only give us moments, instead of a coherent and complete story, from Susan's and Avraham's lives throughout "Deir Yassin". 7 In "The Pale of Settlement," Singer jumps between Susan's mother's stories and Susan's complicated relationship with her boyfriend, James. Organized in a similar fashion, "Body Count" bounces between Susan's job as a reporter and her relationship with her coworker and his girlfriend. As previously mentioned, Singer also fragments "Hazor" amongst Avraham trying to reaffirm the traditional historical timeline, his attempts to decipher his sister's past, and his catalogue of artifacts found during his dig at Hazor. How can Susan possibly learn about her past familial trauma when the direct witnesses to it are dead, senile, reticent, or stumbling through a broken past themselves? Her knowledge of her past is relegated to fragmentation in the form of artifacts like the Cuneiform tablet or her mother's diary that cannot adequately tell a complete story and to which she has no access. Her stories, due to being composed of these unique vignettes, function like memory itself: reliant on a quick succession of images of poignant moments in our lives, but ones that do not tell the whole history. These vignettes include both prose and poetry, which are both deliberate ways to force us into new ways of thinking. Each section relies on strong imagery, but by introducing the poetic form Singer pushes us to consider the language she uses anew. Perhaps introducing new forms of language can unmask the past and tap into the lost worlds through a new perspective.

Singer's deliberate fracturing of language through her poetic forms and vignettes mirrors not only the fragmentation the third generation experiences, but also the profound silence that pervades their attempts at recovery. Her characters represent hope that this reticence can be broken. Avraham and Susan's occupations strive to give a voice to the silence surrounding the past (both the distant past that Avraham studies at archaeological sites and the recent past that Susan tries to report) and especially give a voice to those who did not get to speak for themselves. Avraham even admits that memory resembles a "story you invent in the shape of your desire" instead of "something you could excavate, analyze, piece together, solve." Singer implies that the third generation cannot simply rely on physical artifacts to create their narratives. The fact that Avraham and Susan attempt to go behind the records, and beyond the fragmented artifacts they discover, demonstrates the necessity of these imaginative leaps in thirdgeneration narratives; they have no other way to tell the story.

These creative manipulations of form indicate that the third generation feels much less restricted than the second and first generations to tell an absolutely factual story about the Holocaust. Instead, these narratives focus more on how they tell the story and on their search for identity. To do this, the third generation must be willing to take imaginative leaps to glue together their fragmented knowledge. Without a clear sense of their own familial history, the grandchildren's imaginative leaps in content often include the use of myth or fable.

Foer, in Everything Is Illuminated, essentially creates his own originary myth. For many third generation writers who face "the absence of historical 'facts,' myth becomes a valid alternative to illuminating one's origin."'19 An origin myth strives to explain where a person came from, to root them in a history that helps them understand their present. Foer begins his origin myth, a "version of the past [that] has no qualms about being openly fictional," with his distant grandmother who is quite literally born into trauma. ${ }^{20}$ After her parents' bizarre deaths in a wagon crash into a river, a newborn girl, "still mucus-glazed," floats to the river's surface amidst the physical wagon fragments, but also the fragments of her lost life. ${ }^{11}$ Foer creates the image of a newborn literally born into wreckage and into a life with no parents and subsequently no explanations of her own familial past. The newborn's fragmentation clearly represents the intergenerational transmission of trauma and the peculiar situation of the third generation. The only direct witnesses to the event are the fictional Jonathan's distant grandmother's parents (who died) and a few townsfolk (who did not actually see anything).

This passage depicts not only the struggle the third generation faces when trying to piece together the fragments of their past, but also the unique way in which they choose to do so. Foer does not try to recreate a factually-based, historical representation of his family's origins; instead he paints a picture of a child destined for trauma, a child floating amidst the remnants of a lost world, destined to search for meaning amongst the fragments. As Monica Osborne explains, grandchildren of survivors, unlike their predecessors, experience much more caution when declaring their identity, if they declare one at all. Their writing is "not an assertion of identity" but a "quest for or question regarding identity." 18 Instead of laying claim to an identity, the third generation, in part due to the gaps in knowledge, questions their identity; they search for it in these narratives but never seem to find a definite answer. It is, therefore, precisely the third generation's distance that affords them more freedom to take more imaginative leaps than survivors, who felt absolutely compelled to explain what the camps were actually like, and the second generation, who tried to recreate their parents' experiences. 
Singer's short story "Deir Yassin" clearly indicates the continued intergenerational transmission of trauma throughout her narrative with fairy-tale-like elements. At one point, Susan and Avraham's clocks freeze at exactly the same time signifying that the inheritance of Holocaust trauma that troubled the second generation continues to plague the third generation. When their clocks simultaneously stop, Singer indicates that they both feel drawn to and paradoxically trapped in the past. Singer poignantly describes the nature of indirectly experiencing trauma, as those that suffer from postmemory and post-postmemory do due to their distance but strong emotional connection to the actual event, when she writes that "Even those who escape dismemberment will suffer from an endless ringing in their ears." " Like Avraham "constructing an impossible story from the barest of facts" when trying to reassemble his sister's life, the third generation often takes leaps of imagination to create a complete story from just a "ringing in their ears." As Singer suggests, transmitted Holocaust trauma continues to haunt the third generation but they choose to describe it in fantastical ways.

Although Singer's "Deir Yassin" reflects the absence of storytelling, another of her stories demonstrates a clear preoccupation with what exactly storytelling is, and how myth and fable shape the tales we hear. Singer includes a storyteller, Susan's boyfriend, in "The Pale of Settlement." At night, James seduces Susan with his tales of the ancient Aborigines by describing their creation myth set in a time "before the world was fully awake."21 What James refers to as "Dreamtime" recalls Susan's earlier nostalgia because it exists "just below the surface of consciousness." 21 What attracts Susan to this myth, however, is how she imagines the ancient Aboriginal ancestors "cracking through the earth." 21 Unlike Susan's, these Aboriginal ancestors can break through their metaphorical and physical darkness and shed light on their history. Susan's memories and stories of her ancestors remain lost in their own half dreamlike state in which Susan can hear "the faintest tinkling of bells" or feel "a pressure on [her] chest" but where she cannot name the feeling or memory itself. ${ }^{7}$

The most important storyteller present in "The Pale of Settlement," however, is Susan's mother because she may actually be able to enlighten Susan about her familial trauma. Each night, Susan's "mother told her bedtime stories. The stories were always about her mother's childhood and they were always sad." 21 Despite the solemnity of her stories, Susan continues to ask to hear them. In Singer's narrative, Susan first asks to hear about her great-grandfather and his banishment to Siberia. Susan wants to hear about the persecution and encampment of her Jewish ancestors. The question remains: why does Susan continue to ask for these kinds of stories? The answer lies in the fact that lost worlds pervade her mother's stories, along with lost places and people that drive Susan to try to uncover as much as possible about them. "The places her mother talked about had vanished," Singer writes, "into a pink blotch that spread across the top of the map that pulled down over the blackboard in Susan's classroom like a window shade." 21 Putting the story's locations on a map in a classroom indicates that Susan should learn something from these bedtime stories.

The map unfortunately also serves as a window shade, something that blocks out light. In other words, the map paradoxically represents something Susan needs to learn from and a dead end with no way to see past the vanished places. Susan cannot even hope to visit these places because "You couldn't go to those parts of the world any longer. They were gone." ${ }^{1}$ Even Susan's homecoming to Israel in "Deir Yassin," a visit punctuated by a haunting nostalgia and a sense of hollowness of self, reflects the impossibility of retuning to the lost worlds Singer includes throughout her collection. Similarly in "The Pale of Settlement," Susan's "mother's stories gave her a hollow feeling behind her ribs, as if there was a trapdoor inside her that dropped open to her mother's pain." 21 While this image clearly implies the intergenerational transmission of trauma and the empathetic bond created by such transmission, the trapdoor also implies a hidden secret, something Susan cannot name. Susan seeks to fill that hollowness behind her chest, but she can never fully uncover her past's mysterious pull because so much of it has been lost both physically and emotionally.

The only way Susan can really recover these stories is through her own imagination. Without any "photographs of her mother's childhood home... she had to make it up." 21 Susan builds the setting of her mother's childhood through creative manipulations of her mother's memories as they have been passed onto her. Even though these stories obviously refer to her mother, Susan notes that her mother would begin her stories with "Once upon a time... as if the stories might be made-up tales." 21 By destabilizing the classic children's bedtime story and morphing it into an ongoing story that shares familial trauma, Singer not only distances the trauma but also reminds us how ingrained this trauma becomes in the lives of the grandchildren of survivors. Susan asks questions of her mother like "But what was it like? When she died?" only to receive silence. ${ }^{21}$ Despite her mother refusing to answer such inquiries, Susan still voices how much third-generation authors desperately want to hear the whole story: "But Susan did need to know, the way she covered her eyes during the scary parts of movies but peeked through her fingers anyway." 21 Susan only hears one happy story from her mother, that of her and Susan's father "falling in love at first sight." 21 Immediately the idea of love at first sight feels reminiscent of childhood fairytales of princesses and princes. Shortly after mentioning this cliché, Susan admits, "she wasn't sure her parents ever really got along." 21 What she searches for in her mother's stories is not necessarily the truth (a historically accurate retelling of the past) but her mother's memories of what happened. The only way Susan can possibly fill the gapping holes in her familial knowledge is through these leaps into fantasy. 
Singer ends this story, and the entire short story collection, with a short meditation on storytelling itself. Susan remembers that Hebrew, the tongue of her ancestors, has "no word for fiction." 21 Instead, the "closest term for fiction was bidayon... a falsehood or a lie." 21 This statement reflects the third generation's fears of losing their own history and the truth behind their family's trauma. How do third-generation authors like Singer and Foer ever get the story straight? As we observe throughout the short stories examined in this paper, Singer's characters often fail; they repeatedly tell an incorrect story or, if not entirely incorrect, disconcertingly incomplete. But Singer's last line of her entire collection reflects a different aspect of third-generation narratives. It reads, "People told you what they needed to believe." ${ }^{21}$ For the third-generation author, therefore, stories reflect a way to share information, but the inclusion of myth or fable allows the author to tell as complete a story as possible. The truth behind the story ultimately does not matter as much as what the teller decides to communicate.

\section{CONCLUSION}

Driven by a strong desire to uncover the truth about their familial history, grandchildren of survivors write to fill in the holes they have about their traumatic past. Emerging from these gaps, the third generation struggles with identity, never claiming a fixed identity but constantly questioning and searching for what it means not only to be Jewish in a post-Holocaust world, but a grandchild of survivors. Unfortunately, they also continually encounter "lost worlds," pieces of memory and history that can never fully be uncovered. To try and piece together their fragmented knowledge and exhume these lost worlds, they create innovative imaginative leaps both in form and content.

The third generation uses innovative, imaginative leaps to fill gaps in knowledge while acknowledging that they may never actually know the full story. For this reason, their stories often openly embrace the fantastic and the mythic. They do not try to recreate their grandparents' trauma but to communicate their own fragmentation. Despite the fragmentation the third generation continually encounters, Foer and Singer's narratives unfailingly demonstrate the persistent presence of inherited trauma and the evolution of postmemory to post-postmemory. As Foer describes in his fictional history of Trachimbrod, the "children had it worst of all, for although it would seem that they had fewer memories to haunt them, they still had the itch of memory as strong as the elders of the shtetl. Their strings were not even their own, but tied around them by parents and grandparents - strings not fastened to anything, but hanging loosely from the darkness." 9 The Holocaust clearly still affects the third generation, illuminated in the ways they choose to write about their traumatic family histories. The intergenerational transmission of trauma and memory continues to transform with each generation, an evolution in modes of bearing witness and Holocaust representation.

\section{ACKNOWLEDGEMENTS}

The author cannot adequately express how thankful she is to Dr. Victoria Aarons and all of Dr. Aarons's tireless help with this project. Reynolds hopes to continue studying this topic in the upcoming years. She is thankful for everyone who listened to her discuss this subject at all hours of the day and night and is especially grateful for everyone who continues to listen.

\section{REFERENCES}

1. Teichman, Milton, and Sharon Leder. "Introduction." Introduction. Truth and Lamentation: Stories and Poems on the Holocaust. Urbana: U of Illinois, 1994. 1-42. Print.

2. Katz, Gil A. "Trauma in action: the enacted dimension of analytic process in a third generation Holocaust survivor." $A$ New Freudian Synthesis: Clinical Process in the next Generation. By Andrew B. Druck. London: Karnac, 2011. 239-47. EBook Collection (EBSCOhost). Web. 27 May 2015.

3. Lange, Sarah C. "Julie Orringer." The Writer 2011: Literature Resource Center. Web. 2 June 2015.

4. Ng, Magdalen, The Read Interview. "Gran inspiration; Julie Orringer's new book is based on her grandfather's experiences in Paris and Hungarian labour camps." Sunday Times, The (Singapore) 12 June 2011: NewsBank. Web. 2 June 2015.

5. Talby-Abaranel, Michal. ""Secretly Attached, Secretly Separate" Art, Dreams, and Transference-countertranference in the Analysis of a Third Generation Holocaust Survivor." A New Freudian Synthesis: Clinical Process in the next Generation. By Andrew B. Druck. London: Karnac, 2011. 219-37. EBook Collection (EBSCOhost). Web. 27 May 2015.

6. Hirsch, Marianne. "The Generation Of Postmemory." Poetics Today 29.1 (2008): 103-128. Humanities Source. Web. 10 June 2015.

7. Singer, Margot. "Deir Yassin." The New Diaspora: The Changing Landscape of American Jewish Fiction. By Victoria Aarons, Avinoam J. Patt, and Mark Shechner. Detroit: Wayne State UP, 2015. 413-432. Print.

8. Singer, Margot. "Hazor." The Pale of Settlement: Stories. Athens: U of Georgia, 2007. 117-47. Print.

9. Singer, Margot. "Body Count." The Pale of Settlement: Stories. Athens: U of Georgia, 2007. 166-87. Print.

10. Zwart, Jane. "Those things tumbling around inside: a conversation with Jonathan Safran Foer." Books \& Culture Jan.-Feb. 2013:

11. Foer, Jonathan Safran. Everything Is Illuminated: A Novel. New York: Harper Perennial, 2008. Print.

12. Pisano, Nirit Gradwohl. Granddaughters Of The Holocaust : Never Forgetting What They Didn't Experience. Brighton, MA: Academic Studies Press, 2012. eBook Collection (EBSCOhost). Web. 18 May 2015. 
35-37. Literature Resource Center. Web. 2 June 2015.

13. Lang, Jessica. "The History Of Love, The Contemporary Reader, And The Transmission Of Holocaust Memory." Journal Of Modern Literature 33.1 (2009): 43-56. MLA International Bibliography. Web. 21 May 2015.

14. Freeman, John. "The story my grandfather couldn't tell me; Interview." Times, The (London, England) 31 Mar. $2007:$ NewsBank. Web. 1 June 2015.

15. Gasiorek, Andrzej. "Michael Chabon, Howard Jacobson, And Post-Holocaust Fiction." Contemporary Literature 4 (2012): 875. Project MUSE. Web. 17 June 2015.

16. Berger, Alan L., and Asher Z. Milbauer. "The Burden Of Inheritance." Shofar: An Interdisciplinary Journal Of Jewish Studies 31.3 (2013): 64-85. MLA International Bibliography. Web. 21 May 2015.

17. Berger, Alan L. "Unclaimed Experience: Trauma And Identity In Third Generation Writing About The Holocaust." Shofar: An Interdisciplinary Journal Of Jewish Studies 28.3 (2010): 149-158. ML A International Bibliography. Web. 21 May 2015.

18. Osborne, Monica. "Representing the Holocaust in Third-Generation American Jewish Writers." The Edinburgh Companion to Modern Jewish Fiction. By David Brauner and Axel Stähler. 1st ed. Edinburgh: Edinburgh UP, 2015. 149-60. Print.

19. Codde, Philippe. "Transmitted Holocaust trauma: a matter of myth and fairy tales?" European Judaism 42.1 (2009): 62+. Literature Resource Center. Web. 21 May 2015.

20. Feuer, Menachem. "Almost Friends: Post-Holocaust Comedy, Tragedy, and Friendship in Jonathan Safran Foer's "Everything Is Illuminated"" Shofar 25.2 (2007): 24-48. JSTOR. Web. 03 June 2015.

21. Singer, Margot. "The Pale of Settlement." The Pale of Settlement: Stories. Athens: U of Georgia, 2007. 188-211. Print.

\section{ABOUT THE STUDENT AUTHORS}

Megan Reynolds graduated in May of 2016. She majored in English and minored in Creative Writing and Spanish at Trinity University in San Antonio, TX. In the fall of 2016, she began her graduate studies in English at the University of Oregon in Eugene, OR.

\section{PRESS SUMMARY}

The work examines how Holocaust trauma changes generationally, specifically how the grandchildren of Holocaust survivors write about their own familial traumas. While the second generation demonstrates signs of Marianne Hirsch's concept of postmemory, the third generation shows the evolution of postmemory to post-postmemory. The third-generation author uses imaginative leaps to demonstrate not only their fragmentation but also their desire to complete the story in any way they can. Overall, inherited trauma continues to affect the grandchildren of survivors, evident in the ways they choose to write about their traumatic pasts. 


\title{
Mathematical Modeling Analysis to Simulate the Dynamics of Immune Cells, HIV, and Tuberculosis
}

\author{
Rumana Abmed *a \&abbubur Rabman ${ }^{b}$ \\ aDepartment of Biology, the City College of the City University of New York, New York, NY \\ bDepartment of Mathematics and Statistics, University of North Florida, Jacksonville, FL
}

Student: rumed1992@gmail.com*

Mentor:

\begin{abstract}
The dynamics of immune cells, HIV, and tuberculosis can be described by a system of differential equations. We developed the formulations for this dynamical system. To evaluate the system as time goes to infinity, we investigated the equilibrium solutions. We established the criteria for stability based on the characteristics of the Jacobian matrix associated with the dynamical system. To further investigate the stability of the system, we developed phase plane diagrams for the sets of assumed values of the parameters. We have investigated the curves for different values of the starting conditions of immune cells and the antigens. Along the curves, we observed the growth and decay processes. The stability of the system has been established by examining the phase plane diagrams as the solution approaches the equilibrium point. Based on phase diagrams, both stable and unstable systems have been simulated and examined in this study. Finally, we developed and evaluated the graphs for the unsteady variations of immune cells, HIV, and tuberculosis to see how the antigens grow because of the diminishing effects of immune cells in the system as time increases.
\end{abstract}

\section{KEYWORDS}

Mathematical Biology; Infectious Disease Modeling; Dynamical System; Simulation of Immune Cells and Antigens

\section{INTRODUCTION}

We performed mathematical analyses to investigate the growth and decay of the population of blood cells and antigens in a host. These analyses lead to the establishment of mathematical models that can be used to simulate the antigenic variations and impact of infectious disease on a human population. ${ }^{1}$ An in-depth analysis includes investigation of the formulations for the population that are infected and susceptible. ${ }^{2} \mathrm{~A}$ major concern is the growth of infection caused by antigens on an HIV patient. There are declining trends on the mortality and morbidity rates of tuberculosis, ${ }^{3}$ however, an HIV patient is highly susceptible to the infection caused by other agents such as tuberculosis.

We developed formulations to evaluate the effects of an infection on an HIV patient. An HIV patient is infected with a virus called lentivirus, which is a subgroup of retrovirus. The infection caused by an opportunistic virus or a bacteria can complicate the conditions of an HIV patient. ${ }^{4}$ A co-infection of $13 \%$ occurred with HIV patients in 2011.5 There will be stress on the immune cells already engaged in fighting the HIV virus. The immune response will occur from the body due to the presence of a new opportunistic agent. An immune system of a healthy and HIV-free person is able to overcome the effects of any pathogen by eliminating it through the immune reactions. However, the pre-occupied and stressed immune system will have to deal with the new pathogen in an HIV patient.

The system in an HIV patient with co-infection will involve the dynamics of the immune cells, the HIV virus, and a new opportunistic pathogen. HIV patients are vulnerable to the infections caused by certain opportunistic pathogens. These pathogens take the opportunity provided by a weak immune system. One such opportunistic pathogen is a bacterium called tuberculosis. An earlier study was performed to develop formulations for the investigation of the long-term dynamics of tuberculosis. ${ }^{3}$ This study focuses on the formulation and investigation of the dynamical system in an HIV patient infected by tuberculosis. In addition, the dynamical system will involve the processes of interaction within the host.

The infections caused by HIV lead to the deaths of infected cells due to the pathological activity (cytopathicity) of HIV or by immune reactions. ${ }^{6} \mathrm{HIV}$ is a group of RNA viruses (ribonucleic acid) that insert a DNA (deoxyribonucleic acid) copy of their genome into the host cell in order to replicate. These processes can lead to a complicated dynamic involving the growth and decay of HIV. Further complications occur with the introduction of a new pathogen. In this study, we developed mathematical relationships to represent the effects of HIV and the effects of tuberculosis on the immune response. The net specific growth rates will include the terms that will represent the interaction of immune cells, HIV virus, and tuberculosis. 
Mathematical modeling analyses have been widely used for the simulation of HIV infection. The population model formulation for the transmission of HIV included susceptible and infected individuals in a community, We performed a study to review the technical approaches for the development of the mathematical models on the population dynamics associated with HIV infection. ${ }^{8}$ The epidemiological models were developed to simulate the transmission dynamics of the spread of HIV. The investigation of HIV in a host requires development of governing equations involving rate constants as parameters for growth, decay, and mass action. ${ }^{9}$ The dynamical system for HIV included the development of the formulations for the concentrations of infected T-cells, uninfected T-cells, and viruses. ${ }^{10}$ The formulations for within-host models included viruses as well as susceptible and infected target cells. In the diversity threshold model, the formulations were developed for the density of virus strains and non-specific T-cells. The dynamics of mature and immature T-cells were formulated in a host with HIV infection. ${ }^{11}$ We performed a mathematical modeling analysis for HIV pathogenesis and treatment. ${ }^{12}$ Through this modeling study, HIV dynamics, disease progression, and therapy were investigated.

In the aforementioned studies, we modeled T-cells and HIV for the investigation of the system in a host and for the investigation of the transmission in the population of a community. The present modeling analysis entails the investigation of the evolution of non-specific T-cells, HIV, and tuberculosis in an infected host. The objectives of the study are as follows.

- Develop the dynamic formulation for non-specific T-cells, HIV, and tuberculosis.

- Derive the equilibrium solution.

- Perform a stability analysis based on the equilibrium solution.

- Perform analysis of the phase plane diagrams for the dynamical system.

- Simulate an example problem.

\section{MODEL FORMULATION}

When attacked by the HIV virus, T-cells are able to fight off the invasion for a period of time. Simultaneously, the HIV virus destroys infection-fighting T-cells. As a result, the immune system becomes less effective at fighting disease (including the spread of HIV). The present model formulation incorporates the forces involved in this process. The forces of growth and decay are included in the formulation, along with the effects on the system involving non-specific T-cells, HIV, and tuberculosis.

T-cells, or immune cells, are an essential and natural component of the human immune system. The primary job of T-cells is to attack and destroy cancerous cells, cells infected with a virus, and in general, any cell containing foreign antigens. The typical Tcell count in a healthy person is about 1000-2000 per cubic millimeter. T-cells are created in the lymphatic tissues. These tissues normally produce T-cells at a uniform (constant) rate, but when a need is detected to combat a virus, additional T-cells are created. T-cells only live for a finite period of time. HIV is measured as a viral load in a sample of blood. The viral load is the number of HIV virus particles in a milliliter of blood. The bacterium for tuberculosis is measured in Colony Forming Units $(\mathrm{CFU})$. The $\mathrm{CFU}$ is defined to be the number of bacteria in a sample (milliliter) of blood. ${ }^{13}$

Let $T$ be the quantity of immune cells (non-specific T-cells), $V_{H}$ be the quantity of HIV, and $V_{T}$ be the quantity of tuberculosis. In the absence of immune cells, the population sizes $V_{H}$ and $V_{T}$ will grow exponentially. ${ }^{6}$ Let's formulate the differential equation for the three populations quantified by the three dependent variables: $T, V_{H}$, and $V_{T}$. The population growth equations for $T, V_{H}$, and $V_{T}$ with the corresponding net specific growth rates can be written as

$$
\begin{gathered}
\frac{1}{T} \frac{d T}{d t}=\mu_{1}, \\
\frac{1}{V_{H}} \frac{d V_{H}}{d t}=\mu_{2} \\
\frac{1}{V_{T}} \frac{d V_{T}}{d t}=\mu_{3}
\end{gathered}
$$

Equation 1.

Equation 2.

Equation 3.

Here $\mu_{1}, \mu_{2}$, and $\mu_{3}$ are net specific growth rates for non-specific T-cells, HIV, and tuberculosis, respectively. The net specific growth rates are dependent on the forces of growth and decay as well as their effects, assuming that the rates of change of the populations are proportional ${ }^{14}$ It is assumed that the net specific growth rate $\mu_{1}$ will be proportional to the population of $V_{H}$ and $V_{T}$, as will the individual net growth rate. The number of T-cells does not increase in an unbounded fashion. The individual net 
growth rate for the immune cells is proportional is to a logistic term: $\alpha\left(1-\frac{T}{T_{\max }}\right)$. Here $T_{\max }$ is the least upper bound for the population of T-cells. HIV and tuberculosis will have adverse effects on the immune cells. Based on the aforementioned assumptions, we can write the net specific growth rate, $\mu_{1}$, for $T$ as

where

$$
\mu_{1}=\alpha\left(1-\frac{T}{T_{\max }}\right)-\beta V_{H}-\gamma V_{T}
$$

$\alpha=$ net growth rate of $T$,

$\beta=$ rate of the destructive effects on $T$ of the interaction of $T$ and $V_{H}$, and

$\gamma=$ rate of effects of the interaction of $T$ and $V_{T}$ on $T$.

Substituting Equation 4 for $\mu_{1}$ in Equation 1, we can write

$$
\frac{d T}{d t}=\alpha T\left(1-\frac{T}{T_{\max }}\right)-\beta T V_{H}-\gamma T V_{T}
$$

Equation 5.

Tuberculosis is the most common co-infection in patients with HIV We found that the HIV load was significantly higher in patients co-infected with tuberculosis, ${ }^{15}$ so it can be assumed that tuberculosis will cause an increase in the growth of HIV. It is known that the immune cells will cause a decrease in HIV. Therefore, the net specific growth rate for HIV can be written as

where

$$
\mu_{2}=-\xi T+\eta+\zeta V_{T},
$$

Equation 6.

$\xi=$ the rate of the effects of the interaction of $T$ and $V_{H}$ on $V_{H}$,

$\eta=$ net growth rate of $V_{H}$, and

$\zeta=$ rate of the effects of the interaction of $V_{H}$ and $V_{T}$ on $V_{H}$.

Substituting Equation 6 for $\mu_{2}$ in Equation 2, we can write the governing differential equations for $V_{H}$ as follows.

$$
\frac{d V_{H}}{d t}=-\xi T V_{H}+\eta V_{H}+\zeta V_{H} V_{T}
$$

Equation 7.

We investigated the impact of HIV on tuberculosis. The study showed that tuberculosis increases in patients co-infected with HIV. ${ }^{16}$ As usual, immune cells have negative effects on the population of tuberculosis. The net specific growth rate for tuberculosis can be written as

$$
\mu_{3}=-\varepsilon T+\delta V_{H}+\sigma
$$

Equation 8.

where

$\varepsilon=$ the rate of the effects of the interaction of $T$ and $V_{T}$ on $V_{T}$,

$\delta=$ the rate of the effects of the interaction of $V_{H}$ and $V_{T}$ on $V_{T}$, and

$\sigma=$ net growth rate of $V_{T}$.

Substituting Equation 8 for $\mu_{3}$ in Equation 3, we can write the governing differential equation for $V_{T}$ as

$$
\frac{d T_{T}}{d t}=-\varepsilon T V_{T}+\delta V_{H} V_{T}+\sigma V_{T}
$$

Equation 9.

The system of governing differential equations representing the dynamical system for the growth/decay of the population of immune cells, HIV, and tuberculosis can be written as follows.

$$
\begin{gathered}
\frac{d T}{d t}=\alpha T\left(1-\frac{T}{T_{\max }}\right)-\beta T V_{H}-\gamma T V_{T} \\
\frac{d T_{H}}{d t}=-\xi T V_{H}+\eta V_{H}+\zeta V_{H} V_{T} \\
\frac{d V}{d t}=-\varepsilon T V_{T}+\delta V_{H} V_{T}+\sigma V_{T}
\end{gathered}
$$


The model remains appropriate as long as each population does not become negative. The parameters $\alpha, \eta$, and $\sigma$ define the growth rates for $T, V_{H}$, and $V_{T}$, respectively. Starting with $T(0)>0$ the only way $T$ can be negative is if $\frac{1}{T} \frac{d T}{d t}<0$ at some time $t$ for which $T(t)=0$. But if $T=0$ the first ordinary differential equation defined by Equation 10 yields $\frac{1}{T} \frac{d T}{d t}=\alpha>0$. This guarantees that $T(t)>0$ for all $t$. Similarly, it can be proven that $V_{H}>0$ and $V_{T}>0$ for all $t$.

As described earlier, a number of parameters $(\alpha, \beta, \gamma, \xi, \eta, \zeta, \varepsilon, \delta$, and $\sigma)$ are used in defining the specific growth rates and interaction of T-cells, HIV, and tuberculosis. The solution will depend on the values of these parameters. As shown in the next section, the equilibrium solution and the stability of the system depend on the parameters describing the growth, decay, and interaction among the T-cells, HIV, and tuberculosis. These parameters are rate constants and are expressed as units over time. The unsteady solutions of the dynamical system (Equations 10, 11, and 12), solutions for equilibrium condition, and stability analysis results have been computed using Maple, based on the derivations. ${ }^{17}$

\section{EQUILIBRIUM SOLUTION}

The equilibrium solution is obtained at a steady state condition that is found as $t \rightarrow \infty$. If we set each derivative equal to zero, we obtain three equations with the equilibrium condition:

$$
\begin{gathered}
\alpha T\left(1-\frac{T}{T_{\max }}\right)-\beta T V_{H}-\gamma T V_{T}=0 \\
-\xi T V_{H}+\eta V_{H}+\zeta V_{H} V_{T}=0 \\
-\varepsilon T V_{T}+\delta V_{H} V_{T}+\sigma V_{T}=0 .
\end{gathered}
$$

\section{Equation 13.}

Equation 14.

Equation 15.

After examining the above equations, we find one of the two equilibrium conditions, $\left(T^{o}, V_{H}^{o}, V_{T}^{o}\right)=(0,0,0)$.

The equilibrium Equations 13, 14, and 15 can be simplified and written in the form

$$
\begin{gathered}
\alpha\left(1-\frac{T}{T_{\max }}\right)-\beta V_{H}-\gamma V_{T}=0 \\
-\xi T+\eta+\zeta V_{T}=0 \\
-\varepsilon T+\delta V_{H}+\sigma=0
\end{gathered}
$$

After solving the above three equations for three population sizes, we get the solution of the equilibrium equations:

$$
\begin{gathered}
T^{*}=\frac{T_{\max }(\alpha \delta \zeta+\beta \sigma \zeta+\delta \eta \gamma)}{T_{\max }(\beta \varepsilon \zeta+\delta \gamma \xi)+\alpha \delta \zeta,} \\
V_{H}^{*}=\frac{T_{\max }(\alpha \varepsilon \zeta+\varepsilon \eta \gamma-\gamma \sigma \xi)-\alpha \sigma \zeta}{T_{\max }(\beta \varepsilon \zeta+\delta \gamma \xi)+\alpha \delta \zeta}, \\
V_{T}^{*}=\frac{T_{\max }(\alpha \delta \xi-\beta \varepsilon \eta+\beta \sigma \xi)-\alpha \delta \eta}{T_{\max }(\beta \varepsilon \zeta+\delta \gamma \xi)+\alpha \delta \zeta} .
\end{gathered}
$$

Equation 19.

Equation 20.

Equation 21.

The above solutions show the second equilibrium point $\left(T^{*}, V_{H}^{*}, V_{T}^{*}\right)$ for the dynamical system defined by the Equations 19 , 20 , and 21.

STABILITY ANALYSIS

The differential equations representing the dynamical system for T-cells, HIV, and tuberculosis can be denoted

$$
\begin{aligned}
& \frac{d T}{d t}=f\left(T, V_{H}, V_{T}\right) \\
& \frac{d V_{H}}{d t}=g\left(T, V_{H}, V_{T}\right)
\end{aligned}
$$




$$
\frac{d V_{T}}{d t}=h\left(T, V_{H}, V_{T}\right)
$$

Equation 24.

where

$$
\begin{aligned}
& f\left(T, V_{H}, V_{T}\right)=\alpha T\left(1-\frac{T}{T_{\max }}\right)-\beta T V_{H}-\gamma T V_{T} \\
& g\left(T, V_{H}, V_{T}\right)=-\xi T V_{H}+\eta V_{H}+\zeta V_{H} V_{T} \\
& h\left(T, V_{H}, V_{T}\right)=-\varepsilon T V_{T}+\delta V_{H} V_{T}+\sigma V_{T}
\end{aligned}
$$

The stability of the system can be examined by evaluating the stability matrix, a Jacobian matrix, $J$, defined as

$$
J=\left[\begin{array}{ccc}
\frac{\partial f}{\partial T} & \frac{\partial f}{\partial V_{H}} & \frac{\partial f}{\partial V_{T}} \\
\frac{\partial g}{\partial T} & \frac{\partial g}{\partial V_{H}} & \frac{\partial g}{\partial V_{T}} \\
\frac{\partial h}{\partial T} & \frac{\partial h}{\partial V_{H}} & \frac{\partial h}{\partial V_{T}}
\end{array}\right] .
$$

By evaluating the derivatives, the Jacobian matrix, $J$, can be written as

$$
J\left(T, V_{H}, V_{T}\right)=\left[\begin{array}{ccc}
\alpha\left(1-\frac{T}{T_{\max }}\right)-\alpha \frac{T}{T_{\max }}-\beta V_{H}-\gamma V_{T} & -\beta T & -\gamma T \\
-\xi V_{H} & \eta-\xi T+\zeta V_{T} & \zeta V_{H} \\
-\varepsilon V_{T} & \delta V_{T} & \sigma-\varepsilon T+\delta V_{H}
\end{array}\right] .
$$

\section{STABILITY AT THE FIRST EQUILIBRIUM POINT}

Substituting the first equilibrium point $\left(T^{o}, V_{H}^{o}, V_{T}^{o}\right)=(0,0,0)$ into the Jacobian matrix, we get

$$
J(0,0,0)=\left[\begin{array}{lll}
\alpha & 0 & 0 \\
0 & \eta & 0 \\
0 & 0 & \sigma
\end{array}\right]
$$

The above matrix is diagonal. The determinant and trace are $\operatorname{det}(J(0,0,0))=\alpha \eta \sigma$ and $\operatorname{tr}(J(0,0,0))=\alpha+\eta+\sigma$, respectively.

To investigate the stability, check the trace and determinant. For the system at the first equilibrium to be stable, the determinant must be greater than 0 and the trace must be less than 0 . These conditions are written as $\alpha \eta \sigma>0$ and $\alpha+\eta+\sigma<0$.

Since the Jacobian matrix at the first equilibrium point is diagonal, its eigenvalues, $\lambda_{1}, \lambda_{2}, \lambda_{3}$, are the diagonal elements. Therefore $\lambda_{1}=\alpha, \lambda_{2}=\eta$, and $\lambda_{3}=\sigma$.

For the system to be stable, the eigenvalues must be negative. With the parameters $\alpha$, $\eta$, and $\sigma$ having positive values, the determinant, trace, and the eigenvalues are all greater than 0 . This indicates that the system is not stable at the first equilibrium point. 


\section{STABILITY AT THE SECOND EQUILIBRIUM POINT}

Substituting the second equilibrium point $\left(T^{*}, V_{H}^{*}, V_{T}^{*}\right)$ into the Jacobian matrix, we get

$$
J\left(T^{*}, V_{H}^{*}, V_{T}^{*}\right)=\left[\begin{array}{ccc}
\alpha\left(1-\frac{\hat{\alpha}}{p}\right)-\frac{1}{p}(\alpha \hat{\alpha}+\beta \hat{\beta}+\gamma \hat{\gamma}) & -\beta \frac{T_{m} \hat{\alpha}}{p} & -\gamma \frac{T_{m} \hat{\alpha}}{p} \\
-\xi \frac{\hat{\beta}}{p} & -\xi \frac{T_{m} \hat{\alpha}}{p}+\zeta \frac{\hat{\gamma}}{p}+\eta & \zeta \frac{\hat{\beta}}{p} \\
-\varepsilon \frac{\hat{\gamma}}{p} & \delta \frac{\hat{\gamma}}{p} & -\varepsilon \frac{T_{m} \hat{\alpha}}{p}+\delta \frac{\hat{\beta}}{p}+\sigma
\end{array}\right],
$$

where

$\hat{\alpha}=\alpha \delta \zeta+\beta \sigma \zeta+\delta \eta \gamma$

$\hat{\beta}=T_{m}(\alpha \varepsilon \zeta+\varepsilon \eta \gamma-\gamma \sigma \xi)-\alpha \sigma \zeta$,

$\hat{\gamma}=T_{m}(\alpha \delta \xi-\beta \varepsilon \eta+\beta \sigma \xi)-\alpha \delta \eta$, and

$p=T_{m}(\beta \varepsilon \zeta+\delta \gamma \xi)+\alpha \delta \zeta$.

The determinant of the Jacobian at the second equilibrium point is $\operatorname{det}\left(J\left(T^{*}, V_{H}^{*}, V_{T}^{*}\right)\right)=\frac{\hat{\alpha} \hat{\beta} \hat{\gamma}}{p^{2}}$.

The second equilibrium point is stable if $\operatorname{det}\left(J\left(T^{*}, V_{H}^{*}, V_{T}^{*}\right)\right)>0$. This implies that $\frac{\hat{\alpha} \hat{\beta} \hat{\gamma}}{p^{2}}>0$.

The trace of the Jacobian matrix at the second equilibrium point is

$$
\operatorname{tr}\left(J\left(T^{*}, V_{H}^{*}, V_{T}^{*}\right)\right)=\alpha\left(1-\frac{\hat{\alpha}}{p}\right)-\frac{1}{p}\left(\alpha \hat{\alpha}+\beta \hat{\beta}+\gamma \hat{\gamma}+\xi T_{m} \hat{\alpha}-\zeta \hat{\gamma}+\varepsilon T_{m} \hat{\alpha}-\delta \hat{\beta}\right)+\eta+\sigma .
$$

For stability, the trace of the Jacobian matrix should be less than 0 . That is

$$
\alpha\left(1-\frac{\hat{\alpha}}{p}\right)-\frac{1}{p}\left(\alpha \hat{\alpha}+\beta \hat{\beta}+\gamma \hat{\gamma}+\xi T_{m} \hat{\alpha}-\zeta \hat{\gamma}+\varepsilon T_{m} \hat{\alpha}-\delta \hat{\beta}\right)+\eta+\sigma<0
$$

The eigenvalues, $\lambda_{1}, \lambda_{2}, \lambda_{3}$, can be obtained by setting $\operatorname{det}(J-\lambda I)=0$. The matrix $J-\lambda I$ can be written as

$$
J\left(T^{*}, V_{H}^{*}, V_{T}^{*}\right)-\lambda I=\left[\begin{array}{ccc}
\tilde{\alpha} & -\beta \frac{T_{m} \hat{\alpha}}{p} & -\gamma \frac{T_{m} \hat{\alpha}}{p} \\
-\xi \frac{\hat{\beta}}{p} & \tilde{\eta} & \xi \frac{\hat{\beta}}{p} \\
-\varepsilon \frac{\hat{\gamma}}{p} & \delta \frac{\hat{\gamma}}{p} & \tilde{\sigma}
\end{array}\right],
$$

where

$$
\begin{aligned}
& \tilde{\alpha}=\alpha\left(1-\frac{\hat{\alpha}}{p}\right)-\frac{1}{p}(\alpha \hat{\alpha}+\beta \hat{\beta}+\gamma \hat{\gamma})-\lambda I, \\
& \tilde{\eta}=-\xi \frac{T_{m} \hat{\alpha}}{p}+\xi \frac{\hat{\gamma}}{p}+\eta-\lambda I, \text { and }
\end{aligned}
$$




$$
\tilde{\sigma}=-\varepsilon \frac{T_{m} \hat{\alpha}}{p}+\delta \frac{\hat{\beta}}{p}+\sigma-\lambda I \text {. }
$$

The characteristic equation for eigenvalues can be obtained by writing $\operatorname{det}\left(J\left(T^{*}, V_{H}^{*}, V_{T}^{*}\right)-\lambda I\right)=0$. By evaluating the determinant, the characteristic equation for eigenvalues can be written in a cubic polynomial form as

$$
\lambda^{3}+u \lambda^{2}+v \lambda+w=0
$$

Equation 25.

where

$$
\begin{aligned}
& u=\frac{b}{a}, \\
& v=\frac{c}{a}, \\
& w=\frac{d}{a} \\
& a=-\left[\frac{T_{\max }(\beta \varepsilon \zeta+\delta \gamma \xi)+\alpha \delta \zeta}{p}\right]^{2},
\end{aligned}
$$$$
b=\frac{-T_{m} \alpha^{2} \delta \zeta(\beta \varepsilon \zeta+\delta \gamma \xi)-\alpha(\beta \sigma \zeta+\delta \eta \gamma) p-\alpha^{3} \delta^{2} \zeta^{2}}{p^{2}}
$$$$
c=c_{1}+c_{2}+c_{3}+c_{4}+c_{5}+c_{6}
$$$$
c_{1}=\frac{T_{\max }^{2} \alpha^{2} \delta \xi \zeta(\beta \varepsilon \zeta+\delta \varepsilon \gamma)+T_{\max }^{2} \alpha \varepsilon \xi \zeta^{2}\left(\alpha \delta^{2}+\beta^{2} \sigma\right)+T_{\max }^{2}(\gamma+\zeta)\left(\alpha \varepsilon \eta \gamma \xi \delta^{2}-\alpha \beta \delta \eta \zeta \varepsilon^{2}+\beta \delta \varepsilon \eta \gamma \sigma \xi\right)}{p^{2}},
$$$$
c_{2}=\frac{T_{\max }^{2} \beta \delta \varepsilon \eta \gamma \sigma \xi \zeta+T_{\max }^{2}(\eta+\sigma)\left(2 \alpha \beta \delta \varepsilon \gamma \xi \zeta+\varepsilon \gamma \sigma \xi \zeta \beta^{2}\right)}{p^{2}},
$$$$
c_{3}=\frac{T_{\max }(\varepsilon \zeta-\gamma \xi)\left(T_{m} \alpha \beta \delta \sigma \xi \zeta-T_{m} \beta \delta \varepsilon \gamma \eta^{2}+\alpha \beta \delta \eta \sigma \zeta\right)}{p^{2}},
$$

$c_{4}=\frac{-T_{\max }^{2}\left[\alpha \sigma \zeta\left(\alpha \delta^{2} \xi^{2}+\eta \beta^{2} \varepsilon^{2}\right)+\beta \gamma\left(\beta \zeta \sigma^{2} \xi^{2}+\delta \gamma \varepsilon^{2} \eta^{2}\right)\right]-T_{\max } \alpha \zeta(\beta \sigma \xi \zeta+\delta \varepsilon \eta \gamma)(\alpha \delta+\beta \sigma)}{p^{2}}$,

$c_{5}=\frac{-T_{\max }^{2} \beta \delta \gamma \sigma \xi^{2}(\eta \gamma+\sigma \zeta)-T_{\max } \alpha \delta\left[\alpha \delta \zeta^{2}(\varepsilon \eta+\sigma \xi)+\beta \xi \sigma^{2} \zeta^{2}+\delta \varepsilon \eta^{2} \gamma^{2}\right]}{p^{2}}$,

$c_{6}=\frac{-T_{\max } \alpha \eta \gamma \zeta \delta^{2}(\varepsilon \eta-\sigma \xi)+\eta \sigma \alpha^{2} \delta^{2} \zeta^{2}}{p^{2}}$,

$d=d_{1}+d_{2}+d_{3}+d_{4}+d_{5}+d_{6}$,

$d_{1}=\frac{T_{\max }^{2} \delta \xi \alpha^{2} \zeta^{2}(\alpha \delta \xi-\beta \varepsilon \eta)+\delta \zeta \alpha^{2}(\beta \sigma \zeta+\delta \eta \gamma)\left(2 T_{\max }^{2} \varepsilon \xi+\eta \sigma\right)}{p^{2}}$,

$d_{2}=\frac{T_{\max }^{2} \beta \delta \gamma \sigma \xi(2 \varepsilon \eta-\sigma \xi)(2 \alpha \zeta+\eta \gamma)}{p^{2}}$ 


$$
\begin{aligned}
& d_{3}=\frac{T_{\max }(\varepsilon \eta-\sigma \xi)\left[T_{m} \eta \gamma\left(\alpha \gamma \xi \delta^{2}-\varepsilon \sigma \zeta \beta^{2}\right)+\alpha\left(\beta^{2} \sigma^{2} \zeta^{2}-\delta^{2} \eta^{2} \gamma^{2}\right)\right]}{p^{2}}, \\
& d_{4}=\frac{T_{\max }^{2}\left[\varepsilon \eta \gamma \xi \zeta \beta^{2} \sigma^{2}-\alpha \sigma \zeta\left(\alpha \gamma \xi^{2} \delta^{2}+\eta \zeta \beta^{2} \varepsilon^{2}\right)\right]}{p^{2}}, \\
& d_{5}=\frac{T_{\max }^{2}\left[\alpha \beta \varepsilon \zeta\left(\beta \xi \zeta \sigma^{2}-2 \delta \varepsilon \gamma \eta^{2}\right)-\beta \gamma\left(\beta \zeta \sigma^{3} \xi^{2}-\delta \gamma \varepsilon^{2} \eta^{3}\right)\right]}{p^{2}}, \text { and } \\
& d_{6}=\frac{-T_{\max }\left[\alpha^{3} \delta^{2} \zeta^{2}(\varepsilon \eta+\sigma \xi)+2 \delta \zeta \alpha^{2}\left(\beta \xi \zeta \sigma^{2}+\delta \varepsilon \gamma \eta^{2}\right)\right]+\eta \sigma \alpha^{3} \delta^{2} \zeta^{2}}{p^{2}} .
\end{aligned}
$$

The function in the left side of the characteristic equation, Equation 25, for eigenvalues is a polynomial of degree three. This third degree polynomial has at most three roots representing the three eigenvalues of the Jacobian matrix. The equilibrium point $\left(T^{*}, V_{H}^{*}, V_{T}^{*}\right)$ will be stable if all the eigenvalues of the Jacobian matrix are negative (if real) or have negative real parts (if complex). So, for stable equilibrium, we need $\operatorname{Re} \lambda_{i}<0, \forall i$.

The general criteria, called Routh-Hurwitz criteria, ${ }^{18}$ (described in Appendix A) can be used to determine whether all the roots of the characteristic equation (a third degree polynomial equation) for eigenvalues have negative real part or not. For the above cubic polynomial equation, evaluated at the eigenvalues, Routh-Hurwitz criteria are $u>0, v>0, w>0$, and $u v>w$.

\section{ANALYSIS OF PHASE DIAGRAMS}

The mathematical study of dynamical systems entails investigation of the changes of the topology of the phase plane. Assigning the assumed values of the parameters, we obtained and analyzed the phase diagrams to observe the stability of the solution. The values of the parameters were assigned in order to investigate the topology of the phase plane diagrams. Based on the assumed values of the parameters, the phase plane diagrams were developed using XPPAUT software. ${ }^{19}$

Through the investigation of the phase plane diagrams, we evaluated the stability of the present dynamical system. Figures 1 through $\mathbf{6}$ show the phase diagrams for different values of the parameters. The phase diagrams showing a set of closed curves are illustrated in Figures 1 and 2. These curves represent the variations of T-cells with HIV (Figure 1) and the variations of T-cells with tuberculosis (Figure 2) for different initial conditions. Each curve corresponds to an initial condition, which was defined graphically through XPPAUT. The phase plane diagrams with curves around a center represent a neutrally stable system, ${ }^{20}$ so Figures 1 and 2 are examples of phase plane diagrams for neutrally stable systems showing a cycle of growth and decay associated with T-cells, HIV, and tuberculosis. Here, the system approaches the equilibrium point at the center with stability.

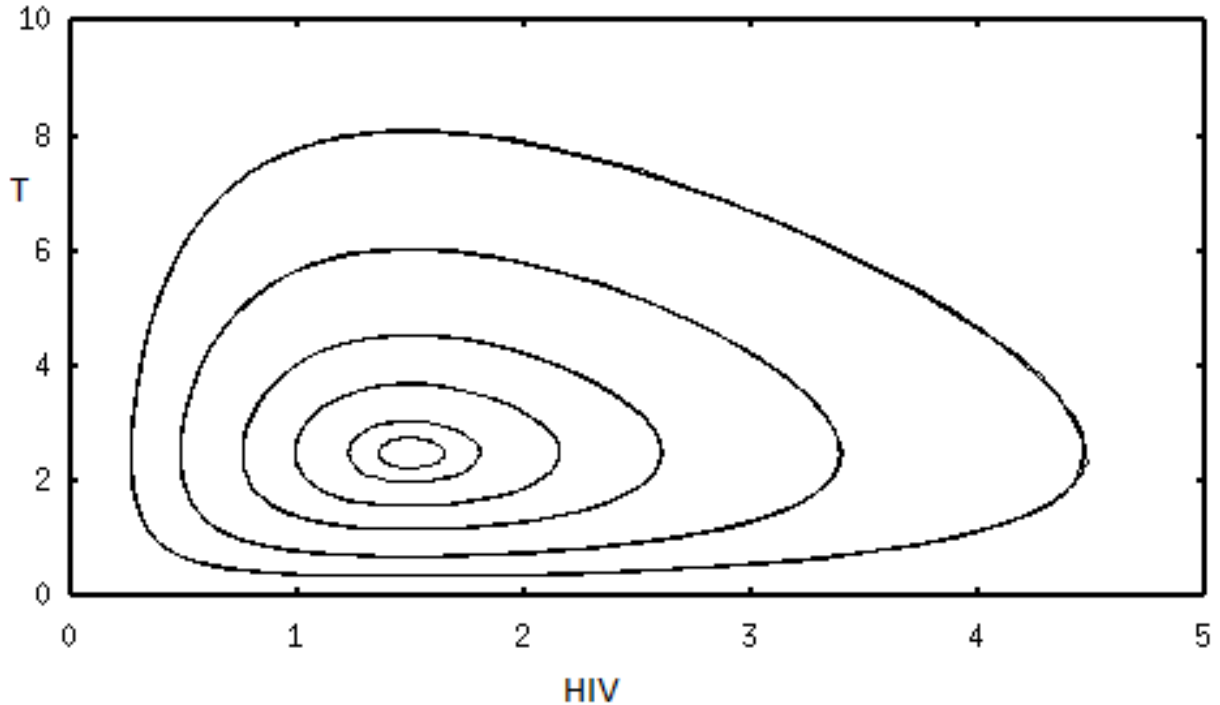

Figure 1. Phase plane topology showing a neutrally stable system for T-cells versus HIV $(\alpha=3, \beta=2, \gamma=0.01, \xi=-1, \eta=-2.5, \zeta=0.01, \varepsilon=0.01, \delta=0.01, \sigma=$ 0.01 , and $\left.T_{\max }=10000.0\right)$. 


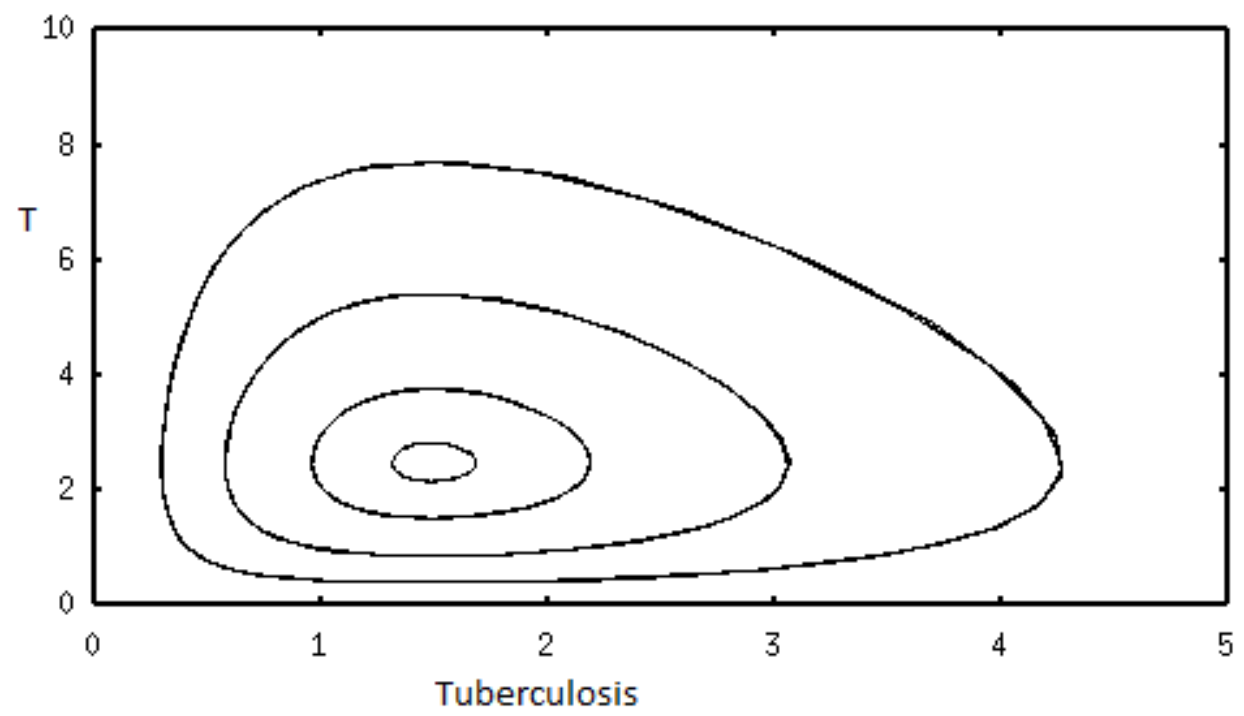

Figure 2. Phase plane topology showing a neutrally stable system for T-cells versus tuberculosis $(\alpha=3, \beta=0.01, \gamma=2.0, \xi=0.01, \eta=0.01, \zeta=0.01, \varepsilon=-1.0, \delta$ $=0.01, \sigma=-2.5$, and $\left.\mathrm{T}_{\max }=10000.0\right)$.

Figure 3 shows that the set of curves illustrating the variation of T-cells with HIV, for different initial conditions, approaching a spiral point. Similar observations are made in Figure 4 for the set of curves showing the variation of T-cells with tuberculosis. The spiral point indicates the equilibrium condition for the system. The curves approaching a spiral point represent an asymptotically stable system. ${ }^{20}$ Here, the systems for T-cells with HIV and T-cells with tuberculosis approach the equilibrium conditions at their spiral center with stability.

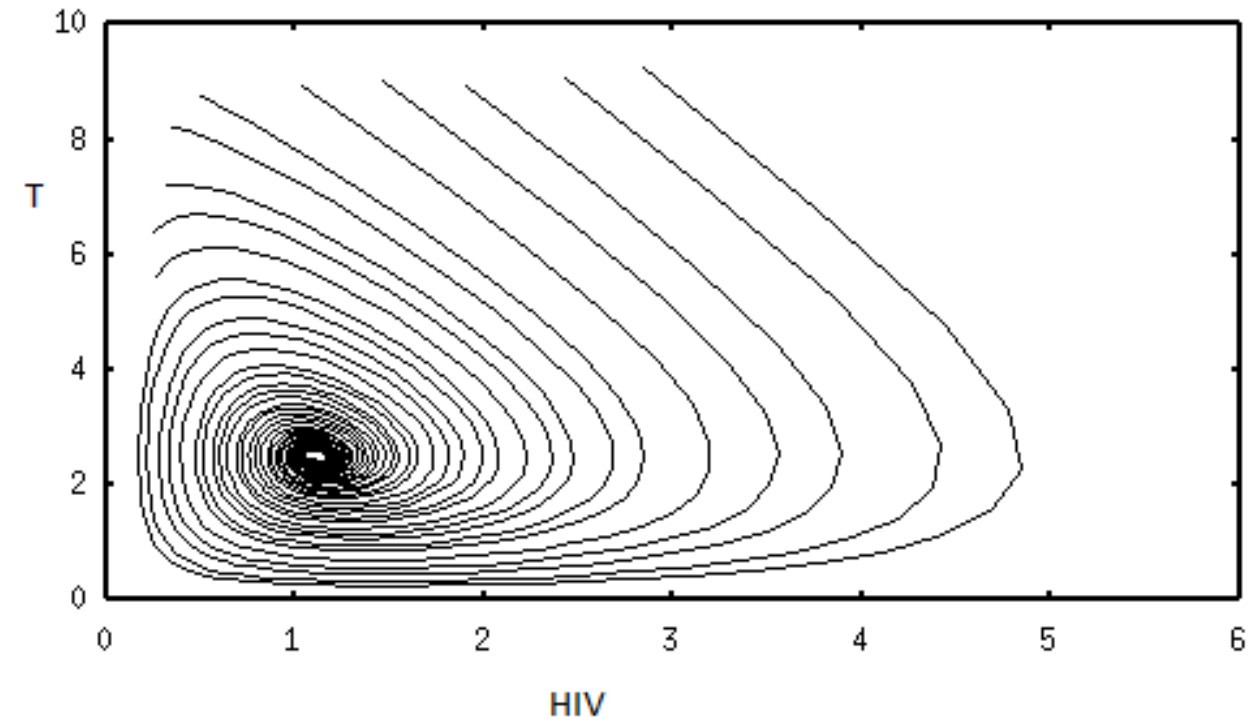

Figure 3. Phase plane topology showing an asymptotically stable system for tuberculosis versus $\operatorname{HIV}(\alpha=3, \beta=2, \gamma=0.01, \xi=-1, \eta=-2.5, \zeta=0.01, \varepsilon=0.01, \delta$ $=0.01, \sigma=0.01$, and $\left.\mathrm{T}_{\max }=10\right)$. 


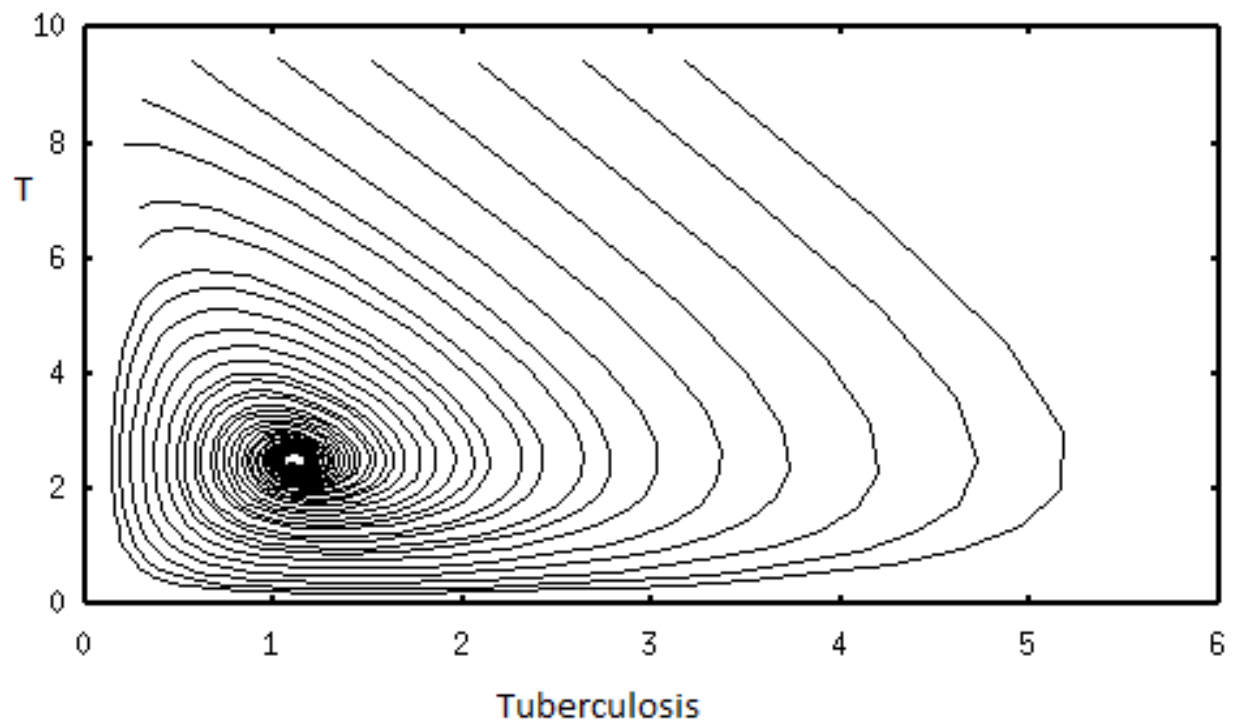

Figure 4. Phase plane topology showing an asymptotically stable system for T-cells versus tuberculosis $(\alpha=3, \beta=0.01, \gamma=2.0, \xi=0.01, \eta=0.01, \zeta=0.01, \varepsilon=$. $1.0, \delta=0.01, \sigma=-2.5$, and $\mathrm{T}_{\max }=10$ ).

Figure 5 shows the phase plane diagram illustrating the variation of T-cells with HIV. For various values of initial conditions, the set of curves shows distinct characteristics as it approaches the horizontal and vertical axes. Based on the initial conditions, the curves asymptotically approach the horizontal axis on the right side. This shows the extinction of both T-cells and HIV as $t \rightarrow \infty$. On the left side, if the initial condition for HIV is small, then the curves asymptotically approach the vertical axis with the increase of T-cells and extinction of HIV as $t \rightarrow \infty$. This is a practically possible scenario that can occur in a real life condition. Similar conditions occur in the phase diagram illustrating the variations of T-cells with tuberculosis as shown in Figure $\mathbf{6}$. The set of parabolic curves approaching the horizontal and vertical axes in a phase plane diagram is described as an unstable system ${ }^{20}$. Here the curves shown in Figures $\mathbf{5}$ and $\mathbf{6}$, based on the set of parameter values and on the initial conditions, illustrate an unstable system.

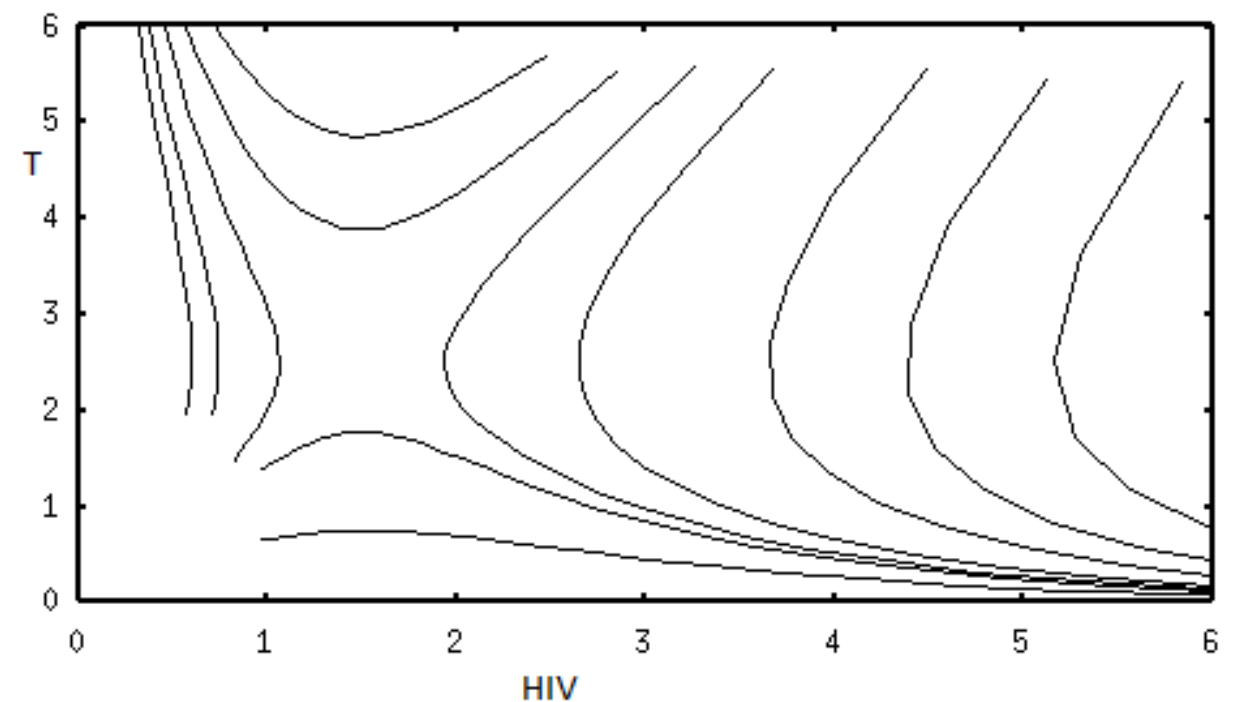

Figure 5. Phase plane topology showing an unstable system for tuberculosis versus HIV $(\alpha=3, \beta=2, \gamma=0.01, \xi=1, \eta=2.5, \zeta=0.01, \varepsilon=0.01, \delta=0.01, \sigma=$ 0.01 , and $\left.\mathrm{T}_{\max }=10000\right)$. 


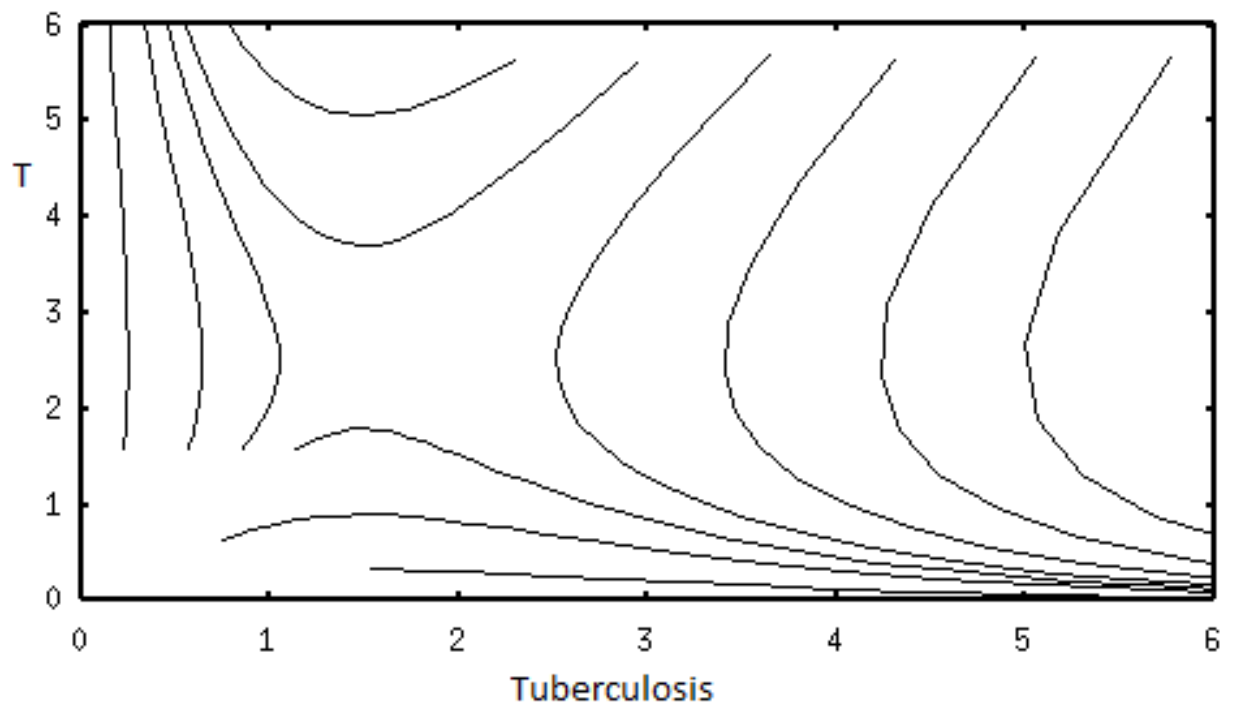

Figure 6. Phase plane topology showing an unstable system for T-cells versus tuberculosis $(\alpha=3, \beta=0.01, \gamma=2.0, \xi=0.01, \eta=0.01, \zeta=0.01, \varepsilon=1.0, \delta=$ $0.01, \sigma=2.5$, and $\left.\mathrm{T}_{\max }=10000\right)$.

\section{EXAMPLE OF UNSTEADY SIMULATIONS}

Maple software ${ }^{17}$ was used to obtain the unsteady solutions based on the Runge-Kutta method. The values of the model parameters were assigned $\left(\alpha=0.1 \mathrm{day}^{-1}, \beta=0.01 \mathrm{day}^{-1}, \gamma=0.01 \mathrm{day}^{-1}, \xi=0.01 \mathrm{day}^{-1}, \eta=0.02 \mathrm{day}^{-1}, \zeta=0.01 \mathrm{day}^{-1}, \varepsilon=0.01 \mathrm{day}^{-1}\right.$, $\delta=0.01$ day $^{-1}$, and $\sigma=0.03$ day $^{-1}$ ) to perform the simulations for T-cells, HIV, and tuberculosis. We investigated two time varying solutions as shown in Figures 7 and 8. Different starting conditions for T-cells were considered, in order to see how they were affected by HIV and tuberculosis over time.

In Figure 7, the initial conditions are the same for all the three dependent variables (T-cells, HIV, and tuberculosis). The simulation shows how the T-cells initially increase but decline over time with the increase of HIV and tuberculosis. This shows the variation of T-cells, HIV, and tuberculosis over time. The immune cells grow but eventually vanish. At this point, HIV and tuberculosis tend to increase without bound as shown in Figure 7.

Figure 8 starts with a higher initial amount of T-cells. The adverse effects occur due to infection caused by HIV and tuberculosis. With time, the population of T-cells decline but the population of HIV and tuberculosis increase. As shown, the population of Tcells tends toward zero while the populations of HIV and tuberculosis start swiftly increasing at the end of simulation. By varying the values of the parameters, a number of solutions can be obtained to simulate the variation of T-cells, HIV, and tuberculosis with time.

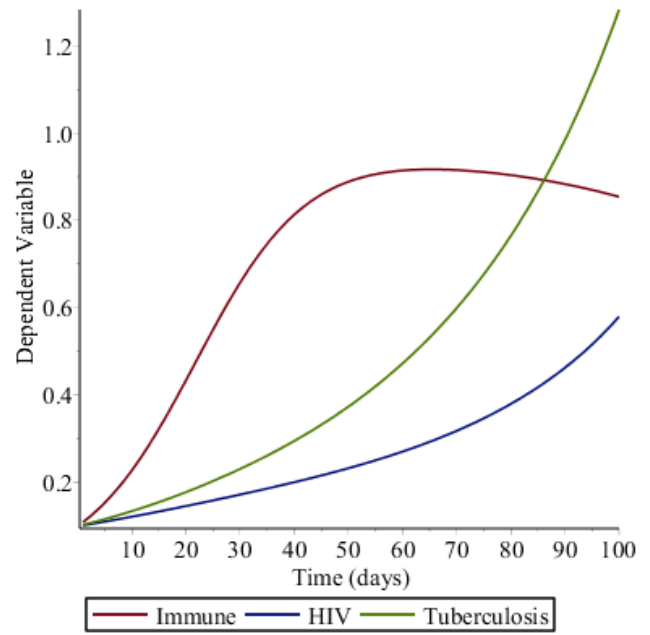

Figure 7. Simulation showing variation with time having the same starting conditions for the dependent variables. The units for T-cells (immune cells) are in thousands per cubic millimeter, the units for HIV are in thousands per milliliter, and the units for tuberculosis are in thousands CFU. 


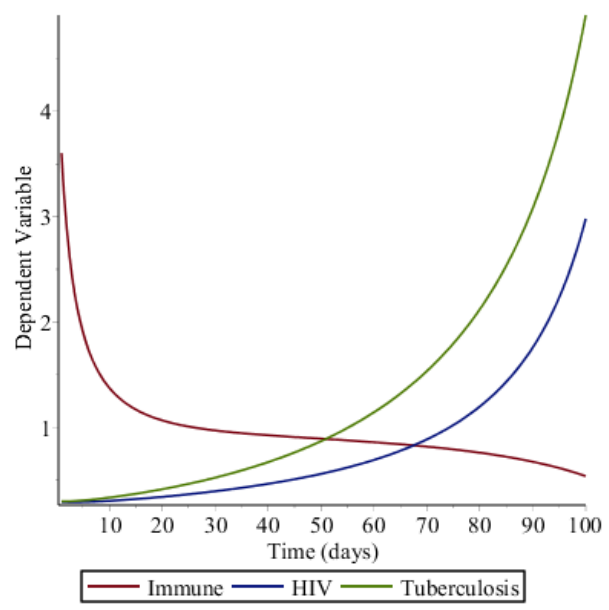

Figure 8. Simulation showing variation with time having a higher starting condition for T-cells. The units for T-cells (immune cells) are in thousands per cubic millimeter, the units for HIV are in thousands per milliliter, and the units for tuberculosis are in thousands CFU.

\section{ASSUMPTIONS, LIMITATIONS, AND FURTHER STUDY}

In the present model, it is assumed that the T-cells become infected once HIV and tuberculosis are introduced into the system. A more detailed analysis can be done by separating the T-cells into two parts; one part will represent the normal T-cells and the other part will represent the infected T-cells. This allows the simulation of the variations of normal T-cells and infected T-cells. A separate equation can be developed and solved for the infected T-cells. The dynamical system will consist of normal T-cells, infected T-cells, HIV, and tuberculosis. Further study can be done to investigate this system with four dependent variables.

The present study entailed developing mathematical models and example applications for simulating T-cells, HIV, and tuberculosis. The mathematical models included differential equations and equilibrium solutions. The unsteady solutions are computed using a set of hypothetical values of the model parameters. We performed a few trials to determine the parameters describing the rate coefficients of the net growth rates. ${ }^{21,22}$ There are not much practical data available for the parameters involved in the system, so a practical application of the system was not performed in this study. However, a separate study can be done to examine the possibility of real world applications based on the real world data of the parameters.

\section{CONCLUSIONS}

In this study, we developed formulations for describing the unsteady variations of T-cells, HIV, and tuberculosis. To examine the stability of the system, we developed formulations based on the equilibrium solutions. We obtained and analyzed the equilibrium solutions to examine the stability of the dynamical system as time goes to infinity. The stability analysis included the investigation of the Jacobian matrix and its characteristics. Several characteristic factors involving the determinant, trace, and formulation for eigenvalues of the Jacobian matrix were developed.

Stability analysis was done by investigating the phase diagrams for T-cells varying with HIV and for T-cells varying with tuberculosis. Using sets of different parameter values, the phase planes were obtained. Graphs illustrated the growth and decay processes as time increases after the body is infected by the antigens. Graphs also illustrated the approach toward the equilibrium conditions based on different parameter values as time goes to infinity.

We investigated the stability of the dynamical system for different parameter values by examining the phase plane diagrams. We generated graphs to illustrate the stable and unstable systems as the solutions approach the equilibrium point. The phase plane diagrams showed neutrally stable systems with closed curves around a center. Along these curves, a cycle of growth and decay associated with T-cells, HIV, and tuberculosis was illustrated. Using different sets of parameter values, we obtained phase plane diagrams for unstable systems. Based on different initial conditions, these curves illustrated the progress of solutions with time.

The unsteady variations of T-cells, HIV, and tuberculosis were obtained using the assigned values of the parameters. As time increases, the growth of T-cells diminishes and gradually vanishes from the system. Through the process of the decrease of $\mathrm{T}$ cells, HIV and tuberculosis increase with time. The antigens cause unbounded vanishing of T-cells.

Further study can be performed by extending the mathematical model to four variables: normal T-cells, infected T-cells, HIV, and tuberculosis. This will require developing a differential equation for normal T-cells and infected T-cells separately. The 
equilibrium solutions, stability, and unsteady solutions can be investigated further to examine how the normal T-cells and the infected T-cells vary in a host infected by HIV and tuberculosis. Future work can include investigation of the values of the model parameters for a real world application.

\section{APPENDIX A: THE ROUTH-HURWITZ CRITERIA}

A general polynomial equation with real coefficients $a_{1}, a_{2}, a_{3}, \ldots, a_{\mathrm{n}}$ can be written as

$$
p(x)=x^{\mathrm{n}}+a_{1} x^{\mathrm{n}-1}+a_{2} x^{\mathrm{n}-2}+\cdots+a_{\mathrm{n}-1} x+a_{\mathrm{n}}=0
$$

For the polynomial $p(x), n$ Hurwitz matrices can be written as

$$
H_{1}=\left(a_{1}\right), H_{2}=\left(\begin{array}{cc}
a_{1} & 1 \\
a_{3} & a_{2}
\end{array}\right), H_{3}=\left(\begin{array}{ccc}
a_{1} & 1 & 0 \\
a_{3} & a_{2} & a_{1} \\
a_{5} & a_{4} & a_{3}
\end{array}\right), \cdots, H_{\mathrm{n}}=\left(\begin{array}{ccccc}
a_{1} & 1 & 0 & \cdots & 0 \\
a_{3} & a_{2} & a_{1} & \cdots & 0 \\
a_{5} & a_{4} & a_{3} & \cdots & 0 \\
\vdots & \vdots & \vdots & \cdots & \vdots \\
0 & 0 & 0 & \cdots & a_{\mathrm{n}}
\end{array}\right) .
$$

The roots of the polynomial equation are negative or have negative real parts if the coefficients $a_{1}, a_{2}, a_{3}, \ldots, a_{\mathrm{n}}$ and the determinants of the Hurwitz matrices are positive. The Routh-Hurwitz criteria for $\mathrm{n}=3$ can be written as $a_{i}>0, I=1,2$, and 3 .

Then $\operatorname{det} H_{2}=\operatorname{det}\left(\begin{array}{cc}a_{1} & 1 \\ a_{3} & a_{2}\end{array}\right)>0$, and so $a_{1} a_{2}>a_{3}$.

\section{REFERENCES}

1. Anderson R. M. (1994) The Croonian Lecture, 1994: Populations, Infectious Disease and Immunity: A Very Nonlinear World. Philosophical Transactions: Biological Sciences, 46:1318.

2. Doura K., Meléndez-Morales J. D., Meyer G. G., and Pérez L. E. (2000) An S-I-S Model of Streptococcal Disease with a Class of Beta-Hemolytic Carriers. Cornell University. https:/ / ecommons.cornell.edu/ bttps:// ecommons.cornell.edu/bitstream/ bandle/1813/32116/BU-1524-M.pdf? sequence =1

3. Pava-Salgado E. D. L., Salguero-Rivera B., Aparicio J. P. (2001) Social Mobility and the Evolution of Tuberculosis. Cornell University. https:// ecommons.cornell.edu/ https:// ecommons.cornell.edu/bitstream/ handle/1813/32185/BU-1589-M.pdf?.sequence=1

4. Pawlowski A., Jansson M., Rottenberg M. E., and Källenius G. (2012) Tuberculosis and HIV Co-Infection. Pathogens, a Journal of Public Library of Science (PLOS), 8:2.

5. Pondei K. and Lawan E. (2013) Human immunodeficiency virus and pulmonary tuberculosis co-infection: Need for coordinated collaborative detection and treatment services. Journal of Medicine and Medical Sciences. 4:3, pp. 107-111.

6. Reibnegger G., Fuchs D., Hausen A., Werner E. R., Werner-Felmayer G., Dierich M. P., and Wachter H. (1989) Stability Analysis of Simple Models for Immune Cells Interacting with Normal Pathogens and Immune System Retroviruses. Proc. Natl. Acad. Sci. 86:2026-2030.

7. Akpa O. M. and Oyejola B. A. (2010) Modeling the transmission dynamics of HIV/AIDS epidemics: an introduction and a review. I Infect Dev Ctries; 4(10):597-608.

8. Alizon S. and Magnus C. (2012) Modelling the Course of an HIV Infection: Insights from Ecology and Evolution. Viruses, 4, 1984-2013.

9. Perelson A. S., and Ribeiro R. M. (2013) Modeling the within-host dynamics of HIV infection. BioMed Central (BMC), 11:96.

10. Srivastava V. K., Awasthi M. K., and Kumar S. (2014) Numerical approximation for HIV infection of CD4+ T-cells mathematical model. Engineering Physics and Mathematics, Ain Shams Engineering Journal. Vol. 5, pp. 625-629

11. Hraba T. and Dolezal J. (1996) A Mathematical Model and CD4+ Lymphocyte Dynamics in HIV Infection. Emerging Infectious Diseases, Vol. 2, No. 4, pp. 299-305.

12. Wodarz D. and Nowak M. A. (2002) Mathematical models of HIV pathogenesis and treatment. BioEssays 24:1178-1187.

13. Peñuelas-Urquides K., Villarreal-Treviño L., Silva-Ramírez B., Rivadeneyra-Espinoza L., Said-Fernández S., and León M. B. de. (2013) Measuring of Mycobacterium tuberculosis growth. A correlation of the optical measurements with colony forming units. Brazilian Journal of Microbiology. 44:1. pp. 287-289.

14. Mesterton-Gibbons M. (1995) A Concrete Approach to Mathematical Modelling. John-Wiley \& Sons. 597p. 
15. Toossi Z, Mayanja-Kizza H, Hirsch C S, Edmonds K L, Spahlinger T, Hom D L, Aung H, Mugyenyi P, Ellner J J, and Whalen C. W. (2001) Impact of Tuberculosis (TB) on HIV-1 Activity in Dually Infected Patients. Clin. Exp. Immunol. 123:2, pp. 233-238.

16. Zumla A, Malon P., Henderson J., Grange J. M. (2000) Impact of HIV Infection on Tuberculosis. Postgraduate Medical Journal. 76: pp. 259-268.

17. Maplesoft. (2014) A division of Waterloo Maple Inc. Waterloo, Canada.

18. Allen L. J. S. (2006) Introduction to Mathematical Biology. Addison-Wesley.

19. University of Pittsburg. (2016) XPPAUT: X-Windows Phase Plane Plus Auto. http://wmw.math.pitt.edu/ $\sim$ bard/xpp/xpp.html

20. Borrelli R. L., Coleman C. S. (1998) Differential Equations - A Modeling Perspective. John Wiley \& Sons, Inc. 706p.

21. Culshaw R. V. and Ruan S. (2000) A delay-differential equation model of HIV infection of CD4+ T-cells. Mathematical Biosciences. 165. pp. 27-29.

22. Ribeiro R. M., Qin L, Chavez L. L., Li D., Self S. G., Perelson A. S. (2010) Estimation of the initial viral growth rate and basic reproductive number during acute HIV-1 infection. J. Virology. 84:12, pp. 6096-6102.

\section{ABOUT THE STUDENT AUTHOR}

Rumana Ahmed received her B.S. in Civil Engineering from the University of North Florida, Jacksonville, FL in Fall 2015. She worked as a research intern at the Mayo Clinic, Jacksonville, FL in Summer 2013. Her study included the incremental cost effectiveness ratio analysis for three methods of treatment of liver metastases. In Summer 2015, she worked as a researcher under the Travelers Summer Research Fellowship Program at Cornell University, Ithaca, New York. The research project entailed the analysis of the characteristics of carbon black-filled silicone material for pressure sensing.

For the present research paper, Rumana Ahmed worked under the guidance of Professor Mahbubur Rahman at the University of North Florida. She started working on this research in Summer 2014 and continued the work until Fall 2015. During her undergraduate years, she was actively involved as the vice president of the University of North Florida student chapter of the Society of American Military Engineers. Ms. Ahmed worked as a project engineer with Fusion Engineering, New York in the areas of hydraulic and environmental engineering. Currently she is a graduate student pursuing her M.S. in biology at the City College of the City University of New York since Fall 2016.

\section{PRESS SUMMARY}

Mathematical biology is an evolving area where mathematical and numerical analyses are performed to simulate the biological processes. It is a challenge to develop stable formulations for simulating the growth-decay and the interaction processes in a biological system. In this study, formulations based on ordinary differential equations have been developed by incorporating growth-decay and interaction of the population of blood cells and antigens in a host. This research focused on the simulation of the dynamics of immune cells, HIV, and tuberculosis. Equilibrium solutions were developed and investigated as time goes to infinity. The criteria for the stability of the dynamical system have been established. In addition, stability analysis has been performed by investigating the phase plane diagrams. Finally, the unsteady state solutions were generated to simulate the variations of T-cells, HIV, and tuberculosis with time. 


\title{
Gender and Sexuality in Medieval Islamic Mysticism: A Comparative Study of Ibn 'Arabi and al-Ghazali
}

\author{
Emily Dovel* \\ History Department, University of Portland, Portland, OR \\ Student:dovel16@up.edu* \\ Mentor:franco@up.edu
}

\begin{abstract}
Mysticism, defined as a direct experience with God that cannot occur through intellectual knowledge, has the potential to offer women opportunities disallowed by a patriarchal society. Because mysticism exists outside of religious institutions and hierarchies, female mystics could receive opportunities for public expression often prohibited by Medieval Islamic societies. Islamic Mysticism, or Sufism, has a long history of prominent female mystics. However, Sufi thought in the $12^{\text {th }}$ and $13^{\text {th }}$ centuries was certainly affected by the misogynistic influences of the greater society. In order to explore the ideological conflict within medieval Sufism, between the potential for gender egalitarianism within mysticism and the influences of patriarchy, this paper examines the theology of two prominent Sufi mystics, Ibn 'Arabi and al-Ghazali, and proposes some explanations for the large disparity between the two Sufis' opinions on gender and sexuality.

Specifically, al-Ghazali fully supports the subjugation of women, and even equates the perpetuation of patriarchy to religious piety. This paper argues that, living under the politically turbulent and authoritarian reign of the Seljuks in Iraq, during the late $11^{\text {th }}$ and early $12^{\text {th }}$ centuries, al-Ghazali was particularly disinclined to question traditional orthodoxy, particularly with regard to gender. Ibn 'Arabi, by contrast, accepts the spiritual, intellectual, and legal equality of women to a remarkable extent. Raised in Muslim Spain in the late $12^{\text {th }}$ and early $13^{\text {th }}$ centuries, Ibn 'Arabi was exposed to female mystics as teachers and experienced little political pressure to conform to traditional doctrine. Further, Ibn 'Arabi subscribes to Oneness of Being theology in which the created, material universe is an emanation of God, and is ultimately part of the same divine being. As such, unlike many religious thinkers within patriarchal societies, who tend to reject worldliness_-along with women and female sexuality — in an attempt to reach God, Ibn 'Arabi believes that all things material—including women and the human body_are ultimately connected to divinity
\end{abstract}

\section{KEYWORDS}

Islam; Sufism; Gender; Sexuality; Theology; Medieval History

\section{INTRODUCTION}

Celebrated $13^{\text {th }}$ century Muslim mystic Ibn 'Arabi once wrote, regarding one of his female disciples, "I wrapped her in the raiment of piety, / That raised her above gender." "He was suggesting, like many mystics in the Islamic tradition, that true devotion to God outweighs gendered human constructs of value and power. Mysticism, defined as direct experience with God, often has dimensions independent from traditional religious hierarchy. As a result, mysticism has the potential to offer women an opportunity for a voice of authority when dominant religious institutions reject or silence women's voices. ${ }^{2}$ The Islamic mystical tradition, called Sufism, was particularly prominent throughout much of the Middle Ages and frequently held women in high regard. From its beginnings, Sufism recognized many prominent female mystics within its ranks. As a result, Sufi ideology tended to contain more egalitarian thought than was allowed by orthodox theologians. Women were often barred, by tradition or law, from participating in the normative religious practices which occurred in mosques. However, neither tradition nor law could prevent women from claiming a special connection with God through mystical experience.

At the same time, Sufi theological and philosophical thought was certainly never exempt from influences of androcentric interpretations of holy texts; indeed, like in most major religions, men in both Sufism and Islam most often interpreted and applied religious doctrine in such a way as to privilege the male gender. Nor was Sufism exempt from the rampant misogynistic discourse in both legal and political realms, which could be distrustful or outright hostile towards women. Sufi mystics were often respected members of the community, well integrated into normative society. As such, they were undeniably susceptible to the cultural prejudices and patriarchal assumptions of the Medieval Islamic world. Further, Sufism had a powerful ascetic strain, and as a result, tended to associate women with worldliness, sexual temptation, and distance from God. ${ }^{3}$ Medieval Sufism, therefore, represents a fascinating area of conflict between the patriarchal influences within normative Islamic theology and the inclination 
often found within mysticism to reach God through transcending human power constructs. By studying gender ideology within Medieval Sufism, historians can better understand the ways political power, religious authority, traditional interpretive doctrine, and individual experiences with the divine, affect the extent to which gender norms are reinforced or challenged.

Through an examination of two exceptionally prominent Sufi thinkers of the $11^{\text {th }}-13^{\text {th }}$ centuries, this paper investigates the tension within Sufism, between the influence of misogyny often prevalent in mainstream Medieval Islamic theology and the influence of Sufi mysticism, in which female mystics derived voices of authority directly from God. Sufism has the potential to radically challenge power structures and value assumptions created by humans, including those of patriarchy. However, when Sufi thought is absorbed into orthodox theological discourse, and the propaganda of political authorities interested in preserving the societal status quo, it can become a powerful tool for reinforcing prevailing gender ideology. This is the case with one of the most widely read scholars in Sufi history, Abu Hamid Muhammad ibn al-Ghazali. As a highly educated theologian and teacher, fully ensconced in both theological orthodoxy and systems of political authority of the late eleventh and early twelfth century Near East, al-Ghazali endorsed and perpetuated the dominant orthodox tradition with regard to gender. His Sufi theology does not question patriarchal discourse, but reinforces traditional gender norms. Indeed, al-Ghazali advocates for a system of behavior which requires devout men and women to perpetuate patriarchal power dynamics in order to live truly pious Muslim lives. His writings on gender in the Ihya' Ulum al-Din (The Revival of Religious Sciences) provide an excellent example of the extent to which mysticism can reinforce normative power structures, including that of patriarchy.

In contrast to al-Ghazali, another prominent mystic in Sufi history, Andalusian Sufi master Abu 'Abd Allah Muhammad ibn 'Ali ibn Muhammad ibn 'Arabi al-Hatimi at-Ta'i, never succumbed to pressure from either orthodox theological authorities or the political powers of Andalusia. In Ibn 'Arabi's most famous theological treatise, Fusus al-Hikam (The Bezels of Wisdom), his autobiographical work, Al-Futūhāat al-Makekiyya (The Meccan Openings) and his book of poetry, the Tarjumān al-Ashwāq (The Interpreter of Desires), he exhibits significant disregard for traditional interpretations of Qur'anic and Hadith texts, including theological discourse with regard to gender. Indeed, Ibn 'Arabi expresses remarkable support for women's participation in all aspects of religious experience. Ibn 'Arabi's educational and personal experiences with female mystics in late $12^{\text {th }}$ century Andalusia helps explain his radically egalitarian beliefs. Further, because Ibn 'Arabi subscribes to what he calls a Oneness of Being theology, in which all existence in the universe is merely an emanation from God, he avoids the misogyny which usually results from associating women with worldliness, sin, and distance from God. Ibn 'Arabi's mystical thought, largely free from the political and theological pressures al-Ghazali experienced, represents an instance in which Sufism used the authority behind mystical experience to challenge deeply held patriarchal assumptions. The divergent views of Ibn 'Arabi and al-Ghazali, on the place of women in Islam, help to illustrate the immense differences within Sufi thought. The considerable authority behind a direct connection to God can be used to reinforce normative patriarchal theological and political power structures, or it can be used to challenge misogyny and assert social justice and spiritual equality for women.

\section{HISTORIOGRAPHY}

In one of the most thorough examinations of gender in Islamic history, Leila Ahmed traced the decline of women's opportunities in the Near East, from relative freedom during the lifetime of the Prophet Mohammed and immediately after, to exceptional subjugation by the mid-ninth century. She argues that women in the tribal Near East during jabilia, and in the first few generations after the Prophet's lifetime, were largely free to contract their own marriages, own and handle property, and even had a voice in politics and religion. Unfortunately, as Ahmed puts it, "such free participation in community affairs would soon be curtailed by the formal introduction of seclusion." 4 While the Prophet's wives were the first to be restricted, seclusion and other patriarchal practices were codified into legalist Islam to such an extent that, by the beginning of the 'Abbasid Caliphate in 850 , religious authorities assumed that a patriarchal interpretation of the Qur'an was applicable in all circumstances and for all time. Moreover, with the rising wealth of the $9^{\text {th }}$ century came a thriving sex trade industry in the Near East, resulting in the severe devaluation of women. As Ahmed argues, everyone in 'Abbasid society, by "virtue of the knowledge of the ordinariness of this transaction, and for elite men in particular because of the intimate and direct level on which they experienced that knowledge, one meaning of woman in a very concrete, practical sense, was 'slave, object purchasable for sexual use."'4 The practices of polygamy, concubinage and unconditional divorce for men, Ahmed argues, all meant a significant loss of position for women in the urban Middle East. ${ }^{4}$

While more recent scholars of gender in the Medieval Muslim world complicate Ahmed's arguments to some extent, they largely agree that women lost significant opportunities as Muslim religious texts were codified into legal practices. As Kecia Ali contends, between the late $8^{\text {th }}$ century, when important legal scholars lived, and the early $10^{\text {th }}$ century, when schools of jurisprudence systematized Islamic theological doctrines, "a coherent notion of marriage and licit sexuality, centered on exclusive male dominion of female sexual capacity, emerged." 5 Laws regarding marriage, divorce, slavery, and reproduction were largely constructed so as to allow men and male institutions absolute control over female sexual and reproductive behavior. Ali further states that, while Muslim women enjoyed rights of property ownership unrivaled anywhere in the medieval world, marriage laws and customs for women closely mirrored the institution of slavery. ${ }^{5}$ 
It is important to note, as Marion Holmes Katz does, that legal restrictions on women's movement could result from an aversion to women's prominent participation in public life. She contends that women's mosque attendance throughout the $11^{\text {th }}$ century, especially in Iraq and Syria, was quite significant, and that "the most vehement and categorical prohibitions on women's mosque attendance were produced in contexts where women were highly visible."6 In other words, proscriptions against women's mosque attendance were reacting to women's significant presence. Nevertheless, throughout the $10^{\text {th }}$ and $11^{\text {th }}$ centuries, the prohibitions from legal scholars became more effective as jurisprudence placed more emphasis on sexuality. Increasingly, discourse among theologians and political authorities became more concerned with the extent to which female sexuality could distract and corrupt male worshipers. Fears surrounding women's bodies and sexuality served as a "global rationale for restrictions on women's participation in public worship."' Further, as Katz notes, social norms, which placed a woman's reputation in severe danger if she appeared publicly, were often far more effective than legal prohibitions in controlling women's movements. ${ }^{6}$

Nevertheless, Islam has never been controlled by a single sect or institution. Although the 'Abbasid Empire is often considered to be the high point of Islamic history, the success of 'Abbasid society led to both wealth and corruption and, as a result, an ascetic backlash against rampant materialism. As such, a mystical ascetic movement called Sufism developed, which asserted the basic spiritual equality of all humans. While law, tradition, and social norms often barred women from participation in institutions of religious or political authority, mysticism provided women with opportunities for authority and self-expression through direct experience with God. ${ }^{7}$ Although Sufi thinkers were never exempt from the misogyny of the dominant society in the Near East, female mystics were important to the mystical movement from its beginnings. Significantly, one of the most important founding figures of Sufism, who is credited with changing the focus of Sufism from asceticism to divine mystical connection through love, was an Iraqi slave woman named Rabi'a al-'Adawiyya al-Qaysiyya. ${ }^{8}$ As a result of conflicting influences, between the dominant patriarchal tradition within Medieval Islamic thought, and the often prevalent egalitarian ideology within of Sufi theology, Sufi views on women and gender have always been controversial.

Sufism often offered women the opportunity for an identity beyond sexual and reproductive capacity. There is some tendency among historians to overestimate the extent to which Sufism accepted female Sufis into the mystical fold. It is true that, as Sachiko Murata states, Sufis asked "fundamental questions concerning gender within the matrix of ultimate reality." However, Murata's statement that "Islam's basic view of men and women postulates a complementarity of functions" overestimates the extent to which Islam or Sufism ever supported gender equality. ${ }^{9}$ Sadiyya Shaikh similarly, but more cautiously, argues that Sufism is critical of power configurations that assert the superiority of particular people over others, including those that value men over women, but that Sufism never unreservedly accepted women into the mystical tradition. ${ }^{1}$ The most widely published expert on Medieval Sufism, Annemarie Schimmel, argues that Sufism was at best ambivalent in its relationship with gender equality. ${ }^{3}$ Ultimately, Sufi thought on gender throughout the $11^{\text {th }}, 12^{\text {th }}$, and $13^{\text {th }}$ centuries represents a complex debate between the patriarchal outlook of dominant legalist Islam, and the potentially radical egalitarian views of mysticism. While many scholars have remarked on the significant disparities within the writings of Sufi masters on gender, a comparative work suggesting some reasons for the difference of opinion has not yet been written.

Ibn 'Arabi and al-Ghazali are two of the most prominent and widely read thinkers in Sufi history, and represent two divergent opinions with regard to the place of women in religious experience. Both Sufi masters are widely studied, by both academic scholars and spiritual seekers. However, historical examinations of both Ibn 'Arabi and al-Ghazali, tend to focus on theology and cosmology. Historians address gender much less often. Although scholars throughout the $20^{\text {th }}$ century often mentioned Ibn 'Arabi's radically egalitarian positions with regard to gender, a thorough investigation was written only recently. While Sadiyya Shaikh's important book, Sufi Narratives of Intimacy: Ibn 'Arabi, Gender and Sexuality, is a revolutionary examination of Ibn 'Arabi's thoughts on gender and sexuality, her work does not thoroughly connect Ibn 'Arabi's gender ideology to the society in which he lived. No historian has examined al-Ghazali's thoughts on the position of women in Muslim society, presumably because his thoughts on gender fail to represent an interesting departure from typical misogynistic discourse.

Analyses on al-Ghazali's philosophical theology, however, are fairly extensive. As noted by Frank Griffel, al-Ghazali is most famous for examining the major points of Greek philosophy determining which aspects were heretical to Islam and which could be absorbed by Muslim theology. ${ }^{10}$ As a result, much of the historiography related to al-Ghazali debates whether al-Ghazali should be blamed for the elimination of Greek philosophy from Islamic thought or whether he should be credited for allowing certain aspects to be assimilated into Muslim theology. ${ }^{10}$ Al-Ghazali's thought is usually situated within a debate on the influence of Greek culture within Islam and, more broadly, within discourse on the extent to which rational inquiry has a place in religion. His thoughts on women are rarely acknowledged within the historiographical debate on gender in Medieval Islam.

Historians have written a great deal more on Ibn ‘Arabi’s views on gender and sexuality. Henry Corbin, the first Western historian to examine the works of Ibn 'Arabi, provides a thorough investigation into 'Arabi's cosmological philosophy, even examining 
'Arabi's theory that a feminine element of God, namely Compassion, is responsible for creation.11 Corbin's work was later criticized, as he seems to use Ibn 'Arabi for his own larger philosophical project, without addressing how the Sufi master might have fit into broader trends within Sufi or Islamic thought. ${ }^{2}$ More recent scholars, among them Binyamin Abrahamov and Denis McAuley, theorize about the influences of various thinkers on Ibn 'Arabi. Abrahamov analyzed 'Arabi's attitude toward various Sufi masters and the extent of their influence on him. ${ }^{13}$ McAuley argues that Neoplatonic ideas reached Ibn 'Arabi indirectly, and influenced the Sufi master's theology. ${ }^{14}$ The most thorough and widely cited examination of Ibn 'Arabi's writings, by William Chittick, provides an investigation into the theological and philosophical beliefs of this great Sufi Master, but rarely mentions women or gender in 'Arabi's broader cosmological view. ${ }^{12}$ Claude Addas' important biography, by contrast, successfully examines Ibn 'Arabi's life within the context of Andalusian society, but does not draw any conclusions about 'Arabi's cosmology and rarely mentions the place of female saints either in 'Arabi's writings or in Muslim Spain. ${ }^{15}$

Most relevant to this project, however, is Sadiyya Shaikh's work on Ibn 'Arabi's gender philosophy and its potential applications for Muslim feminism. With the stated purpose of using 'Arabi as an important Muslim authority to help endorse ethical feminism within Islam, Shaikh thoroughly examines Ibn 'Arabi's opinions on the extent to which women can participate in religious experience and in the broader society. ${ }^{1}$ Nevertheless, Sufi Narratives of Intimacy often does not place Ibn 'Arabi's thoughts on women and gender within his societal context. As Leila Ahmed writes, "the extent to which the different mores of Arab Spain shaped Ibn al-'Arabi's different attitude to women . . . has yet to be explored."4 Further, historians have not yet connected Ibn 'Arabi's tendency to question orthodox theology and political power structures to his egalitarian thoughts on gender and sexuality.

\section{ABU HAMID AL-GHAZALI}

Al-Ghazali's theology of gender is quite different from Ibn 'Arabi's. Although Sufi theology throughout its long history often questioned dominant institutions of authority within Islamic society, even to the point of challenging gender norms, some Sufi ideology, including that of Abu Hamid al-Ghazali, reinforced existing gender power configurations. Al-Ghazali's writings on gender and sexuality provide an excellent example of the ways Sufism perpetuated and strengthened dominant patriarchal ideology within a particular Muslim society. Al-Ghazali spent his life in Iraq and Syria under the political rule of the Seljuks, who conquered in 1058. With the Seljuk takeover of the Near East came, in the words of historian Hamid Dabashi, "the rapid systemization of the various modes of authority in juridical, philosophical, mystical and political domains." 16 Uprisings by the Shi'a minority, attacks from the Ismail'is in Egypt, and continued unrest from former 'Abbasid rulers, meant that the new Seljuk rulers were politically insecure, and were therefore particularly eager to solidify and legitimize their rule. ${ }^{16}$ They often did so by claiming the exclusive right to interpret and enforce Islamic orthodoxy. Heterodoxy in any form was rarely tolerated. ${ }^{10}$ As Dabashi puts it, "the more the Sunnis and the Shi'ites fought each other, the more they consolidated their respective orthodoxies against both mysticism and philosophy."16 Indeed a generation before al-Ghazali's birth, a particularly prominent Sufi mystic, al-Hallaj, was executed for heresy. ${ }^{16}$ As the Seljuks continued to solidify their authority, Sufism in the greater Levant became less likely to espouse uncontrolled ecstatic utterances, instead giving way to "cooler codifications and systemic classifications of doctrines and traditions."16 The environment was particularly dangerous for Sufi mystics, leading many to continuously prove their alignment with orthodox Islamic law and theology. ${ }^{17}$ In the words of Dabashi, "Islamic mysticism has had to respond cautiously and conservatively to the violent reactions of jurists and dogmatists to their ecstatic indiscretions." 16

Recognizing the great respect communities in the Near East had for Sufi mystics, the Seljuks also worked to absorb Sufism into larger political and theological structures, thereby controlling potentially politically threatening thought. Seljuk leaders institutionalized Sufism into orders and schools, often adjacent to the theologically orthodox madrasas. ${ }^{18}$ Eastern Sufism "manifested a progressive structurization," which began during al-Ghazali's lifetime, while mysticism in the West remained an individualized practice for centuries longer. ${ }^{19}$ As a result of Sufism developing into established orders and schools, women's access to Sufi mysticism was increasingly restricted. ${ }^{20}$ As established power structures of the Seljuk Empire absorbed Sufism, Sufi thinkers had little reason to question orthodoxy, especially with regard to gender.

As a Sufi master living in the Near East during all this political and ideological upheaval, Abu Hamid al-Ghazali would have been particularly disinclined to challenge the theological orthodoxy of the Seljuks. Moreover, before al-Ghazali converted to Sufism, the Seljuk rulers employed him as a teacher of law and theology in Baghdad. ${ }^{10}$ Although al-Ghazali refused patronage by political leaders after he began following the Sufi Way in 1095, he did not change his theological or philosophical beliefs. ${ }^{10}$ Al-Ghazali's decision to follow the Sufi path and his retreat from Seljuk politics did not mean a retreat from the orthodox theology he had been educated within. As a result, al-Ghazali's writings tend not to question existing theological doctrine or social taboos. He is even credited with integrating Sufi thought into traditional orthodox theology. ${ }^{18}$ Al-Ghazali's major work on ethics, the Ihya' Ulum al-Din (Revival of Religious Sciences) combines three traditional genres: books on Shari'ah, philosophical works on ethics, and Sufi mystical handbooks. ${ }^{10}$ As a result of this synthesis, al-Ghazali's Sufi thought often agrees with and reinforces orthodox theology. Al-Ghazali's particular disinclination to question or reject traditional thinking contributed to his thoughts on gender and sexuality, which certainly lean towards the traditionally patriarchal. 
In addition to his tendency towards normative and conservative theology, al-Ghazali's conversion to Sufism in 1095 resulted in a greater emphasis on asceticism. He rejected all worldly pleasures, resigned from his post in Baghdad, and traveled to Mecca. Because he associates women and female sexuality with sin and distance from God, al-Ghazali's ascetic thought thoroughly devalues women. For al-Ghazali, women, and particularly women's bodies, represent a threat to the religious devotion of men. As a result, he advocates for the seclusion of women in order to protect men's search for God from the nefarious and destructive influences of female sexuality. ${ }^{6}$ As such, both al-Ghazali's earlier political career-which influenced his theology towards the conservative — and his converstion to asceticism—which caused him to reject all things worldly, including women—contributed to his thoughts on the place of women within Islam. Not only does al-Ghazali fail to challenge dominant gender norms, but he uses Sufi theology and authority to reinforce and strengthen a patriarchal system. Indeed al-Ghazali believes that spiritual achievement for men entails perpetuating the subjugation of women. Further, al-Ghazali connects the piety of women to submissive acceptance within the patriarchy.

Because Al-Ghazali accepts typical patriarchal fears of uncontrolled female sexuality destroying the Godly devotion of men and the order of society, he believes women should be allowed no public persona at all. Instead, he argues that a woman "should remain in the inner sanctum of her house and tend to her spinning; she should not enter and exit excessively; she should speak infrequently with her neighbors and visit them only when the situation requires it."21 Al-Ghazali further demands that women only visit less-frequented market places and dress in worn out clothing so as not to be recognized. ${ }^{21} \mathrm{~A}$ good reputation for a woman is no reputation. Interestingly, al-Ghazali even corrects Muhammad's policies on the seclusion of women: "the Prophet permitted women to go to the mosques; the appropriate thing now, however, is to prevent them, except for the old. Indeed such was deemed proper during the days of the companions." 21 The Sufi theologian was so firmly ensconced in the extreme patriarchy of his time, that not even the practices of the Prophet compelled him to question current practice. The seclusion of women, for al-Ghazali, was necessary for the preservation of a faithful Muslim community.

While some Qur'anic verses or Hadiths could easily be read as affirmations of women's value, al-Ghazali reinterprets them in a context of a strictly patriarchal society, removing special protections for, or appreciation of, women. The Prophet famously forbade female infanticide, which was common practice in the Arabian Peninsula before Islam. While this injunction could be interpreted as an affirmation of the value of female children, al-Ghazali believed that the law existed only to encourage continued reproduction within the Muslim community, arguing that "divine legislation exceedingly made the killing of children and the burying [of girls] alive an abomination, for such acts were forbidden for the fulfilment of existence."21 Similarly, Ibn "Abbas, a companion to the Prophet and one of the earliest Qur'anic scholars, declared that "the best of this nation is mostly women," in an admiration of early Muslim women. Al-Ghazali, however, claimed "Abbas must have meant that "since sexual desire was a predominant force in the temperament of the Arabs, the frequency of marriage among their righteous men was more common." ${ }^{21}$ In other words, a nation with many women was not great because of the women, but because its men had a sufficient number of wives. Al-Ghazali was less interested in obeying foundational religious texts than in preserving gender norms within his own society.

Like many scholars in the Middle East during the early Seljuk period, and perhaps characteristic of thinkers in patriarchal systems more broadly, most of al-Ghazali's concern with the place of women relates to satisfying men's sexual desire. ${ }^{4}$ Although much early Sufi thought regarding marriage and sexuality was characterized by tension between an ascetic desire to reject all worldly pleasure and a desire to live like the Prophet, ${ }^{1}$ Sufis in the eleventh century tended to accept marriage as necessary for a true spiritual life. Al-Ghazali agreed, arguing that marriage provides men with convenient and doctrinally-approved sexual satisfaction, allowing them to devote more concentration to pious pursuits. He notes, "the corrupting factor in a man's religion lies for the most part both in his sexual organs and stomach, he can satisfy one of them by marriage."21 Ghazali provides an anecdote, in which some mystics criticize a fellow Sufi master for being married, and therefore distracted from God. This Sufi master, alGhazali reports, claimed that regular sex with his wives meant that he, unlike other worshipers, was never distracted from prayer by sexual fantasy. ${ }^{21}$ In this view, women and women's bodies become a tool used for the spiritual growth of men.

Moreover, al-Ghazali supports a marriage paradigm in which men have the unlimited right to discard their wives. He notes that "al-Hasan, the son of 'Ali, was a great lover having married more than two hundred women. Perhaps he would marry four at a time, and perhaps he would divorce four at a time replacing them with others ... It was said that his indulgence in marriage is one of the characteristics in which he resembled the Messenger of God."21 Al-Ghazali's admiration of al-Hasan suggests both that he believes marriage in extreme numbers could be compatible with a good Muslim man's life, and that he has little regard for the women affected by men's right to unrestricted divorce. In al-Ghazali's opinion, the legal system which placed a married woman at the mercy of a husband's whims was good and necessary to preserve the devotion of Muslim men. 
Further, Al-Ghazali advocates for marriage, arguing that for men marriage to women could make one a more patient and resolute Muslim because he must endure the vicissitudes of an irrational woman. Al-Ghazali thinks “toleration of a woman's tongue would try the saints," but by marrying and learning the compassion and patience necessary for living with women, a man can become a better Muslim. ${ }^{21} \mathrm{He}$ often advocates for patronizing self-sacrifice: "know ye that good conduct with her does not mean not harming her, but rather enduring harm from her and forbearance in the face of her fickleness and anger in emulation of the Prophet; for his wives used to talk back to him, and on occasion one would leave him for the whole night." 21 Al-Ghazali both perpetuates the stereotype of the irrational woman and suggests that men are the more rational, patient beings burdened with wives to take care of. He assumes that the generosity of a man tolerating his wives will ultimately benefit the man: "disciplining the self and training it to be mindful, faithful, loyal, and respectful of the rights of the wives." 21 In this model, a man's marriage is training for the stoic endurance of hardship. Al-Ghazali unites significant devaluation of women with support for marriage as an institution, thus reinforcing both pervasive misogynistic ideas about women and the existing marriage paradigm.

Similarly, according to al-Ghazali, by supporting and enduring a family, a man works for the salvation of others, thus gaining entrance into heaven for himself. Al-Ghazali even states that "bearing the burden of wives and of offspring is equivalent to jihad for the sake of God" because "the one who is preoccupied with reforming himself and others is not the same as the one who is preoccupied with reforming himself only." 21 Presumably a man, as the superior religious person, is duty-bound to drag his ignorant and impious wives up to heaven with him. Unlike prayer and religious ritual, which only benefits oneself, providing for a family benefits others: "enduring the burden of dependents, which is a form of exercise and struggle to provide for them and sustain them, is an act of worship in itself." 21 Al-Ghazali uses his authority as a Sufi master to reinforce patriarchal gender norms by connecting the traditional marriage institution to the piety of men and the male struggle for God.

Al-Ghazali further encourages devout Muslim men to enforce traditional doctrine within the home by controlling the level of education a wife can gain. The relationship between genders is one of divinely ordained domination, as "It is a man's right to be followed, not to be a follower. God has appointed men as trustees over women and has called the husband 'master."' 21 Further, it is a husband's duty to teach his wives about religion, paying specific attention to enforcing orthodoxy. He should "teach her the proper beliefs of the followers of the Sunnah, to remove from her heart every innovation should she lend an ear to it, and to make her fear God should she be lax in matters of religion." 21 Al-Ghazali seems worried that women might stray from 'correct' religious doctrine, and charges the husband with eliminating divergent or heterodox thought. The lessons, moreover, are to be uncompromising. Al-Ghazali warns men against any concessions: "the woman's behavior depends on you: If you slacken her reins a little, she will run off for a long distance." 21 He also is careful to forbid women from acquiring knowledge without her husband's consent, stating "no matter how much she learns about her obligations, she should not go out to attend a dhiker nor to receive instruction in superfluous knowledge without the consent of her husband." 21 When al-Ghazali connects absolute control over the education and behavior of women to the piety and religious obedience of men, he becomes part of a system which uses religious authority to enforce patriarchal values.

While al-Ghazali does provide some advice regarding the behavior of women, he is ultimately much more concerned with perpetuating and strengthening a patriarchal system than with the spiritual well-being of women. A woman's life should revolve around her husband's: "she should always observe the rules of personal hygiene, and be ready at all times for him to enjoy her whenever he wishes." 21 Obedience and sexual availability are of the utmost importance. Further, a woman's mood should be dependent on the presence of her husband. She should be "melancholy in the absence of her husband, and to return to her sprightliness and happiness in his presence." 21 This injunction has the result of preventing a woman from having open relationships with anyone but her husband. Her happiness should not be a feeling of and for herself, but her feelings should exist only to sustain the happiness of her husband. Al-Ghazali goes so far as to argue for cowardly, prideful and stingy behavior among women, because such conduct benefits a husband. A cowardly woman obeys her husband and stays in the house out of fear; a stingy woman best preserves her husband's property; and a prideful woman will not damage her husband's reputation. ${ }^{21}$ Wives should only be concerned with providing household services. He notes, "the virtuous woman who takes care of the house abets religiousness in this manner, and any disturbance of these preoccupations would perturb the heart and impede life." ${ }^{21}$ In other words, true piety for a woman is in creating an environment allowing for her husband to most effectively seek God.

Despite the overt misogyny in much of al-Ghazali's writings, it would be unwise and reactionary to judge al-Ghazali by the standards of modern feminism. He was a man of his time, unquestioningly supporting the dominant cultural discourse on gender within $11^{\text {th }}$ and $12^{\text {th }}$ century Middle East culture, but he does not conceive of the female sex as unworthy of compassion and good treatment. For example, fathers should exercise caution on behalf of the daughters they marry off, because "she becomes a slave by the marriage and cannot be freed from it, while the husband is able to obtain divorce at all times." ${ }^{11}$ He advocates for good treatment of women, but does not question the legal system which fails to enforce fair treatment for women. Al-Ghazali also recognizes the existence and importance of female sexuality, advising that "once the husband has attained his fulfillment, let him tarry until his wife also attains hers. Her orgasm may be delayed, thus exciting her desire; to withdraw quickly is harmful to the 
woman."21 Moreover, al-Ghazali cautions that "one should not be overjoyed with the birth of a male child, nor should he be excessively dejected over the birth of a female child, for he does not know in which of the two his blessings lie."21 While AlGhazali acknowledges that the system might be harmful to women, he never challenges any institutional practice itself. In the case of al-Ghazali mysticism, which had the potential to radically challenge predominant conventions within a highly patriarchal society, became a tool for political and theological authorities in the Middle East to reinforce gender norms.

\section{IBN 'ARABI}

By contrast, when Sufism was not coopted by established religious doctrine and used to perpetuate the status quo, mystical thought could be very threatening to orthodox theology and its claims to absolute truth. As a Sufi master born in Muslim Spain in 1165, separate from the political pressure put on mystics in the East, Abū 'Abd Allāh Muhammad ibn 'Alī ibn Muhammad ibn 'Arabī al-Hātimī aț-Ṭ̂' '̄̄ was one of the more revolutionary thinkers in Sufi history. Because he lived most of his life free from the political and theological pressures of dominant society, Ibn 'Arabi often demonstrates blatant dismissal for traditional dogma, even to the point of rejecting dogmatic thinking entirely. Although his thoughts on gender are certainly grounded in the context of a society which valued men over women, Ibn 'Arabi expresses remarkable support for gender equality. His disregard for traditional interpretations of religious scripture, his larger theology of Oneness of Being which values material existence, and the influences of his female teachers all help explain Ibn 'Arabi's conviction that men and women are spiritually and intellectually equal.

Modern scholars are often so impressed by the intellectual and cultural achievements of Muslim Andalusia, that they tend to graft a certain amount of gender equality onto Andalusian culture that may not have existed. However, as historian Maria Luisa Avila argues, the biographical sources from Andalusia during the Middle Ages do not represent greater opportunities for women than in any other Muslim society. ${ }^{22}$ Chronicles and biographical sources which mention women often only do so in relation to powerful men. ${ }^{23}$ Nevertheless, Sufism in Andalusia in the $12^{\text {th }}$ and $13^{\text {th }}$ centuries lacked institutional structure and proscribed regulations regarding how one could become a Sufi. ${ }^{24}$ While Eastern Sufism progressively developed more institutional structure throughout the $11^{\text {th }}$ and $12^{\text {th }}$ centuries, Andalusian Sufism remained largely an individual pursuit until much later. ${ }^{19}$ Indeed the lack of hierarchy and regulation among Andalusian Sufis helps explain why Ibn 'Arabi was exposed to several female mystics during his formative years, while al-Ghazali seems never to have considered the possibility of a female Sufi master. Because no established rules existed regarding who was to be considered a Sufi master, people who were recognized by the broader community as mystics became Sufi masters. Andalusian Sufism during Ibn 'Arabi's lifetime was not a system of institutional authority legitimized by the political powers, but was a popular movement, wherein lay people in a community decided who constituted a Sufi mystic. ${ }^{25}$ In practical terms, when mysticism has dimensions of independence for hierarchy, it is often much more open to women. ${ }^{2}$ As a result, it was not uncommon for a woman in Andalusian society to be revered as a Sufi. ${ }^{20}$

Ibn 'Arabi's biographical stories in Andalusia demonstrate both that female Sufi masters existed during his lifetime, and that Ibn 'Arabi's female teachers deeply influenced both his mystical experience and his theological opinions. Ibn 'Arabi describes one of his most significant instructors, Nuna Fatimah Bint ibn al-Muthanna of Seville, as a mystic of "profound devotion."26 She lived as an ascetic in a hut built by 'Arabi, and ate only scraps left by the community of Seville. Ibn 'Arabi considered her his spiritual mother. ${ }^{24}$ Further, the women mystics 'Arabi writes of were reportedly capable of miracles, including levitation, speedy travel, and the ability to influence politics through divine intercession. ${ }^{26}$ In his praise of female mystics, Ibn 'Arabi is firmly complementary, never suggesting that these women were spiritually accomplished despite being female. Zainab al-Qual'iyyah, a woman of reportedly great beauty and wealth, with whom Ibn 'Arabi travelled from Mecca to Jerusalem, was "the companion of many eminent men of the Folk, a" suggesting that Sufi men accepted her as legitimate. ${ }^{26}$ She was also, according to "Arabi, "one of the most intelligent people of her time."26 Similarly, a woman named Shams, Mother of the poor, had greater control over her soul than anyone Ibn 'Arabi had ever met. ${ }^{26}$ Of a slave girl from Qasim al-Dawlah he wrote "I have never seen one more chivalrous than her in our time." 26 The fact that Ibn "Arabi overtly admires the female mystics in his life, and the fact that he does not qualify his praise with 'for a woman,' suggests a complete disregard for the notion that men have greater access to God. Ibn 'Arabi's exposure to a number of female Sufi masters helps explain why he was willing to affirm the spiritual capacities of women.

In addition, Ibn 'Arabi's indifference toward traditional theological interpretations of religious texts contributed to his significant support for gender equality. While al-Ghazali uses the authority behind Sufi mysticism to reinforce orthodoxy, Ibn 'Arabi displays flagrant disregard for Islamic orthodoxy in his pursuit of mystical truth. Political authorities in Andalusian society were much more politically secure than the Seljuks in the East, and as such were much less likely to enforce traditional dogma in an effort to legitimize their rule. Although the Almohads from North Africa took Spain and attempted to set up an autocratic theocracy shortly before Ibn 'Arabi was born, the new rulers, in the words of Addas, "gradually succumbed to the seductive refinements of

a Ibn 'Arabi refers to Sufis as the Folk. 
Andalusian society."'15 While Ibn 'Arabi had close ties to the intellectual elite and official religious circles, both during his early life in Spain, and after he left Andalusia to travel in 1201, he was never financially dependent on any political figure. ${ }^{15}$ Further, because Ibn 'Arabi was raised in the more lenient Spanish society, and because he spent much of his life travelling, he was subjected to little political or theological pressure to adhere to normative dogma. As a result, traditional gender norms did little to restrict Ibn 'Arabi's theology.

A particularly vivid example of his unwillingness to conform to orthodoxy is Ibn 'Arabi's reinterpretation of the myth of Noah and the flood, in which he casts the drowned peoples, not as sinners, but as mystics. The flood story, according to 'Arabi, is a metaphor for the disagreements between those who understand God as a transcendent being unreachable to humans, and those who believe in an immanent God manifested directly into the created universe. The mystics "recoiled" from Noah's words because their inner selves were more drawn to an immanent understanding of God, while Noah only knew a transcendent and unreachable God. ${ }^{27}$ The flood waters represented, not a punishment for sin, but the gift of perplexity from God. A true Sufi experiences drowning in perplexity and confusion when he or she contemplates the paradox of a God that is at once incomprehensible and transcendent, and an immanent God that can be known through manifestation in creation. The "transgressions" mentioned in the Quranic story referred, not to sin, but to the ways mystics move beyond their own sensory reality to contemplate a greater truth. ${ }^{27}$ If God were to "deliver them [from the seas of gnosis] onto the shore of Nature He would be lowering them from an eminent state [of spiritual attainment]." 27 Ibn 'Arabi's subversive reinterpretation of the flood story exhibits both a brazen disregard for traditional interpretations of Qur'anic verse, and for the customary view of God as absolutely superior and beyond human comprehension.

Ibn 'Arabi even overtly questions the value of religious traditions, doctrines, and laws. He argues that "he who is not a gnostic calls on Him in ignorance and is bound by tradition," suggesting both a disregard for tradition itself and a belief that mystics of any religious tradition can truly know God. ${ }^{27}$ Indeed Ibn 'Arabi often implies that strict and exclusionary orthodoxy obscures truth: "One who believes [in the ordinary way] believes only in a deity he has created himself." 27 All the extra trappings of ritual, dogma and religious law which people ascribe to God are only human creation. Instead, Ibn 'Arabi recommends openness to all forms of doctrine. ${ }^{27}$ Even polytheistic idol worship is valid, because every object of worship in the cosmos contains a manifestation of God. ${ }^{27}$ Differences of religion, for 'Arabi, exist because God willed it, even though God prefers Islam. To be sure, Divine Wisdom could change Muslims to Christians at a whim. ${ }^{27}$ The perfect gnostic sees truth beyond the particulars of ritual worship and "regards every object of worship as a manifestation of God."27 Significantly, Ibn 'Arabi's apparent neglect for tradition and doctrine helps explain why he was exceptionally willing to dispute prevailing gender ideology. Ibn 'Arabi's predisposition towards disregard of the rituals, to which humans ascribe significance, meant he was not so ensconced in the dominant ideologies of his day that he could not challenge a deeply embedded patriarchal belief system.

Ibn 'Arabi, to be clear, certainly did not advocate for the abolition of legalist or orthodox Islam. On the contrary, he often emphasizes the importance of respecting both Shari'a and people in positions of authority. In his written dialogue between Moses and al-Khidr, 'Arabi demonstrates the tension between Sacred Law and mystical knowledge, noting that, while the mystic al-Khidr might have true knowledge, he is still respectful of Moses' position as representative of God's law. ${ }^{27}$ Ibn 'Arabi further believes that divine law, brought by the Prophets, is a gift to humans and is meant to be followed. ${ }^{27}$ Law provides much needed guidance, especially for those who cannot perceive the ultimate truth. ${ }^{27}$ While he argues that another gift from God is "the power of legislation through the exercise of individual judgement," Ibn 'Arabi's belief that society is as God willed it can be interpreted as a tacit acceptance of that status quo within political organization. ${ }^{27}$ Ibn 'Arabi's support for the political status quo could be interpreted as a rejection of the women's incorporation into societal power structures. However, 'Arabi’s endorsement for women's political and spiritual equality is remarkably robust.

Despite his acceptance of the extent to which some people hold worldly power over others, Ibn 'Arabi unambiguously emphasizes the absolute spiritual equality of all human beings. Because all people are descendants of Adam, a "single spiritual essence" unites all of humanity. ${ }^{27}$ This belief implies that, as a result of this single spiritual origin, gender must be a secondary and unimportant characteristic. ${ }^{14}$ Indeed Ibn 'Arabi is careful to emphasize that "there is no spiritual qualification conferred on men which is denied women." As a doctrine which tends to emphasize spiritual development over all else, Sufism has the potential to challenge claims by political authorities regarding the "natural" or "rightful" supremacy of certain types of people over others. ${ }^{3}$ 'Arabi absolutely fulfills this potential with regard to his assertions about the equal spiritual capacities of women.

Further, while Islamic orthodox theology after the $11^{\text {th }}$ and $12^{\text {th }}$ centuries increasingly emphasized the danger inherent in women's sexuality, Ibn 'Arabi's cosmological beliefs offer a powerful counterargument to the way theological convention tends to disassociate women from divinity. ${ }^{5}$ Monotheistic religions, including Islam, often conceive of the universe as a dichotomy between the material, worldly reality and a nonmaterial, divine plane of existence. This worldview values the transcendent reality of God, spirituality and intellect over experienced, physical existence. At the same time, patriarchal ideology regards male as the 
ideal human, with the capacity to transcend nature, emotion and sexuality. As Simone de Beauvoir famously articulated, women are 'othered' by patriarchal discourse, and associated with the lower form of existence that constitutes nature. ${ }^{29}$ The hierarchy between material and nonmaterial reality connects male humans with intellect, spirituality and divinity, while female humans become relegated to the less valued realm of nature and corporeal existence. As a result, religious doctrine interpreted by and for men often assumes that women and spirituality are fundamentally incompatible. ${ }^{30}$ Ascetic practice is especially prone to reject and devalue women, just as it rejects nature and bodily experience in an attempt to reach God. As Ahmed has argued, a great deal of Medieval Islamic theology definitively accepted this formulation, especially in its unyielding advocacy for women's veiling and seclusion. ${ }^{4}$ The Islamic legal tradition often restricted women's movements in order to protect men from temptation and sin. AlGhazali demonstrates a significant amount of concern for women's ability to distract men from God through sexuality.21

However, by rejecting a material/nonmaterial dichotomy within his beliefs about the nature of being, Ibn 'Arabi also implicitly rejects much of the misogyny that results from associating women with a lower form of existence. Ibn 'Arabi's cosmology asserts a Oneness of Being principle, wherein God's Essence emanates from God and manifests in creation. God, as the only unchanging presence, represents true, unchanging Being. Everything else in the cosmos is in flux, existing partially in Being and partially in Nonbeing. ${ }^{12}$ Because the universe derives its existence from God, every created being shares in the Essence of God. Therefore, the material world is not, as more orthodox theologians have claimed, radically separate from an unknowable and transcendent God. ${ }^{27}$ Instead, for Ibn Arabi, the created universe is a mirror for God, in which God can contemplate God's own image. ${ }^{27}$ The cosmos is nothing other than God's self-manifestation. As 'Arabi notes, "there is naught but He."27 As a result, the natural world is essentially good and part of God. One cannot understand God without understanding God's creation. Ibn 'Arabi criticizes the theology of al-Ghazali directly on this point, arguing that "certain sages, among them Abu Hamid al-Ghazali, have asserted that God can be known without any reference to the created cosmos, but this is mistaken." 27 God is part of creation, and creation is part of God. For Ibn 'Arabi, "the truth is that the Reality [God] is manifest in every created being and in every concept."27

Because the created universe is part of God, the material world and nature should not be rejected. Although Ibn 'Arabi, like many thinkers in a male-dominated world, associates women with passivity and with nature, his appreciation of nature itself means that he avoids the extreme misogyny often prevalent in the opinions of ascetics attempting to transcend the natural world. Ibn 'Arabi's admiration of God's creation, as well as his admiration of the feminine aspects of the created world, are evident in his writings. In his theory of cosmology, 'Arabi believes that the masculine Spirit is the spark of life, but without the passive receptivity of the feminine Nature, no life could exist. ${ }^{27}$ While Spirit rules Nature, both are necessary for existence, and both result from the emanation of God's being. In his words, the earth "gives all of the benefits from her essence and is the location of all the good" and as a result, "she is the most powerful of bodies." He recognizes the power and the value within the natural world. For Ibn "Arabi, the earth was created by God, "brought into existence upon His own form" and therefore is "beautiful in the extreme; there is no ugliness in it." 31 If the natural world was made in the image of God, it is not to be transcended, conquered, or rejected. Similarly, because Ibn 'Arabi conceives of nature in feminine terms, femininity is also not something to be transcended and rejected. Ultimately, Ibn 'Arabi does not associate femininity with distance from God because he does not believe in the concept of distance from God.

Ibn 'Arabi's admiration of the natural world lends itself toward a positive view of human sexuality. He has no desire to reject the human body in an attempt to get closer to God. Instead, 'Arabi believes that knowledge of God can be gained through use of the body. ${ }^{1} \mathrm{He}$ claims that "the soul loves the body because all of her knowledge of the Truth is gained through her imprisonment in the body and through her making use of it in order to serve God."1 As a result, humans are superior to the angels, who live in a purely spiritual realm, because humans have physical existence. In the words of Ibn 'Arabi, humanity "harmoniously embraces and incorporates physical, spiritual, emotional, and mental realms, which together function as instrumental in giving humanity its unique station, the possibilities of becoming the most complete mirror of the divine."' The body, for "Arabi, is vital to the human experience, and to humanity's experience with God.

Theologians within patriarchal traditions often assume that the spirit and intellect, associated with masculinity, are limited and opposed by the emotions and sexuality, associated with femininity. ${ }^{32}$ However, by rejecting the hierarchy of spirituality over nature, Ibn 'Arabi disputes assumptions regarding the corrupting force of female sexuality to male devotion. Indeed for 'Arabi, sexuality is an important part of religious experience. When both partners recognize the divine image in each other, and are aware of the fact that all pleasure ultimately comes from God, then the self-annihilation brought about through absorption in the sexual act is a way for humans to contemplate God. ${ }^{33}$ Accordingly, sex is "the most complete union possible in love, and there is in the elemental sphere no greater union than that between the sexes." 27 The ablution which Islamic tradition requires after intercourse is not, for 'Arabi, a ritual cleansing after an unclean act, but is required because God becomes jealous that anyone finds pleasure in anything but God. ${ }^{27}$ Further, 'Arabi notes that women's bodies are not shameful, and that veiling is for modesty only. ${ }^{1}$ If sexuality is only another method by which one worships God, then women's sexuality is an aspect of religious experience, not a threat to men's relationship with God. Women are not a threat to divinity, or male piety, but are fellow humans capable of participating in 
this type of worship. As a result, Ibn 'Arabi never adopts an accusatory narrative, wherein the sexuality of women is responsible for men's temptation into sin.

Because Ibn 'Arabi does not assume sexuality and spirituality are opposing forces comparable to darkness and light, he implicitly challenges a system of thought which assumes that female sexuality is incompatible with female piety. ${ }^{34}$ When 'Arabi defends one of his female disciples against accusations of sexual misconduct, emphasizing that she was "untouched by suspicion, chaste," he seems to tacitly accept the idea that female sexuality and spirituality are opposed. ${ }^{31}$ However, Shaikh argues that he shows awareness of the "predilection for vicious targeting of Sufi women of superior spiritual character that is so characteristic of patriarchal fury and envy." "Arabi may have conceived of sexuality as a virtuous part of human existence, but he lived in the real world, and knew threats to a woman's sexual reputation amounted to a threat to her spiritual authority. To be clear, 'Arabi absolutely idealizes female virginity. He places a great deal of importance on the virginity of Mary, suggesting that, when Mary first refused Gabriel because she thought he was a human wanting to have sex, she earned the approval of God. ${ }^{27}$ However, for 'Arabi, a woman can embody both sexuality and superior spiritual achievement. This is evident in his portrayal of the Persian Sufi Nizam bint Makin al-Din. Sadiyya Shaikh remarks that Ibn 'Arabi admires her, not only her spiritual achievements and wisdom, but also her beauty and sensuality. ${ }^{1}$ Nizam inspired Ibn 'Arabi's book of love poetry, the Tarjuman al-Ashwaq (The Interpreter of Desires). The Sufi insisted, after being accused of eroticism, that the erotic poetry in the Tarjuman should be interpreted as a metaphor for mysticism. ${ }^{1}$ However, Ibn 'Arabi's poetry and much of his writing fail to make a clear distinction between sexual and mystical experience, suggesting that he did not see one. ${ }^{35}$ His belief system implies that, just as a truly pious human life incorporates both spirituality and sexuality, so too can a woman embody both spiritual and sexual desire.

Unfortunately, Ibn 'Arabi's cosmological belief system does not always lend itself towards gender equality. In his theory of creation, 'Arabi states that just as man was created from God's essence, woman was created from man's essence. Woman's existence is secondary to, and dependent on, that of man. Therefore, woman longs for man in the same way man longs for God, "as one longs for that place to which one belongs."27 Because woman's existence emanated from man in the same way man emanated from God, the best way for a man to contemplate God is by contemplating woman. When a man looks at a woman, he can better understand God, because he embodies active creation in relation to her. ${ }^{27}$ As Shaikh has noted, this paradigm lends itself towards a theological hierarchy of being, wherein man's existence is prior and superior to that of woman. ${ }^{1}$ While Ibn 'Arabi warns against self-deification elsewhere, his theory of creation implies that man is to woman what God is to man. ${ }^{27}$ Further, and perhaps more insidiously, Ibn 'Arabi, similar to al-Ghazali, seems to recommend that men use women as tools for spiritual development. Although 'Arabi warns that any man who interacts with a woman for his own pleasure without recognizing divine essence in her misses the point, this theology might lead to an idealization of the female form without recognition of real women's spiritual needs. Nevertheless, because Ibn 'Arabi believes divinity is best contemplated in woman, he avoids much of the misogyny that characterizes women as antithetical to God.

Further, Ibn 'Arabi suggests that women and femininity hold a special position in the divine order of the universe. As Henry Corbin famously illustrated, Ibn 'Arabi refers to the most powerful aspect God, namely Mercy, in feminine terms." Ibn 'Arabi also notes that in the prophetic saying, "three things have been made beloved to me in this world: women, perfume, and prayer," Muhammad used feminine thalath, not masculine thalathah, to denote the number three. This grammatical choice, to Ibn 'Arabi, suggests that the Prophet gave "precedence to the feminine over the masculine, intending to convey thereby a special concern with and experience of women." 27 Similarly, "Arabi observes that feminine terms are prominent in every school of Islamic thought. ${ }^{27}$ While he does not go on to draw any conclusions from such an observation, Ibn 'Arabi's concern for recognizing femininity within the divine is significant. For 'Arabi, neither God nor human religious experience can be defined on exclusively male terms.

Theologies which make use of feminine metaphors to understand God do not necessarily recognize the value of human women. ${ }^{30}$ Indeed female representations of wisdom are often used as narrative tools for men to convey a particular story. ${ }^{36} \mathrm{However}$, Ibn 'Arabi absolutely advocates for women's right to have a voice in human society. As Sadiyya Shaikh has thoroughly explained, Ibn 'Arabi asserts not only the spiritual equality of men and women, but also advocates for equal treatment in law and society. ${ }^{1}$ Women can reach the highest level of sainthood, speak as an imam before a congregation, and share legal obligations equal to men.1 "Arabi even claims that "there is nothing in the created universe greater in power than women." $\mathrm{He}$ believes that the Qur'anic story in which the Prophet calls on God, all of the righteous believers, and the angels to counter the strength of 'Aisha and Hafsa, does not demonstrate the folly of these two women, but their strength. ${ }^{1}$ As 'Arabi notes, "all of this is to counter the strength of two women." "Therefore, women's strength must be significant. Clearly Ibn 'Arabi was remarkably progressive in his support for women's right to participate fully in both religious experience and human society. 


\section{CONCLUSIONS}

Ibn 'Arabi represents the level of subversion Sufi thought could attain when allowed to flourish without appropriation by orthodox theology or political leaders interested in preserving the status quo. His formative experiences with female mystics, his willingness to challenge traditional orthodoxy, and his Oneness of Being theology all help explain Ibn 'Arabi's remarkable support for gender equality. Ultimately, Ibn 'Arabi's Sufi thought successfully used the authority behind mystical experience to challenge patriarchy. Al-Ghazali, by contrast, used his authority as a Sufi master to reinforce normative gender power dynamics in his society. For al-Ghazali, truly devout Muslim men and women are those who perpetuate a system which oppresses and devalues women.

As has been noted by Sadiyya Shaikh, mysticism itself is comparable to feminism, in that it deconstructs human epistemologies which value the external characteristics of humanity over spiritual and intellectual abilities. ${ }^{1}$ Sufi mysticism has the power and the potential to challenge the traditional notion that patriarchy is inevitable and divinely ordained. However, mystical experience has never occurred in a vacuum. The way mystics understand and experience God and the world around them is dependent on the cultural context in which they live. Sufi thought, therefore, was never exempt from the androcentric ideologies which permeated much of Islamic theology throughout the Medieval period. Further, mysticism can include a fixation on transcendent ecstasy, which often becomes only another attempt by a patriarchal culture to abandon the body. ${ }^{2}$ Sufism could be used as a powerful tool to reinforce both established gender norms and established political rule, or it could be used to validate calls for gender equality and justice.

Medieval Islamic Sufism provides a fascinating medium through which historians can study interaction and conflict between patriarchy and egalitarianism, between established religious authority and individual experiences of God, and between traditional orthodox theology and direct connection to the divine. Despite ideas which appear prevalent in Western media, Islam is not inherently antithetical to gender equality or to justice for women. A great number of writings exist within the Islamic tradition which sanction and approve gender equality. As the study of gender within Islam continues to progress, shedding more orientalist influences and ideas, it will gain more accurate representations of the experiences of Muslim women and men within their own culture. Ultimately Islam is, like any other religion, only what the people who practice it make of it. One can either use religious authority to enforce justice and compassion for all people, or one can use it to perpetuate existing institutions of political power which often devalue women.

\section{REFERENCES}

1. Shaikh, S. (2012) Sufi Narratives of Intimacy: Ibn 'Arabi, Gender, and Sexuality, pp. 13, 42, 82-105, 129, 133-138, 167, 183, 225, 231, University of North Carolina Press, Chapel Hill.

2. Sölle, D. (2001) Definitions, Methods, Delimitations, in The Silent Cry: Mysticism and Resistance, Forty Press, Minneapolis.

3. Schimmel, A. (1975) Mystical Dimensions of Islam, pp. 85, 426-428, University of North Carolina Press, Chapel Hill.

4. Ahmed, L. (2010) Women and Gender in Islam: Historical Roots of a Modern Debate, pp. 53, 60, 84-87, 100, Harvard University Press, Cambridge.

5. Ali, K. (2010) Marriage and Slavery in Early Islam, pp. 15, 47, 114, Harvard University Press, Cambridge.

6. Holmes Katz, M. (2014) Women in the Mosque: A History of Legal Thought and Social Practice, pp. 11, 104, 123, 149, Columbia University Press, New York.

7. Schimmel, A. (1982) Women in Mystical Islam, in Women and Islam, pp. 1-30, Pergamon Press, Oxford.

8. Smith, M. (2001) Muslim Women Mystics, pp. 1-47, Oneworld Publications, Oxford.

9. Murata, S. (1992) The Tao of Islam: A sourcebook on gender relationships in Islamic thought, pp. 3, 14, State University of New York Press, Albany.

10. Griffel, F. (2009) Al-Ghazali’s Philosophical Theology, 35, 40, 43, 48, Oxford University Press, Oxford: Oxford University Press.

11. Corbin, H., (1969) Alone with the Alone: Creative Imagination in the Sufism of Ibn 'Arabi, pp. 157-159, Princeton University Press, Princeton.

12. Chittick, W.C. (1989) The Sufi Path of Knowledge: Ibn al-'Arabi’s Metaphysics of Imagination, pp. 6, 77, 96, State University of New York Press, Albany.

13. Abramahov, B. (2014) Ibn al-'Arabi and the Sufis Anqa Publishing, Oxford.

14. McAuley, D.E. (2012) Ibn 'Arabi's Mystical Poetics, University of Oxford Press, Oxford.

15. Addas, C. (1993) Quest for the Red Sulphur: The Life of Ibn 'Arabi, The Islamic Texts Society, Cambridge.

16. Dabashi, H. (1993) Historical Conditions of Persian Sufism During the Seljuk Period, in Classical Persian Sufism: from its Origins to Rumi, pp. 139 -143, 161, Kaniqahi Nimatullahi Publications, London.

17. Alexander Knysh, Islamic Mysticism: A Short History (Leiden: Brill, 1999), 116. 
18. Nasr, S.H. (1993) The Rise and Development of Persian Sufism, in Classical Persian Sufism: From its Origins to Rumi, pp. 15, Kaniqahi Nimatullahi Publications, London.

19. Karamustafa, A.T. (2007) Sufism: The Formative Period, pp. 113, University of California Press, Berkeley.

20. Schimmel, A. (1999) My Soul is a Woman: The Feminine in Islam, pp. 42, 45, Continuum, New York.

21. Al-Ghazali, A.H., Ihya' Ulum al-Din, trans. Farah, M. (2012) Marriage and Sexuality in Islam, in Revival of Religions Sciences, Islamic Book Trust, Selangor.

22. Avila, M.L. (2002) Women in Andalusi Biographical Sources, in Writing the Feminine: Women in Arabic Sources, I.B. Tauris Publishers, London

23. Viguera Molins, M.J. (2002) A Borrowed Space: Andalusi and Maghribi Women in Chronicles, in Writing the Feminine: Women in Arabic Sources, I.B. Tauris Publishers, London.

24. Addas, C. (1992) Andalusi Mysticism and the Rise of Ibn 'Arabi, in The Legacy of Muslim Spain, pp. 910, 928, E.J. Brill, New York.

25. Chodkiewicz, M. (1993) Seal of the Saints: Prophethood and Sainthood in the Doctrine of Ibn 'Arabi, pp. 14, Islamic Texts Society, Cambridge.

26. Abū 'Abd Allāh Muḥammad ibn 'Alī ibn Muḥammad al-Ḥātimī aṭ-Ṭā' ̄̄ ibn 'Arabi, Ruh al-quds, trans., Austin, R.W.J. (1971) Sufis of Andalusia, pp. 142-155, University of California Press, Berkeley and Los Angeles.

27. Abū 'Abd Allāh Muḥammad ibn 'Alī ibn Muḥammad al-Ḥātimī aṭ-Ṭā' 'ì ibn 'Arabi, Fusus al- Hikam, trans. Austin, R.W.J. (1980) Bezels of Wisdom, pp. 50, 54, 57, 74, 77-80, 87, 92-93, 98-103, 132, 137, 168, 175, 213, 247-266, 274-278, Paulist Press, Inc., New Jersey.

28. Abū 'Abd Allāh Muḥammad ibn 'Al̄̄ ibn Muḥammad al-Ḥātimī aṭ-Ṭầ' ī ibn 'Arabi, trans. Nicholson, R.A. (1911) Tarjuman al-Ashwaq: A collection of mystical odes, pp. 49, Royal Asiatic Society, London.

29. De Beauvoir, S. (1949) The Second Sex, 1949, trans. Constance Borde and Sheila Malovaney-Chevallier (2011) Random House Inc., New York.

30. Hein, Hilde (1989) Liberating Philosophy: An End to the Dichotomy of Spirit and Matter, in Women, Knowledge, and Reality: Explorations in Feminist Philosophy, pp. 293, Routledge, New York and London.

31. Ibn 'Arabi, Al-Futuhat al-makkiyya, trans. Chodkiewicz, M., Chittick, W.C., and Morris, J.W. (2004) The Meccan Revelations, pp. 182, Pir Press, New York.

32. Carr, A. (1988) Transforming Grace: Christian Tradition and Women's Experiences, pp. 177, Harper and Row, San Francisco.

33. Derin, S. (2012) Earthy and Spiritual Love in Sufism: Ibn 'Arabi and the Poetry of Rumi, in Love and Devotion: From Persia and Beyond, pp. 58, Macmillan Art Publishing, Oxford.

34. Lerner, G. (1986) The Creation of Patriarchy, Oxford University Press, New York.

35. Lutfi, H. (1985) The Feminine Element in Ibn 'Arabi's Mystical Philosophy, Journal of Comparative Poetics 5, pp. 7-

36. Clark, E.A. (1998) The Lady Vanishes: Dilemmas of a Feminist Historian after the 'Linguistic Turn,' Church History 67, no. 1, pp. 1-31.

\section{ABOUT THE STUDENT AUTHOR}

Emily Dovel graduated from the University of Portland in 2016 with a Bachelor of Arts in History, and minors in Gender and Women's Studies and Political Science. She had received a Fulbright Grant to teach English in Turkey for the 2016-2017 school year. However, after the United States Department of State canceled the Fulbright ETA Grants to Turkey, Emily instead enrolled in an intensive Arabic language program at the Qalam wa Lawh Center for Arabic Studies in Rabat. Emily plans to continue to work towards fluency in Arabic before entering a PhD program in Middle Eastern History.

\section{PRESS SUMMARY}

This article examines the ways in which the political contexts and theological beliefs of two prominent Sufi mystics represent gender ideology within medieval Islamic societies. Al-Ghazali, a theologically conservative Sufi, who also lived under the enormous political pressures of Seljuk rule, uses his Sufism to reinforce traditional gender norms. Ibn 'Arabi, by contrast, was largely free from the political and theological pressures of dominant institutions, and was therefore free to use his theological beliefs to advocate gender equality. The ways in which prominent religious figures in Islamic history perceived gender and sexuality can help modern people to better understand gender ideology in the Islamic world today. 


\title{
Breaking the Chain of Silence: Political Activism and Social Justice in Omar Offendum's Syrian-American Hip-Hop
}

\author{
Harry Olafsen ${ }^{a}$, Mohammed Ali, Mikayla McCord ${ }^{k}$, \& Dr. Roxana Cazan * \\ ${ }^{a}$ Department of Literature and Languages, Saint Francis University, $P A$ \\ ${ }^{b}$ Pre-Medicine Track, Indiana University of Pennsylvania, $P A$ \\ ${ }^{\circ}$ College of Arts and Sciences, University of South Carolina in Columbia, SC
}

Mentor:RCazan@francis.edu*

\begin{abstract}
Dissatisfied with the decisions of the Western political class to remain uninvolved in helping settle the conflict in Syria, many hiphop, rap, and pop artists from Syria and the surrounding region have been creating and performing politically charged music that promotes liberty, and justice in the Middle East. One artist in particular, Omar Offendum (in the United States), writes and brings to the stage his hip-hop music in a way that continues and enhances this political-artistic movement across the Atlantic. Employing rhymes and rhythms that foster commotion and make noise, Offendum breaks the global indifference accumulated around the topics of the Syrian war and the unsolvable debates about allowing a certain number of Syrian asylum seekers to apply for refugee status in Western nations. He underscores that apathy is not an option for those who oppose the oppressor. In this paper, we argue that Offendum's music constitutes an effective tool of political propaganda that can raise social consciousness of the needs of Syrians today and inspire social justice. Because the political-ideological space that feeds his creative act is set in a civil-rights-conscious U.S., Offendum often appeals to a heritage, reminding the listener of the activism of the Black Panthers, the legacy of Malcom X, and the freedom battles of Rodney King and his followers. In many of his songs, Offendum uses Arabic, both as a means of highlighting the authenticity of his hybrid identity and as a method of marking a cultural space for a diverse audience to come together. In this paper, we offer a brief historical look at the role of hip-hop in the struggle for civil rights in the US in order to locate the legacy Offendum's music builds on and to assess its power. We then perform a close analysis of three of his most famous songs and conclude with a brief discussion of the impact of Offendum's on social media platforms globally.
\end{abstract}

\section{KEYWORDS}

Hip-Hop; Activism; Social Justice; Omar Offendum; Social Consciousness; Syrian War; Syrian Refugees; Civil Rights

\section{INTRODUCTION}

When the world witnessed Mohamed Bouazizi's self-immolation as a means of protesting against a regime whose lack of transparency and violent rulings had stopped representing the Tunisian people, few could have predicted the ways in which the series of revolutions that mark the recent history of the Middle East, known as the "Arab Spring", would unfold. ${ }^{1}$ Only a few months later in Syria, a group of students who painted anti-government graffiti slogans in the city of Daraa were caught and tortured by government forces. ${ }^{1}$ As civil unrest ensued, the Syrian government led by President Bashar Al-Assad pushed to promote the notion that the Syrian unrest had been, in fact, created by foreign conspiracies and by sectarian disputes. ${ }^{2}$ As the Syrian revolt crystalized into a civil war that ran entire cities into ruin, waves of displaced people were driven out of their homes, their towns, and even their own country, so much so that eleven million Syrians have abandoned their homes since 2011. ${ }^{3}$ The situation has been aggravated by the terrorist actions of Da'esh, ${ }^{a}$ a militant group that calls itself Islamic and controls much of Syria's oil assets in the east of the country. Sadly, the crisis shows no signs of resolution in Syria and elsewhere in the Middle East, with the Turkish coup attempt of July 15, 2016 indicating that other regimes continue to fail in serving the needs of their citizens. ${ }^{4}$ Perhaps "fearful of offending the pro-Assad Iranian government with which he [negotiated] a nuclear arms deal," United States President Barack Obama and others like him, including for instance, Germany's Chancellor Angela Merkel, have failed to take systematic action to alleviate the conflict. ${ }^{5}$

Dissatisfied with the decision of the Western political class—a group of elites who control most of the wealth and power across the world— to remain uninvolved, many hip-hop, rap, and pop artists from Syria and the surrounding region have been producing a kind of music that has received global attention for promoting equality, liberty, and justice in the Middle East. Among these performers are Kurdish Iranian Helan Adbullah known on stage as Helly Luv, Syrian group Syrian Hip Hop Unity, or Syrian solo artists Amer Akka, Abdul Rahman Masri, and Mohammad Abu Hajar who live and perform as refugees in European countries. Their performances aim to raise awareness about the Syrian Civil War, the destruction caused by Da'esh, the greed of politicians to the detriment of every-day citizens, the civilian casualties of a war that seems to kill women, children, and the elderly first, or the lack of efficient involvement from Middle Eastern state coalitions, Islamic brotherhood groups, and Western alliances. These 
artists generally record songs in Arabic and film low budget videos that circulate on social media platforms, accompanied by English subtitles, in order to captivate a mixed audience and to bridge the East and the West. Their employment of Western music genres, often merging traditional Arabic melodies, indicates that their ideological intent politicizes music production by placing an emphasis on North American-born activism through protest, performance, and consumption. Although he lives and works in the United States, one artist in particular, Omar Offendum, creates and performs music from the U.S. in a way that continues and enhances this political-artistic movement across the Atlantic.

Syrian-American hip-hop performer, Offendum uses music and poetry to speak out against the violence in Syria. According to the biographical notes listed on his website, ${ }^{6}$ Offendum was born in Saudi Arabia, but moved to the United States at the age of four. As an artist, Offendum calls Los Angeles his home, a space that allows him to record and distribute both his music and his political activism. Much of Offendum's music and verse stem from a deep feeling of guilt for having had the privilege of a much quieter destiny than his brothers and sisters in Syria. In fact, this is visible in his choice of name: Offendum is derived from the English verb "to offend" and from the Arabic word for "Sir," and aims to unsettle the listeners' assumptions and stereotypical representations of Middle Easterners in the Western world. In a sense, Offendum's ideas oppose a particular political view in the U.S., a view that has been reenergized by the President of the United States, Donald Trump and his xenophobic attitudes towards immigrants, and Muslims in particular. Employing rhymes and rhythms that foster commotion and make noise, Offendum breaks the global silence accumulated around the topic of the Syrian war and argues that apathy is not an option for those who oppose the oppressor. Offendum's music constitutes an effective tool of political propaganda that can raise social consciousness of the needs of Syrians today, allow Syrians self-determination, and afford Syrian-Americans equal participation in a society modeled to meet their needs through "cooperation between citizens regarded as free and equal." 7 In this paper, we argue that Offendum combines rhetorical, linguistic, and musical choices from his Syrian background with arguments referencing the U.S. civil rights movement in a way that energizes groups of young Western hip-hop listeners, in order to educate his audiences about the current Syrian conflict.

A careful analysis of his lyrics shows that Offendum aims to accomplish several goals with his music. First, he raises awareness about the state of war in Syria, Syria's extremely diverse citizenry, and its rich culture. Second, the performer's music moves the masses into action — both physically and an ideologically_as they consider the fate of Syrian refugees in the world today and the unearned privileges others get to experience. Third, Offendum encourages Syrian refugees and immigrants to take an active role in reforming the future for the sake of the next generations. Because the political-ideological space that feeds his creative act is set in a civil-rights-conscious United States, Offendum often appeals to a heritage, reminding the listener of the activism role of the Black Panthers, the legacy of Malcom X, and the freedom struggle of Rodney King. In many of his songs, Offendum uses Arabic, both as a means of creating cultural authenticity and as a method of delineating a cultural space for a diverse audience to come together. We offer a brief historical look at the role of hip-hop in the struggle for civil rights in the U.S. in order to contextualize the power and legacy of Offendum's music. We then perform a close analysis of three of his most famous songs about Syria and conclude with a brief discussion of the impact Offendum's music has on social media platforms globally.

\section{HIP-HOP HISTORY, POLITICAL ACTIVISM, AND THE ARAB SPRING}

In recent years, many debates have been led on whether hip-hop as a phenomenon is culturally enhancing or degrading. For instance, performers and producers such as Jesse Jackson, KRS-One, Q-Tip, Estelle, P. J. O'Rourke, Jaron Lanier, as well as poets and scholars joined a talk show moderated by BBC host Emily Maitlis in June of 2012 to determine the cultural value of this genre. $^{8}$ In his article "From Civil Rights to Hip Hop: Toward a Nexus of Ideas," intellectual historian Derrick P. Alridge argues that socially and politically conscious hip-hop continues an ideology solidified by the Civil Rights Movement and the Black Freedom Struggle. ${ }^{9}$ Echoing Alridge's claim, in her book The Cultural Politics of Slam: Race, Identity, and the Performance of Popular Verse in America, Susan Somers-Willet compares hip-hop to spoken word poetry, but underlines that despite their similar ideological concerns, the first genre is solely driven by its commercial goals while the second is not. ${ }^{10 \mathrm{~b}}$ Somers-Willet argues that spoken word poetry, a genre concerned with creating a discursive poetic space for speakers whose identities have been historically and systematically pushed to the margins or erased, opposes the gangster rap phenomenon that emerged in the aftermath of Rodney King's trial in 1991.10 While gangster rap celebrates "black criminality, promiscuity, misogyny, drug use, and ghetto violence," spoken word poetry and non-commercial hip-hop are concerned with declaring marginalized identities, praising their authenticity, and speaking against prejudice. ${ }^{10}$

To really understand the significance of hip-hop's cultural value, one must take a closer look at the emergence of hip-hop and the civil rights agendas that hip-hop aimed to underscore. Hip-hop was born in 1973 in an apartment in one of New York's poorest neighborhoods - the Bronx — when 18 year-old, Jamaican-born Clive Campbell (more commonly known as Kool DJ Herc) decided to do something new on the turntable. While entertaining his younger sister's back-to-school party, he began to extend the beat of the records by "breaking" them or using two turntables to meld popular dance songs with percussion tracks. His goal was simply to liven up the party's atmosphere, but what developed was a lasting trend that became the root of the new genre: hip- 
hop.11, 12 DJ Herc's style did not simply offer a different kind of music, but it also produced a new way of thinking about inner-city life. For example, hip-hop inspired American DJ Afrika Bambaataa to found an organization called the Zulu Nation in November 1976, which aimed to promote an awareness about the consequences of gang violence in the Bronx and to end it. ${ }^{12}$ What started out as a trend in New York City's shabbier neighborhoods gained worldwide eminence with the release of The Sugarhill Gang's song "Rapper's Delight" in 1979.11

The golden age of hip-hop began in the mid-eighties and lasted until the early nineties with the introduction of rock style hip-hop which later became more influenced by jazz, soul, R\&B, reggae, and newer audio-editing technology. During the 1980 s, the popularity of hip-hop music at parties coupled with the emergence of breakdancers and graffiti artists gave rise to a culture of hiphop that never previously existed, primarily embraced by African American youth. ${ }^{11}$ This era is notable because many of the singers began to focus their attention more consistently on addressing social and political issues. For instance, when he created Do the Right Thing featuring Public Enemy's now famous anthem "Fight the Power," in 1989, director Spike Lee set to portray the boiling big-city racial tensions. In a Rolling Stone interview Hank Shocklee commented on the civil rights value of this song:

It was Public Enemy's and Spike Lee's defining moment because what ["Fight the Power"] had done was it had awoken the black community to a revolution that was akin to the Sixties revolution, where you had Martin Luther King or Malcolm X. It created such an energy surge throughout the community that it became the template for every artist, every filmmaker, every rapper, singer, and it also sparked community leaders and teachers to understand the power of hiphop. ${ }^{13}$

If scholars like Dave Ramsaran and Simona Jill locate the beginning of hip-hop culture in the 1980 s, ${ }^{14}$ others argue that in the following decade, this culture diversified greatly. For example, fueled by the court injustice done to Rodney King, two specific styles of hip-hop developed in the nineties: the rap of New York and the G-Funk of Los Angeles. ${ }^{15}$ Many groups continued the trend of using hip-hop for social change. For example, when the members of the musical group NWA first started to perform in their home neighborhood, Compton, one of LA's poorest and most violent districts, they rapped about the injustice and police violence in their neighborhood. ${ }^{16}$ These hip-hop styles were notably different than earlier styles, as they began to incorporate more profanity and depictions of drug-use, sex, and misogyny. However, the turn of the twenty first century hailed a new stage of hip-hop music that is a lot less rigid in its definition of the genre and is characterized primarily by its diversity and constant evolution. ${ }^{17}$ For instance, singers like Jay Z, Eminem, and Kanye West have all been attributed with revolutionizing the genre within the last decade and broadening its depth.

Many scholars have commented on the potential for equal rights activism that hip-hop displays. For example, Adam Haupt explains the ways in which black hip-hop artists used sampling — a type of music collage — as a subversive way to seize the normative, white-centered means of production and appropriation. ${ }^{18}$ Todd Boyd also stresses the inherently political nature of hip-hop. ${ }^{19}$ The civil rights movement was propelled primarily by the force of music that unified and inspired chiefly by combining gospel music, Negro spirituals, and blues. ${ }^{20}$ The power of this unique combination was that it gave a feeling of historical continuity while simultaneously hailing evolution. This genre imagined that each individual was strong and that as a group, the performers were united in a struggle that transcended boundaries and even generations. For example, the song "Walk Together Children" encouraged young black men and women to march toward freedom with unyielding perseverance. ${ }^{21}$

In many ways, hip-hop picked up where these "freedom songs" left off. Hip-hop is frequently described as a weapon that pierces the mind and forces one to think by removing all barriers to the truth. For instance, African, African American, and Caribbean Studies professor, Reiland Rabaka, argues that despite some controversy, golden age rap, that touts African American insurgent organizations or activists (the Black Panther Party, Malcom X, Nation of Islam, and others),

reinvigorate[s] black historicism and black cultural consciousness enables black youth—who, without one word of hyperbole, as late as the close of the first decade of the twenty-first century, have little or no access to authentic African American studies (as opposed to Eurocentric African American studies) — to comprehend and connect the conditions of the past with the parlous circumstances of their present, archeologically and aesthetically utilizing the past as a seminal source for cultural creation, social reflection, political resistance, and movement rallying in the present. ${ }^{22}$

By echoing the political ideologies of past activists, hip-hop artists were able to extend their influence and preserve their memory. For instance, Beyonce's R\&B/hip-hop song entitled "Freedom" and featuring Kendrick Lamar focuses on denouncing police brutality in an effort to demilitarize officers; this will give people of color, who are disproportionately impacted by police violence, access to freedom. 
In the song, Lamar raps:

Eight blocks left, death is around the corner.

Seven misleadin' statements 'bout my persona.

Six headlights waivin' in my direction.

Five-O askin' me what's in my possession.

This sequence reflects some of the recent fatal attacks on the African American community by some police officers. In this way, rap songs, such as "Freedom," push the narrative arguing that social change continues to be an important goal and mirror the ideologies of both Martin Luther King Jr. and Malcom X.

Hip-hop's influence is not felt only by Americans but by the international community at large. For example, post-apartheid South Africa has developed kwaito, a homegrown style of music which is similar to hip-hop and used to heighten and honor black pride. ${ }^{23}$ Likewise, in Cuba "el rap" is used to highlight government corruption and unfair discrimination against black Cubans. ${ }^{23}$ Additionally, in Rio de Janeiro, impoverished children are being encouraged by former drug dealers who have reformed their lives to become involved in the production of hip-hop as opposed to getting involved in the drug trade. ${ }^{23}$ Even half-way across the globe, hip-hop is being lauded by the younger generation in Japan and is helping to spread diversity and cultural acceptance. ${ }^{23}$ What makes hip-hop so powerful is the force that characterizes it. Hip-hop activism has been used worldwide to stand up for social issues, from environmental racism to global poverty and police brutality.

The most celebrated themes in American hip-hop are the need for "freedom" and "opportunity" for minority groups who have been historically excluded from political life and civil rights. However, a new type of hip-hop today asks audiences to reconsider the targeted group and highlights that throughout history, such privileges have been refused also for immigrants and refugees to the U.S. This new type of hip-hop reminds the listener that at almost every crucial point in recent history America has failed to open its door and heart to refugees, whether they were Jews after WWII, Vietnamese in the 1970s, Cubans in the 1980s, Haitians in the 1990s, or most recently Mexicans and Syrians. ${ }^{c}$ Considering the antipathy directed against the Syrian refugee crisis that represents a concern for many liberal individuals and groups in the U.S., it is no surprise that as of May 24, 2016, the U.S. had admitted merely 2,540 Syrian refugees since the civil war began five years earlier, (although today, the U.S. has met its 10,000 quota). ${ }^{24}$ This lag in response is unsurprising when considering the barrage of racist and Islamophobic vitriol that rose up again in the months following the November 2015 Paris attacks. Islamophobia in the U.S. is not new. Moustafa Bayoumi, associate professor of English at Brooklyn College, follows W. E. B. Du Bois's argument that African Americans constituted a "problem" particularly at the height of the Jim Crow, when segregation practically dehumanized African Americans to the rest of the world. Bayoumi contends that "since the terrorist attacks of September 11 and the wars in Afghanistan and Iraq, Arabs and Muslims, two groups virtually unknown to most Americans prior to 2001, now hold the dubious distinction of being the first new communities of suspicion after the hard-won victories of the civil-rights era." 25 Leaders of the Republican Party have called for both the registering and branding of Muslims labeling of Syrian refugees as "rabid dogs."26 Roanoke's mayor has gone so far to suggest that internment camps for Muslims would be a viable and acceptable solution in containing terrorism. ${ }^{27}$

While it is fairly known that politically-charged hip-hop has recently become the soundtrack for pro-democracy movements of the Arab Spring phenomenon across the Middle East, ${ }^{\mathbf{d}}$ few discussions arise around the function of American hip-hop in articulating ideologies of peace for Muslims in the world. For example, Palestinian artists create hip-hop in an attempt to re-construct, preserve, and assert their identity in the face of Israeli oppression. ${ }^{28}$ Drawing from urban African American hip-hop, Palestinian performers re-appropriate black culture, which they see as a global culture "transferrable to various marginalized and oppressed cultures and ethnicities." 28 Attention should be paid to the Arab-American hip-hop interventions as alternative ways of identity formation and the crystallization of a collective consciousness. Such performers underscore their hyphenated identities as spaces of cultural hybridity, allowing them to "resist being defined by others." 28 The artistic expression of this hybridity rests in their combination of English and Arabic verses, the music sampling of traditional Arab melodies, or the insertion of lines of famous Arabic poetry, (e.g. the activist work of Nizar Kabbani and Mahmoud Darwish). Ethnomusicologist Mark Slobin explains that in this way, Arab American artists connect both locales (home and abroad, wherever they may be) and many generations in ways that allow them to bridge the past and the present. "28 "They rap about checkpoints, military oppression and refugee camps. Their songs express longing for Jerusalem and anger at the hardships of life in the Gaza Strip and West Bank."29

\section{OMAR OFFENDUM'S HIP-HOP}

Offendum uses his Syrian heritage to his advantage by showing versatility in both Arabic and English. Offendum can get his message across to more people, Western and Eastern alike, by rapping in both English and Arabic. His bilingual lyrics also illustrate a symbolic means of existing in the world as a first or second generation immigrant, whose identity is hyphenated. In the U.S., his Syrian identity often conjures negative connotations, invoking stereotypical association with terrorism, particularly after 
September $11^{\text {th }}$. Associate professor of sociology at Colorado State University, Lori Peek reflects extensively on Muslim discrimination, describing in her book, Behind the Backlash: Muslim Americans after 9/11, that a multitude of self-proclaimed experts on terrorism came out after $9 / 11$ to offer harmful overgeneralizations of Muslims as paragons of evil to an already terrified civil society. Peek offers the strategic example of Evangelical Christian leader, Franklin Graham, who delivered the sermon at President Bush's inauguration and who declared that Islam is an evil religion. ${ }^{30}$ These attitudes have not only persisted, but were aggravated recently. Since November the average number of hate crimes against Muslims in the U.S. has more that tripled from 12.6 to over 38 a month. ${ }^{31}$ The noose seems to be tightening for American Muslims and Syrian refugees, and they are left with nowhere to turn to for relief and reprieve. By weaving Arabic with English throughout his music, Offendum forces his audiences to confront their stereotypical assumptions, set them aside, and lend an ear.

As a Syrian-American, Offendum utilizes an interesting fusion of mainstream hip-hop with Arabic poetry. By doing so he also infuses the inherent story-telling found in Arabic epics with the strength of the political manpower of contemporary music. In his song, "Destiny", he states "It's hard living in the West when you know the East has got the best of me." 32 Having lived in both spaces, the Middle East and the U.S., he sees both areas as two parts of one big geopolitical narrative, where each part gives life to the other. Drawing inspiration from the American black culture, Offendum also builds parallels between the black experience in the U.S. and the current conditions for Muslims, stigmatized throughout the world. Offendum bridges this cultural gap by focusing in particular on the universal struggles of peace and justice that bind humanity together. He is hopeful that his verses speak not only to Arab Americans but to all people, especially those who are suffering. He wants his music to reach the ears of immigrants, students abroad, and refugees: the ones with "hybrid or hyphenated identities." 33

Offendum declares his hopes for justice and peace and prides himself on being an educator using ideas as opposed to a seller of records. Since first hitting the world stage in 2010 , he has made contributions to social justice, political transformation, and intercultural dialogue. ${ }^{34}$ For example, his debut album Syrianamerican A combined Arabic identity with an American outlook. Likewise, his track \#SYRIA, which calls for the downfall of Assad's regime and promises a brighter future for the war-torn country, was so powerful and belligerent that he was officially banned from visiting Syria. ${ }^{35}$ Offendum has been featured around the world, at festivals in Europe; local youth groups' meetings in Southern California; university lectures in Sydney, Australia and Minnesota, U.S.; concerts in Malaysia; and music videos recorded at the prestigious Berklee College of Music in Boston. Throughout his short career, he has also dedicated a large part of his time to humanitarian relief agencies, raising hundreds of thousands of dollars for Palestine, Pakistan, Iraq, Haiti, and most recently Syria. ${ }^{35}$ Offendum has been featured by many well-known news outlets including The LA Times, Aljazeera, Vice, The NY Times, and Rolling Stone. Most notably, he credits his success to the internet and social media platforms that help get his message out. As of August 2016, Offendum has approximately 30,000 likes on Facebook, 12,200 followers on Twitter, and 11,500 followers on Instagram; these media help him reach out to the entire world.

"Destiny"

"Destiny" is perhaps Offendum's most notable song because it lays the grounds for better understanding the complexity of the current conflict in Syria by presenting Syria's modern history. The song begins with perhaps the most important part: the chorus. Like in poetry, the first line of the chorus becomes a repetend throughout the song, drags the audience into the song, and captures attention: "You are my destiny." Offendum uses the collective second person pronoun "you" to refer first to the American listeners who constitute the first intended audience of the song, and second to the Syrian people and their current suffering, both of whom represent his "destiny" as a poet, performer, and educator. They are the reason why his music constitutes an activist platform that aims to raise social consciousness and foster social justice both in the U.S. and the Arab world. The remaining chorus captures the context that renders Offendum's destiny problematic:

It's hard living in the West when I know that the East got the best of me...

could be looking in my eyes - but you'll never really see the rest of me

can you hear me, maseer? Bilingual's what I'm blessed to be

7amamet Salameh - ifta7ee ajni7 atikee oo Geeree

Dove of Peace spread your wings and fly over me.

His ethnically complex identity creates a rift in his global being, where the East and the West are the two ends of a fluid continuum that get polarized and repolarized by conflict. Offendum The speaker feels the pull of the East in the West a lot more vividly, particularly because his family and his compatriots in the East are suffering while he is privileged to live in the West and away from war. The guilt of not being able to share in their agony morphs into a feeling of indetermination in the West, where his identity is being misread, as the line reads, "you'll never see the rest of me." This means that the observer will never be able to comprehend the entirety of his identity, primarily defined displayed through bilingualism. Indeed, the last line of the chorus is sung in Arabic. This message is quite important because it begins to outline Offendum's background as an individual capable of problematizing identity and evidencing its complexity. This ability allows him to communicate with multiple people across the 
world as he sends out his peace message. The last line of the chorus translates to "Dove of Peace, spread your wings and fly over me," suggesting that Offendum ultimately wants the war to end so that people in his Eastern home country can be safe.

Transitioning from the last line of the chorus, the first verse of the song is performed entirely in Arabic. Here is an English translation:

Consciousness? What consciousness - where is it?

Take a walk with me

Here - in this valley between two "mountains"

where the source of love for both "sides" can be found

our mothers like us - but dont like our foul language

so lets keep this between the siblings

the best of Arabs \& Americans

and may God have mercy on all our dead

Songs i sing like the Mahatma ("aghani-d" means these songs ... which sounds like Ghandi \& in turn relates to the next quote)

If we say 'an eye for an eye'

there wont be any eyes left in Sham

Bilad al-Sham (i.e. greater Syria ... since "Sham" refers to Damascus ... but "bilad al-sham" means Greater Syria ... the

distinction is made for the sake of unity across borders)

from Palestine to the mountains of Lebanon

before they made up these borders

from Iskandaroon to Kurdistan - understand?

Genghis Khan never deceived us quite like our "paternal cousins" (Khan also means deceive in arabic)

but our blood is their blood

children of Adam

who built their sins

upon our shoulders

we carried their burden

why?

God knows

but listen, this little firecracker \& bicycle are better for you than 100 million guns - wanna know why?

because they don't like seeing you smile

but smile you will - in your human being

a young cultured/educated Arab male - give them your stamp of approval

and if they still don't accept you then remind them of the words of Elliye (Elliye Abi-Madhee is a famous Lebanese poet who wrote a poem that started with the following words)

"How soon a piece of dirt can forget that that is all he/she really is ... just dirt" (i.e. we are all from this earth \& will come back to it ... so there is no logic in viewing yourself as better than someone else)

and that my friend

is ... our Destiny

In this stanza, Offendum offers a topography of Syria that maps onto its diverse cultural geography. The reference to "the valley between two mountains" succinctly depicts the way the land is laid out in Syria, with the Jabal al-Druze Range bordering it in the south-west and the Taurus Mountain in the north-east dissected by the Great Rift Valley and the Valley of the Euphrates River. ${ }^{36}$ This geographical binary constitutes the "source of love" for the two "sides," a reference that could be interpreted literally as the East and the West, or metaphorically, as in opposites that create conflict in Syria. If the latter is indeed the case, one may notice that Offendum condenses an otherwise extremely complicated war that engages several groups into a rudimentary but forceful opposition of two sides. Considering the references to these two sides in all of Offendum's music, one can understand them as denoting the collective "people" versus a disappointing government. With the following line: "our mothers like us, but don't like our foul language," Offendum further characterizes the conflict as undignified; however, the ability to "keep this between the siblings," or to understand that all families wrestle with conflicts but eventually manage them, constitutes a characteristic of both Arabs and Americans. Offendum believes that no society is devoid of conflict, but as long as solutions can be found, both Arabs and Americans have a chance at restoring peace in their respective regions. While it is not clear from the song what specific conflict Offendum references in regards to the U.S., one can simply follow the daily news to understand that this democracy is not perfect by any means. 
Further, Offendum offers a solution to conflict by referencing a famous quote articulated first by Mesopotamian king Hammurabi and then again by Mahatma Ghandi. The line reads, "An eye for an eye leaves the whole world blind." The idea of "an eye for an eye" alludes to the ideology of non-violence, widely embraced by many leaders throughout the world whose strategies in appeasing the conflicts in their respective nations included peaceful resistance. For Hammurabi, the quote represented a section of a code of laws that he designed to withstand tribal feuds and maintain the cohesion of his empire. ${ }^{37}$ With this same idea of "an eye for an eye," Gandhi condemns state violence against its citizens and warns that revenge only breeds more conflict. Marshaling the Gandhian excoriation, Offendum sings, "if we say 'an eye for an eye'/ there won't be any eyes left in Sham”, condemning state violence against the protestors.

The idea of unity across borders continues in the next lines of the verse, in which Offendum draws the map of a Pan-Syrian land that existed as such until the dissolution of the Ottoman Empire and the formation of the state of Israel. This old country, Offendum tells us, stretches "from Palestine to the mountains of Lebanon/ before they made up these borders / from Iskandaroon (Alexandria) to Kurdistan - understand?" He may be drawing this inclusive map in order to hint at the disputed ideology of Pan-Arabism. Secular Arab nationalist Abu Khaldun Sati al-Husri, for instance, declared in 1964 that "people who spoke a unitary language, have one heart and a common soul. ${ }^{38}$ As such, they constitute one nation, and so they have to have a unified state," in response to his conviction that Arab states were created by European imperialist powers. Political scientist Adeed Dawisha contends that the founders of the Ba'th Party felt the same way as al-Husri almost twenty years before. ${ }^{38}$ Offendum is suggesting here that the borders drawn by the Western powers helped only to create distance and conflict between the people, dividing them both geographically and emotionally into "opposite" camps. Offendum encourages all to unite in fighting against oppressive rulers.

The song continues by romanticizing the past and setting it in stark contrast to the disheartening present. Comparing former rulers and present men of power to Genghis Khan, Offendum invokes the Il-khanid Dynasty during which Iran and neighboring areas witnessed a renascence period under the rule of Mahmud Ghazan. ${ }^{39}$ Unlike him, Syrians " "paternal cousins" —a reference to Christian Westerners, descendants from Isaac and "cousins" through Abraham with Ishmael and the Muslim Arabs of the Middle East ${ }^{40}$ — have disappointed the Syrians with their inability to offer feasible help. However, "Khan" in Arabic also means "to deceive," a translation which transforms this line into a sarcastic commentary on Syrians' general lack of support throughout the ages.

Offendum's insistence on peace and understanding is underscored in the next lines of the verse that discuss humanity's common descent. Offendum points out that although people live in different areas of the world, they all share the same blood as children of Adam. The reference to Adam, however, only helps tie three main religions, excluding still some from this common ancestry, perhaps quite willingly. University of Southern California historian Sarah Gualtieri indicates that the alignment between Syrian immigrants in the West and European Christians is not accidental. Gualtieri argues that the defining of Syrianness within the U.S. racial order helped strengthen Syrians' application for U.S. citizenship and their inclusion in the body politic during the first decades of the $20^{\text {th }}$ century. ${ }^{41}$ The implicit association of the three Abrahamic religions and whiteness as a civic status in the U.S. may then help Offendum establish Syrians' legitimacy in the U.S. Nonetheless, if one takes the Biblical parable of the first humans symbolically as a story of origins, then perhaps similar stories of initial couples giving birth to the rest of humanity constitute a mythical paradigm shared by many more communities than the Abrahamic three. Although Offendum invokes the Biblical story of Adam and Eve as a common belief shared by Jews, Christians, and Muslims, he is also acutely aware of the conflicts throughout the ages between the three communities who have employed religious rhetoric as a means of mobilization. However, precisely because these three communities share the same bloodline, the same original saga, Offendum suggests that they should be able to come together in peace.

The remainder of the verse, then, continues to emphasize the need to reinforce equality among these three cousin communities so that Arab Muslim individuals, whose public image has been thoroughly suffering in the U.S. post 9/11, can regain credence and agency. Offendum says "because they don't like seeing you smile/but smile you will - in your human being/a young cultured Arab male - give them your stamp of approval" to show not only that Syrians, but also Middle Eastern Arabs must be accepted by their respective governments, societies, and the world at large. A poet himself, Offendum references the Syrian-LebaneseAmerican poet Elliye Abi-Madhee (known in the West as Elia Abu-Madi), whose poetry insists on the futility of conflict and the value of communication and understanding. Like many other Arab New Yorker poets deeply affected by the conflicts in the Middle East, Abu-Madi and his colleague Khalil Gibran invested their efforts in forming immigrant cultural circles rather than political powerhouses. ${ }^{42}$ In a poem translated into English on a blog page entitled "The Moor Next Door," Abu-Madi says, "Smile, it is enough that you are even alive, and have no want for friends and well-wishers," thus encouraging the reader to appreciate life. ${ }^{43}$ In Offendum's song, Abu-Madhi wonders rhetorically, "How soon a piece of dirt can forget that that is all he really is - just dirt?" No matter who a person is, one cannot view themselves as better than anyone else because, in the end, we are 
all transitory on earth. The reference to the human body as a piece of dirt may again be connected to the Biblical original parable describing the creation of man from dirt. The fact that all people are ephemeral despite their social and political positions underscores the urgency of Offendum's plea that Arab men's dignity be recognized and respected. In the last line of the stanza, "and that my friend is our Destiny," Offendum capitalizes the word Destiny perhaps to indicate that Destiny itself is one for all of us: we will all eventually perish.

The second verse of the song, written and performed in English, underlines that despite differences, Easterners and Westerners cannot live without one another. Although he does not use the actual Orientalist terminology that splits the world into the East and its supposedly better half, the West, Offendum employs the binary on which Orientalism is constructed. In Edward Said's terms, the East or the Orient was Orientalized and made distinct from the West not only because it was discovered to be Oriental, but also because it was made Oriental. In other words, the East in this Orientalist paradigm exists as a discourse and a system of knowledge that was produced by Western imperialist institutions and exists in an uneven exchange of power with the West. ${ }^{44}$ Defensive, Offendum references this binary in order to subvert the power relations it has cemented and to do away with it. Only by demonstrating that this uneven power structure between the two areas and peoples is unfounded, can Offendum dissolve it. Allusions to the Arabic linguistic and cultural influence in the West are scattered throughout, indicating again the his bilingual consciousness. The verse begins by illustrating the contrast between an English and an Arabic speaker whose main difference rests in the fact that they each write in opposite directions. This distinction - a frivolous and arbitrary one-is symbolic of the struggle to "fit in" that a foreigner faces in a new environment as they reject assimilation.

I write right to left. You write left to right.

Metaphor of a foreigner's plight. Dressed to type.

Stereo and a mic. Scenario of a fight.

The burial of a white Imperial at his height.

A Turkish Rapper's Delight, Semitic etiquette might

just have you rollin' your "R's." Poetic and light.

And grab a hold of your sorrows to relieve your tomorrows.

Make it easier to borrow the aesthetics you bite.

Like all the Arabic loanwords from Spaniards and Moros.

The Karma of Inquisition. Visions of horror.

So who's the explorer? Really was it Columbus?

Muhammad al-Idrisi or Alfaragnus?

Throw a Hobson Jobson while you figure it out.

I'm gonna start with a cipher that's a siffir [zero] - no doubt.

See you might not have learned to live with me,

but sure as hell can't without. I'm your destiny.

The two different systems of writing represent symptoms of the Orientalist tendency to interpret difference as threatening the authenticity of the self because the "other" corrupts the self. This difference creates intolerance for those who are racially, ethnically, culturally distinct from "us." Dressed differently and rapping against intolerance, Offendum himself inhabits the "scenario of a fight" because of his capacity to instigate an unfavorable reaction from listeners. His identity as a Semite "rolling his r's" and as the performer to bridge the East and the West sets him in opposition to a "white Imperial," a phrase that carries historical and political significance as it echoes Rudyard Kipling's conception of the White Man and his "burden."45 Offendum hints at the reality that white imperial forces such as the British, the French, and the American, have manipulated political outcomes in the Middle East for centuries. ${ }^{46,} 47$ The phrase "Turkish Rapper's Delight" references the title of the Sugar Hill Gang's 1979 song "Rapper's Delight," the song credited with creating a market for studio-recorded hip-hop in America. With this reference, Offendum communicates that like Sugar Hill Gang in the U.S., he plays an equally important role of introducing hiphop to the Middle East and locates this birth moment in a geopolitical site-Turkey—that constitutes a literal land bridge between the East and the West. The reference to the sweet-Turkish delight-may also indicate that Offendum is already aware of the difficult position he inhabits: the danger that his music may be taken as a sample of Orientalist exoticism in the U.S. In order to bridge the gap that this difference has created between Middle Eastern and Western individuals, Offendum points out the ways in which Western languages and Arabic share parts of their lexicon. Loanwords are words adopted from another language but preserved almost intact in the borrowing language. For example, the Moors facilitated a linguistic exchange between Arabic and Spanish. Arabic neologisms in Spanish were highly criticized by the Spanish Inquisition whose goal was to purify the community of all elements perceived as threatening Christianity, including foreign elements of language. However, Offendum attempts to rectify history by underscoring that Arabic has actually yielded fantastic contributions to civilization before European cultures added their mark to social progress. 
Offendum questions the Eurocentric perspective in world history where individuals such as the Portuguese Columbus are recognized for their discoveries, when world explorers from the Islamic world predate Columbus and remain unknown. For instance, Offendum forces his audiences to consider Muhammad al-Idrisi, an Arab geographer in the early twelfth century who wrote a book titled "Kitāb nuzhat al-mushtāq fī ikhtirāq al-āfāq" or "The Pleasure Excursion of One Who Is Eager to Traverse the Regions of the World", also known as “The Book of Roger”. Roger II, a Christian king in Sicily, hired al-Idrisi to create a map of the world, the first known map that combined descriptive and astronomical geography long before Columbus set on his transatlantic excursion. ${ }^{48}$ Another historian mentioned in the verse is Alfaragnus (Abù l-'Abbàs A mad al-Farghàni), one of many Muslim astronomers who lived and worked during the Islamic Golden Age, a historical period marked by scientific progress and that began in the $9^{\text {th }}$ century, hundreds of years prior to the Western Renaissance, the European era of progress and exploratory discoveries. ${ }^{49,50}$ Offendum uses these examples of Muslim intellectuals precisely because Orientalist epistemologies continue to marginalize or exclude them altogether. He wants the audiences to understand that greatness has come out of a people that not many consider important to the beginning of the worldwide modern age.

Another such moment of cultural misrecognition is alluded to with the phrase the Hobson-Jobson. The Hobson-Jobson is a glossary of Anglo-Indian words that was written in 1872 by Colonel Henry Yule and A. C. Burnell, to evidence the common vocabulary between English and Hindi. ${ }^{51}$ However, the phrase Hobson-Jobson is also a derogatory locution created by British military men who happened to witness the Shia festival of the Muharram, a period during which Shia Muslims mourn the death of Imam Hussein, and misheard the phrase commonly chanted during this festival: Ya Hassan, Ya Hussain. ${ }^{52}$ Therefore, to throw a Hobson-Jobson at the West would mean to misinterpret and mock a western phenomenon of great religious importance. Offendum recognizes that the cultural misinterpretations and derogatory renditions are offensive and dangerous. In contrast, awareness_-or deciphering the cipher (Siffir in Arabic means both cipher and zero; the English word "cipher" is an Arabic etymon)—can help people respect each other.

The final verse of "Destiny" warns that blaming the current conflict in the Middle East on a slavery-like colonial system will not help end it.

See [Arabs] shooting at each other from Iraq to [Palastine].

Syria to Libnan [Lebanon], Algeria to Sudan.

Pedagogy of the oppressed, tricklin' down.

Conquerin' through divisions and sadly this isn't the first time.

One land, one love, one chance, one blood.

No fuss, no fight? Yeah right, young blood.

AK's cheaper than a book, crooked leaders in a hook

Gettin' fished out, missiles gettin' dished out,

Bitched out by the West. Press gets a big shout.

From the people getting' rich out of this (bout).

Now what's this really all about? Land, money, or power?

It was the colonizer's fault, but now it's really just ours.

Leavin' a sour taste in our mouths like generational slave names.

Whenever speakin' out, out-spoken leaders gettin' taken out.

Quicker than belligerent drunks in a bar.

We a far cry from livin' as one.

The verse establishes that although conflict in the Middle East may have been sparked by colonial conquest, today the cause of the conflict has morphed into something homebred. "Shootin at each other" in Iraq, Palestine, Syria, Lebanon, Algeria, and Sudan represents a phenomenon that stems out of a learned way to oppress and live under oppression. The reference to Paolo Freire's Pedagogy of the Oppressed ${ }^{53}$ helps explain Offendum's understanding that in the Middle East, the state of being exploited is learned and replicated from generation to generation by “conquerin' through divisions, [which] sadly ... isn't the first time.” Oppressive governments have overpowered the people in Egypt, Algeria, Tunisia, Yemen, Lebanon, and Syria by dividing them and turning them against each other. The fact that "AKs [are] cheaper than book[s]" highlights the sad reality that people are more enthralled with war than with education, because, Offendum explains, "crooked leaders in a hook/[are] gettin' fished out/[while] missiles gettin' dished out." This situation in which the persons who are truly at fault never receive their punishment seems to benefit rich sponsors who continue to entertain the conflict and maintain the crisis. We may recognize in Offendum's "calling out" the U.S. position complexly described by Emile Hokayem, Senior Fellow for Regional Security at the Middle East office of the International Institute for Strategic Studies. In his book, Syria's Uprising and the Fracturing of the Levant, Hokayem argues that a series of circumstances, such as the U.S. venture in Iraq or the general post-Bush U.S. tendency to remove themselves from domestic matters in other countries, prevented the U.S. from an active engagement in Syria after $2010 .{ }^{54}$ The media alone, contends 
Offendum, seems to receive financial gains as they create information about the conflict, while no one in the U.S. takes the problem seriously. He wonders who really profits from the conflict in general, and why the conflict continues to take place, but he has no answers. The final message of the verse, ending with the line "we're a far cry from livin' as one", is that although some strides have been made in the Middle East and in Syria specifically, human beings still refuse to live as "One land - one love."

\section{"Syrianamerican A"}

Much like "Destiny," "SyrianamericanA" also denounces the destruction of Syria, albeit from a historical angle of colonial conquest. Before the music starts, the video begins with a newscast dialogue between two male voices who discuss the origins of the name Syriana. The dialogue mimics an interview between a host and an informed speaker, well-versed in the political history of the Middle East. From this dialogue, the audience learns that the European powers were able to redraw the borders of the region known as the Levant after WWI. The voice of the scholar states that "Iraq was a fake country" because it merged together three provinces of the Ottoman Empire in order for the European powers to be able to better control the oil assets in the region. Syriana is, therefore, a coined name that designates an oil-rich territory financially attractive to the European powers. The historian ends by highlighting that Syriana is also a "metaphor for the Middle East" which was "made out of false borders." As the speaker finishes his sentence, the music begins, and we are introduced to Offendum's voice singing what we recognize as the chorus "SyrianamericanA is where I wanna be,/ There I'm honored/ 3iish Nirvana, Peace and Harmony."

To contextualize the video's opening dialogue, the modern history of Syria must be further elaborated upon. In the nineteenth century, Greater Syria denoted a territory comprised of three Ottoman provinces stretching across the modern-day states of Syria, Lebanon, Jordan, and The Palestinian Authority. ${ }^{55}$ Historian Ayse Tekdal Fildis offers a brief history of Syrian management during the first half of the twentieth century. The Skyes-Picot Agreement established between the Allies in 1916 split the territory of the Middle East as follows: Iraq and the Gulf region including Palestine was occupied by Britain, and Syria and the Levant was occupied by France. France's concern in the region included monitoring the development of Arab nationalism in order to prevent its infiltration in North African French colonies. When Amir Faysal Ibn Husayni managed to form an independent Arab government in Damascus, France had to decide whether that would be commensurate with their interests. In 1920, Faysal declared war on France, which ended in a loss for his army. After winning the war, France decided upon a mandate in Syria according to which they would recognize Faysal's partial political independence as long as Syria remained under French military occupation and accepted the mandate. ${ }^{56}$

Offendum recreates the term Syriana as SyrianamericanA. On the one hand, he reimagines this European-dominated space by reprogramming its colonizer's history and locating it in America. SyrianamericanA would then become a constructed space by an American imperial force similar to the European powers alluded to in the song's introduction. To illustrate this point, Offendum chooses to end the term in capital letter: A. Since capital letters usually mark the beginning of proper nouns in English, this notation indicates that we can read the term both from right to left and from left to right, in the style of the Arabic language. Reading the name SyrianamericanA from left to right gives us the logical symmetry of Americanasyriana. Uttered this way, the term emphasizes America, the general appellative for the U.S., as the dominant power in Greater Syria.

Another way to read SyrianamericanA is by splitting the compound noun into its two parts: "Syrian" then denotes ethnic or national belonging while "Americana" becomes a term which reimagines America as an imperial consequence, just like Syriana. By indicating that Syrian(s) dominate the American imaginary, Offendum empowers a small category of Arab-Americans who have become the target of Islamophobic and terrorist accusations over the past few years and among whom he himself identifies. In this space of the SyrianAmericanA, the speaker feels "honored to be," indicating his perceived privilege of belonging to that space and of reimagining the American dream. For Offendum's speaker, the American dream is "peace and harmony." As a destination point for many refugees seeking justice and equality, America is indeed at least imagined as a place of peace and harmony. However, one may interpret Offendum's American dream sarcastically as well: America boils with Islamophobia, racism, and xenophobia, especially this election year, to such an extent that neither harmony nor peace are actually attainable.

In the chorus, Offendum introduces an Arabic term—3iish_-which translates to "life" or "living." This choice foreshadows then the very first stanza sung entirely in Arabic. A translation of this stanza follows:

I work on my issues,

My attendance is essential.

Forced and proud of my roots,

Why be sorry?

They destroyed my constitution

And erased my Arabic eras.

Hey, days and months come and go, go round and round, 
Who could understand the wall, whatever its height, and the cost, whatever its value?

He didn't sell his share,

Nor his tradition and story:

Aleppo pistachio,

Arabic literature,

My misery.

Robbery, prohibition

Used to answer the messenger of the earth's creator

In the past, present, and by order.

Flamed, flaming, flame up the coal,

My thoughts are running like a river

And the source is my brain,

Cold and zamzam

Bomb-shoot!

Shoot your head

You are in Afndam's house,

Misery, family,

A family of mud and blood.

What are your origins?

If you stay this way, you'll regret.

This way, you'll regret and cry.

Here, the speaker bemoans the destruction of a Middle Eastern culture intentionally left ambiguous. The oppressor, crystalized in the collective pronoun "they" as a way of amassing various power groups with interest in the Middle East, has destroyed the speaker's culture, history, and people. Subtle references to the modern history of Palestine and its slow conquest are made throughout the verse, but one line stands out: "Who could understand the wall, whatever the height, and its cost..." Built over sixteen years ago, the wall that delineates the West Bank from Israel cost over $\$ 2.6$ billion to be erected and an annual average of $\$ 260$ million simply to be maintained. ${ }^{57}$ Journalist Mairav Zonszein details that "most of the barrier comprises a set of 2 -meterhigh, electrified barbed-wire fences with vehicle-barrier trenches and a 60-meter-wide exclusion zone on the Palestinian side. But in more densely populated urban areas, particularly those around Jerusalem, ... space limitations prompted the Israelis to instead build (sic) a concrete wall to the height of 8 meters." 57 The remainder of the verse then zoom in and out of specific Middle Eastern areas: If the reference to "Allepo pistachio" hints specifically at Syria, "Arabic literature" again broadens to encompass the Levant and the Arabic peninsula.

Not only this destruction, but also Quranic history become the speaker's personal story, in which the first person pronouns, (I , me, my) morph into the third person (he, Afndam) and back. This way of creative thinking is described in the lines:

My thoughts are running like a river

And the source is my brain

Cold and Zamzam

Bomb-shoot!

The image of the river as symbolizing the rush of thoughts the speaker wants to express in his verse is not surprising, but perhaps the reference to the Zamzam needs explaining. The Zamzam is the name of the Biblical river that sprang up in the desert as a result of Hagar's invocation that God helps her save her sick son, Ishmael. Frightened by the sudden onset of so much water, Hagar cries, "Zamzam" or "stop, stop." Offendum compares his performative power to that of this spring, but more importantly, to its reputation as being unstoppable, arising from unlikely places, leaving a permanent mark that transcends history and providing nourishment and sustenance amidst a bleak, unforgiving background. For many Muslim believers, visiting and drinking from this river remains a pilgrimage recommendation. For Offendum, invoking the Zamzam River symbolizes his resorting to a tradition that he reclaims and that informs his thinking and creativity.

The second stanza turns more explicit in terms of the destruction that war produced in the Middle East. As the speaker works his way into building this complicated image of a devastated place, he defines home as a "poem" that sounds "homesick." The idea of having one's home in a poem, though romantic, underscores this home's lack of specific physical borders. This is a nomad's dilemma: carrying the idea of home with oneself in one's poetry constitutes a way of life among Bedouin and other desert tribes. The spelling of the word homesick with the syllable "home" in parentheses further highlights the ambiguity of the word. Is a (home)sick person sick of their home, a scenario which may easily fit with the disillusionment of Syrian citizenry at the ability of 
their "home" to offer security and safety? Is a (home)sick person someone who feels sick at home? Someone who misses their home to the point of sickness? Offendum's already acute awareness that language is arbitrary and untranslatable allows all these questions to arise.

With the next line, the extended metaphor implicitly compares "home" to a "phone click-clack tone" and pushes the notion of belonging further into the abstract and the absurd. The nonsensical nature of "home" affords death and destruction to find their place in it. The imperative "lift that bone_-give it back to him" illustrates the ruining of "home," because to be able to reclaim "home" as a space of belonging, one needs to recognize their responsibility in creating ruin and returning victims' bones to their own community. Furthermore, to be able to return one's bones symbolizes the need to become accountable for murder, even when one did not directly commit it, to count one's sins like "knots on a rope," or the tasbih, the prayer beads that many Muslims use to glorify God and cleanse the soul through the rhythmic chanting of phrases.

Other references in this stanza build specificity to this space that is being destroyed. Iraq is being identified by name as an epicenter of damage, as "bombs in the sky/ make Iraq bloom." The paradox of imagining bombs as the cause for something to bloom heightens the irony because blooms celebrate renewal, while bombs kill. The speaker expresses his bewilderment at the reason Iraq had to be wrecked, which is the fact that this state, "a modern Babylon, was responsible for the problems in the Fertile Crescent." On the one hand, the symbol of the crescent, which is also fertile, reminds of the grandiosity of the Ottoman Empire. On the other hand, the hilal (crescent moon) populated many pre-Islamic poetic texts as a symbol of friendship and guidance offered to the lonely traveler through the desert. ${ }^{58}$

The casualties of war are always innocent people because, the speaker says, when they murder peasants

and they find men will never learn their lesson, it's a fine line 'tween a smith $\mathrm{n}$ wessun hindsight $20 / 20$.

Responsible only for their agricultural chores, peasants carry no guilt. Yet, they represent the majority of Iraq's agrarian population who, according to Offendum, lost their lives. Indeed, the Waston Institute for International and Public Affairs at Brown University indicates that approximately 165,000 Iraqi civilians have been killed since the U.S. invasion in Iraq, although the actual number might be a lot higher. ${ }^{59}$ Those responsible for their murder (referred to again through the collective and ambiguous third person plural pronoun), however, never learn from their mistakes, and the cycle of senseless killings continues. The phrase "hindsight 20/20," meaning "one understands an event correctly only after it takes place", is usually used with sarcasm as a means to criticize a poor decision. However, we must be aware that the critic in the present has access to information that would not have been available to the person acting on their decision in the past. And yet, the "blessin" of hip-hop music is that it is able to lift the veil of ignorance and reveal the truth.

\section{"\#SYRIA"}

"\#SYRIA" is perhaps Offendum's most popular song on YouTube, with 265,228 views. The music video for the song was produced by Sami Matar, a Palestinian "American music composer and music producer for film, television, video games, and popular music." 60 The song's video presents footage from one of the revolts that took place in Hama on the $22^{\text {nd }}$ of July, 2011. Incorporated into the song's melodic line and chorus, is the slogan chanted on the streets of Hama and throughout the Middle East during the Arab Spring: "alsha3b yureed isqaa6 al-nitham" or "the people want to overthrow the regime." Speaking to the power of this phrase, one of the YouTube audience members listening to this song indicated in the comment section that "We used to [listen to] this song secretly, fearing that if we got caught, we would have been taken and tortured to death by the Assad's intelligence (Mukhabarat)." ${ }^{1}$ Connecting the discourse of the revolution to that of hip-hop, Offendum creates a close connection between art and reality, emphasizing the former's ability to mirror the latter.

The song's first line exposes the overarching aim of Offendum's hip-hop artifacts: "the purpose of these verses is to unify the masses." The notion that revolution can only be achieved through unity drives the song forward as the speaker explains:

from city streets to countryside

Mountain tops to coastal tides

Muslim, Christian, women, men and children

let's keep hope alive

stand in solidarity with all your fellow citizens

peacefully protesting for the end to all the militancy 
This song is the most politically direct in opposing the Assad's rule and unmasking its crimes. However, Offendum does not want his audience to understand this song as a simple government-bashing attempt. Rather, he insists that we receive the song as a plea to the world that we must become aware of the extent of Syrian citizens' daily suffering at the hand of their government. On his blog at offendum.blogspot.com, the rapper states that "I am a human being who believes in dignity, freedom \& equality for allno exceptions ... I am an artist who strives to reflect those ideals in lyrical form ... This is but a small contribution when compared to the sacrifices being made by beautiful, peace-loving Syrian people on a daily basis." 62 This assertions renders explicit the purpose behind his music: to inform in hopes of social justice.

The video ends with more footage from the protest in Hama, where the protest leader, poet Ibrahim Qashoush, recites one of his politically-charged poems and instigates the crowd to a call-and-response game where they chant "Bashar, depart from here." As a result of his non-violent resistance and offensive poetry, Qashoush was found dead in the Assi River weeks after the protest, with his vocal chords ripped out, a warning from the Syrian government to those who might use their voices to criticize the regime that they will be similarly punished. ${ }^{63}$ Both Offendum's and Qashoush's words reflect the teaching of Archbishop Desmond Tutu — a South African social rights activist whose work against apartheid became notable world-wide in the 1980s and whose quote Offendum chooses to list on his website above the video for \#SYRIA. Archbishop Tutu said that "if you are neutral in situations of injustice, you have chosen the side of the oppressor."'64 Archbishop Tutu's wisdom echoes Martin Luther King Jr.'s famous 1967 remark that "In the end, we will remember not the words of our enemies, but the silence of our friends." Music, and in particular Offendum's songs, ensure that what the Syrians remember is their allies' loud voices of support. Qashoush lost his life by choosing not to remain neutral. We can only hope that Offendum's U.S. residence can offer him the protection Qashoush did not have. One thing is clear: poetry, or in Offendum's case, hip-hop, can and will carry its political message loud and clear hoping that we, the audiences, can demand social justice for both Syrian citizens and Syrian refugees.

\section{CONCLUSIONS}

Hip-hop across Middle Eastern society is a diverse and global medium, seen as an art that not only celebrates street culture and resistance, but also appeals to the stigmatized and the oppressed. At the heart of hip-hop is the artist who can use the potential of hip-hop to inspire and instigate change. Offendum is one of these small-time artists who uses hip-hop to make a change in a big way. He has gained critical acclaim for his songs about the popular democratic uprisings throughout the Middle East and North Africa during the Arab Spring. ${ }^{65}$ In fact, his song “\#Jan25”, which went viral in 2011 and became the anthem of revolution in Egypt, is often cited as being the song that spread international hip-hop within the Middle East, although in actuality, Middle Eastern hip-hop stretches further back. ${ }^{66}$ This misunderstanding is largely due to his personal style that he describes as "conscious rap" or "political hip-hop." His music is brave, defiant, and brash, but also underlying it is a yearning and deep-seated pain. He openly admits that the Arab region has taken a sharp turn for the worse but he still remains hopeful in the people. "Equality and human rights for all people: both in the Arab world and at home" is the ideal he preaches. "Apathy is not an option," when beneath everything the root is "real human suffering." 67 Offendum feels the obligation and responsibility to fight for the rights of the oppressed in the pursuit of his vision, in which all people can unite in the spirit of resistance in solidarity with one another.

It is hard to assess the actual outcome of Offendum's songs in establishing awareness, dialogue, and social justice for Syria. Nonetheless, a look at the comments that his Middle-Eastern and non-Middle Eastern viewers have posted on the YouTube pages for his songs reflect a general sense of gratitude and agreement with the his ideal. For example, r.jrjun says "music breaks the boundaries of [race] and religion." Zahra Almosawi posts "he should really be more out there, he's amazing." Fatima Mousa writes "pure talent." S. Kelly notes "Entire album is fantastic. I'm Irish American. Viva Palestina! Long live Syria. And today, Ramadan Mubarak to all my Muslim friends. May the year be full of blessings for you." Yusuf says "amazing" and Burak Ayan posts "Salam from Turkey, to all my brothers and sisters... thanks to Omar Offendum for this excellent rap song." Mohammad xm ponders, "It's true when he said 'AK's cheaper than a book." Bandar Orabi adds "Respect from Kingdom of Saudi Arabia," and Ali Rafsanzani comments in Arabic "Ya hayati," which translates to "You, my life," probably referring to how the song reflects so closely his own experiences. Yasmeen Masalme writes in Arabic "Oh, Syria, Lord oh.” Mobarak Alkhozaei adds, "Love \& respect from Mecca" and Aimen Ben Ltayfa "Much love from Tunisia." Other comments locate the speakers in Palestine, Qatar, and Iraq. By and large, Offendum's fans consider his music timely and effective.

Paying closer attention to the comments posted as reactions to the song \#SYRIA, one discovers that Offedum's lyrics foster not only gratitude, but often complicated political debates about the outcome of war in Syria, the West's involvement in mitigating conflict, or Bashar Al-Assad's culpability. Many Middle Eastern respondents ${ }^{\mathrm{f}}$ agree with Offendum's political stance: Iblis Shahsia, for example, posted in July 2016 that "Bashar is a bad man he is killing Syrian people." Similarly, in April 2016, Marwaan Ahmed posted "Omar, Thanks for your powerful words...Assad will go sooner or later. May God have mercy on al-Qashush's soul!” A year ago, Cherkess warned that "Victory for our glorious revolution... god bless Syrian freedom fighters." Sometimes, the comments reflect strong political views regarding international relations. For instance, Salah Bakr posted in 2015, "Free Syria. Assad cannot make peace in his neighborhood and all what he can do is destroying cities. Why?? Because he is just a good boy for 
Russian and Iranian politics agenda (putin \& hassan rawhani) because they think that if Syria got free it will be no longer available for their dirty business." However, these are not the only voices one can hear as reaction to Offendum's song. Some Middle Eastern commentators support Bashar Al-Assad's regime. For instance, two years ago, Hadi Assaf posted the following comment: "The rebels are only terrorists. They are not fighting for democracy, but only for the difference in ethnicity. So, I'm pro...Assad." Another individual whose YouTube name is area40five replied: "That's what the Iraqis said when the Saddam Regime killed and tortured Shia, the Baath government call Shia rebels fighting for their rights and impunity terrorist, and Israel labels Palestinians resistance squad terrorists too. FSA are the equal fighting force as once the Shia's in Iraq and the ... Palestinians, you shouldn't degrade them because a Sunni force it's on a mission to topple a Shia dictator, you should support any one against a dictator regardless of their beliefs" (sic). Michael Hajd's post also expresses disagreement with Offendum's views despite the fact that he agrees with the ultimate goal of freeing Syria:

Protesting peacefully? You mean taking up arms against a government that is facing pressure from Israel, the U.S.A., and the U.K. What would you like Bashar to do? Whether you support Assad or not, you cannot criticize him for bombing cities with terrorist cells. Let us defeat ISIS, Al Nursa, and actual threats to Syria. The rebels have a fair cause, but siding with terrorists is no means of political process. Making a song that defames a leader who is loved by Alawis, Christians, and Arabs alike also doesn't help anything. You should sing of Syrian unity; free of political allegiance. Defeat ISIS, Al Nursa, and Da'esh before you kill other Syrians. Long live Syria!

Other commentators, especially non-Middle Eastern, become emotionally engaged and perhaps a bit more vocally so. For example, Adrien Hartemann posts a reply to Felicia Adele in July 2016 explaining at length his view on the causes and development of the war. DaN3xeEconomist posts "[the fall of the regime] hasn't happened in 5 years now. They are dreaming, and this Omar guy is an idiot. Act Syrian you idiot not American. You think Americans care about u!' John Smith's angry post from February 2015 reads "Zionist shill," probably a passionate misspelling for an offensive construction. Addressing Offendum directly, David Mastnak wrote the following comment in September 2015: "without Bashar, Syria would became Libya, who would rule? IS, FSA? lol what an ignorant moraas you are, read Noam Chomsky and educate yourself?" What these debates and dialogues indicate is that Offendum's goal of ending a global apathy against the Syrian war seems to be much more difficult than one would expect. Certainly, the commentators who use expletives in reference to him are far from apathetic. However, the anger one can easily read in their contributions represents a barrier against open dialogue. And so Offendum's project is certainly not even nearly close to being complete.

\section{NOTES}

a. Da'esh is also known as the Islamic State of Iraq and Syria (ISIS).

b. While many scholars have engaged in the hip-hop ethics debate from a variety of angles and stand-points such as Tricia Rose's 2008 book, The Hip Hop Wars: What We Talk. About When We Talk. About Hip Hop-And Why It Matters, New York: Basic/Civitas Books or Railand Rabaka's 2012 book Hip Hop's Amnesia: From Blues and the Black Women's Club Movement to Rap and the Hip Hop Movement, Lexington Books, we resort to Somers-Willet's perspective here because she writes of hip-hop's intersections with poetry. We believe that Offendum's hip-hop comes closest to poetry.

c. Mexicans and Syrians occupy two different immigration statuses that we want to acknowledge. While the first category contains mostly immigrant laborers, the latter is composed mostly of asylum seekers, refugees, and beneficiaries of a Temporary Protected Status (TPS).

d.For instance, Tunisian Hamada Ben Amor under the name of El General recorded "Rayes Le Bled," available on YouTube at https://www.youtube.com/watch?v=JupZw4SOwVQ\#action=share. Libyan rapper, Ibn Thabit, recorded the song "Benghazi II," which can be heard on YouTube as well, at https://www.youtube.com/watch?v=hFdTYSdAr A\#action=share. The Egyptian band Arabian Knightz recorded the song "Rebel" featuring Lauren Hill. The lyrics mix Arabic and English. This song is on YouTube at https://www.youtube.com/watch?v=Z696QHAbMIA\#action=share.

e. While it is impossible to know a YouTube respondent's ethnic origins considering solely their chosen screen name, we believe the names chosen to represent geographic disclosures of some sorts. This may not mean that a person identifies ethnically or nationally in a certain way, but it states their declared affinity to a certain cultural space. We have chosen to catalogue these respondents based on their declared affinity to the Middle East through linguistic transparency in "Middle Eastern" and "nonMiddle Eastern," although we are aware of the many complications that arise from this distinction.

\section{REFERENCES}

1. NPR Staff. (2011) The Arab Spring: A Year of Revolution. National Public Radio. http://www.npr.org/2011/12/17/143897126/the-arab-spring-a-year-of-revolution (accessed Aug 2016)

2. Staff. (2016) Syrian Civil War, in Encyclopedia Britannica. https://www.britannica.com/event/Syrian-Civil-War (accessed Aug 2016) 
3. The Syrian Refugee Crisis and Its Repercussions for the EU, Syrian Refugees, July 2016, http://syrianrefugees.eu/(accessed Aug 2016)

4. Turkish President Erdogan Appears in Istanbul to Denounce Army Coup Attempt, BBC News, 16 July 2016 , http://www.bbc.com/news/world-europe-36809083 (accessed Aug 2016)

5. Wehner, P. (2015) President Obama's Hypocrisy on Syria, The New York Times, http://www.nytimes.com/2015/11/28/opinion/president-obamas-hypocrisy-on-syria.html? r=0 (accessed Aug 2016)

6. www.offendum.com (accessed Aug 2016)

7. Rawls, John, (2003) Justice as Fairness. A Restatement, 1; Harvard University Press, Cambridge, MA.

8. Versus: Hip Hop on Trial Debate, https://www.youtube.com/watch?v=r3-7Y0xG89Q (accessed Aug 2016)

9. Alridge, D. P. and Stewart, J. B., (2005) Introduction: Hip Hop in History: Past, Present, and Future, The Journal of African American History, 90. 3 The History of Hip Hop, 193.

10. Somers-Willet, S., (2009) The Cultural Politics of Slam: Race, Identity, and the Performance of Popular Verse in America, 70-72, 101, 104105, University of Michigan Press, Ann Arbor, MI.

11. Blanchard, B. The Social Significance of Rap \& Hip-Hop Culture, Ethics of Development in a Global Environment, Stanford University, https://web.stanford.edu/class/e297c/poverty prejudice/mediarace/socialsignificance.htm (accessed Aug 2016)

12. Williams, J. (2011) Historicizing the Breakbeat: Hip Hop's Origins and Authenticity, Song and Popular Culture 56, $137-139$.

13. Grow, K., Riot on the Set: How Public Enemy Crafted the Anthem "Fight the Power," in Rolling Stone http://www.rollingstone.com/music/news/riot-on-the-set-how-public-enemy-crafted-the-anthem-fight-the-power-20140630 (accessed Aug 2016)

14. Ramsaran, Dave and Simona J Hill, (2009) Hip Hop and Inequality: Searching for the "Real" Slim Shady, 25, Cambria Press, Amherst, New York.

15. Tate, G. Hip Hop: Music and Cultural Movement, in Britannica Online https://www.britannica.com/topic/hip-hop (accessed Aug 2016)

16. Bradley, Adam and Andrew DuBois eds (2010) NWA in The Anthology of Rap, 232, Yale University Press, New Haven, CT

17. Alex, Pate (2009) Defining Rap/Poetry, in African American Cultural Theory and Heritage : In the Heart of the Beat : The Poetry of Rap, 27, Scarecrow Press, Lanham, MD

18. Haupt, A., (2003) Hip-Hop, Gender and Agency in the Age of Empire, in Agenda: Empowering Women for Gender Equity, 57, Urban Culture, 22.

19. Simon, S. Hip Hop: Today’s Civil Rights Movement? NPR http://www.npr.org/templates/story/story.php? storyId=1178621 (accessed Aug 2016)

20. Reed, T. V., (2005) Art of Protest: Culture and Activism from the Civil Rights Movement to the Streets of Seattle, 14, University of Minnesota Press, Minneapolis, MN.

21. Lake, T., (2011) Cultural Resources, in The African American Lectionary, http://www.theafricanamericanlectionary.org/culturalaids.asp (accessed July 2016)

22. Rabaka, Railand, (2012) Hip Hop's Amnesia: From Blues and the Black. Women's Club Movement to Rap and the Hip Hop Movement, 217, Lexington Books, Lanham, MD.

23. Bynoe, Y., (2002) Getting Real about Global Hip Hop, Georgetown Journal of International Affairs 3.1, Special: 9/11: Facing A New Threat, 80-82.

24. Dinan, S. (2016). State Department Sets New Single-Day Record for Syrian Refugee Approvals, The Washington Times, http://www.washingtontimes.com/news/2016/mav/24/state-department-sets-single-day-record-for-syrian/ (accessed Aug 2016)

25. Bayoumi, Moustafa, (2009) How Does It Feel to Be a Problem? Being Young and Arab in America, 3. Penguin Books, New York City, NY.

26. McCarthy and Jacobs, Muslim Databases and "Rabid Dogs": Trump, Carson and GOP in Explosion of Rhetoric over Syrians, The Guardian, https://www.theguardian.com/us-news/2015/nov/20/muslim-databases-and-rabid-dogs-gop-in-ugly-scrambleto-vilify-syrian-refugees (accessed July 2016)

27. Lithwick, D. and Reiman Henneman, L., Refugee-Fearing Mayor Wants to Round Them Up, Slate http://www.slate.com/articles/news_and_politics/jurisprudence/2015/11/roanoke_mayor_on_refugees_and_japanese_inter nment_camps.html (accessed July 2016)

28. Safieh, R., (2013) Identity, Diaspora, and Resistance in Palestinian Hip-Hop, in Palestinian Music and Song: Expression and Resistance Since 1900 (Kanaaneh, M., Thorsen, S. M., Bursheh, H., McDonald, D. A. Eds) 69-72, Indiana University Press, Bloomington.

29. n.a. Halal Hip Hop, Beliefnet, http://www.beliefnet.com/entertainment/music/2006/04/halal-hip-hop.aspx (accessed July 2016)

30. Peek, Lori, (2010) Behind the Backlash: Muslim Americans after 9/11, 5. Temple University Press, Philadelphia, PA. 
31. Lichtblau, E. (2015) Crimes Against Muslim Americans and Mosques Rise Sharply, in The New York Times, http://www.nytimes.com/2015/12/18/us/politics/crimes-against-muslim-americans-and-mosques-rise-sharply.html?_r=0 (access July 2016)

32. Davy, S. For Hip-hop Artist Omar Offendum, Apathy toward Syria Is Not an Option, Public Radio International, http://www.pri.org/stories/2015-05-04/hip-hop-artist-omar-offendum-apathy-toward-syria-not-option (accessed July 2016)

33. Style, A. MOCAfest 2015: Omar Offendum Preaches Love and Justice with Hip-Hop, Aquila-style.com. http://www.aquilastyle.com/wief-marketplace-of-creative-arts/performance-arts/mocafest-2015-omar-offendum-preaches-love-and-justicewith-hip-hop/106280/ (accessed July 2016)

34. Rhythms, Rebels, and Resistance: Omar Offendum on Youth Politics in the Middle East, Sydney Ideas, http://sydney.edu.au/sydney ideas/lectures/2015/omar offendum.shtml (accessed July 2016)

35. Iandoli, K., (2012) Beats, Rhymes, and Death, Vice Media, http://www.vice.com/en ca/read/beats-rhymes-and-death0000345-v19n11 (access July 2016)

36. N.a (2002) Topographic Map of Syria, in Nations Online http://www.nationsonline.org/oneworld/map/syria-topographicmap.htm (accessed July 2016)

37. Mark, J. Joshua. Hammurabi, in Ancient History Encyclopedia, http://www.ancient.eu/hammurabi// (accessed December 2016)

38. Dawishe, Adeed, (2016) Arab Nationalism in the Twentieth Century: From Triumph to Despair, 2-3, 125. Princeton University Press, Princeton, NJ.

39. Il-Khanid Dynasty in The Encyclopedia Britannica, https://www.britannica.com/topic/Il-Khanid-dynasty (accessed December 2016)

40. Shamoun, Sam, Abraham and the Child of Sacrifice: Isaac or Ishmael? in Answering-Islam.org, http://www.answeringislam.org/Shamoun/sacrifice.htm (accessed December 2016)

41. Gualtieri, Sarah (2009) Claiming Whiteness: Syrians and Naturalization Law in Between Arab and White: Race and Ethnicity in the Early Syrian American Diaspora, University of California Press, Oakland, CA

42. A Community of Many Worlds: Arab Americans in New York City, in Allied Media Corp. http://www.allied-media.com/ArabAmerican/NY-Arabs.htm (accessed December 2016)

43. The Moor Next Door, Smile, in The Moor Next Door Wordpress, https://themoornextdoor.wordpress.com/2011/08/09/6837/ (access July 2016)

44. Said, Edward, (1978) Orientalism, 4-15, Routledge, London, UK.

45. Kipling, Rudyard. The White Man's Burden, in Reading About the World: A Reader for the Study of World Civilizations, Washington State University, https://public.wsu.edu/ brians/world civ/worldcivreader/world civ reader 2/kipling.html (accessed December 2016)

46. Oakley, C., US Imperialism and the War for the Middle East, in Marxist Left Review, http://marxistleftreview.org/index.php/no8-winter-2015/118-us-imperialism-and-the-war-for-the-middle-east (accessed July 2016)

47. Woodward, D. The Middle East during World War I, in BBC History, http://www.bbc.co.uk/history/worldwars/wwone/middle east 01.shtml (accessed July 2016)

48. Jwaideh, W. Ash-Sharif al-Idrisi, Arab Geographer, in Encyclopedia Britannica, https://www.britannica.com/biogra phy/alSharif-al-Idrisi (accessed July 2016)

49. Reynolds, Gabriel (2004) A Muslim Theologian in the Sectarian Milieu: Abd al-Jabbar and the Critique of Christian Origins, 68, Brill, Leiden, Netherlands.

50. Goody, Jack, (2010). Rebirth in Islam in Renaissances: The One or the Many? 94-145, Cambridge University Press, Cambridge, UK.

51. Yule, Henry, A. C., (2013) Burnell Hobson-Jobson: The Definitive Glossary of British India, Oxford University Press, Oxford, UK.

52. Pirbhai, Mariam, (2009) Mythologies of Migration, Vocabularies of Indenture: Novels of the South Asian Diaspora in Africa, the Caribbean, and Asia-Pacific, $1^{\text {st }}$ edition, 108, University of Toronto Press, Toronto, Canada.

53. Freire, P. (2000) Pedagogy of the Oppressed, 30 $0^{\text {th }}$ Anniversary Edition, Bloomsbury Academic.

54. Hokayem, Emile (2013) Syria's Uprising and the Fracturing of the Levant, 153, The International Institute for Strategic Studies, London, UK

55. Zachs, Fruma, and Sharon Halevi, (2015) Gendering Culture in Greater Syria: Intellectuals and Ideology in the Late Ottoman Period, 8 , I.B. Tauris, New York City, NY.

56. Tekdal Fildis, Ayse, (2011) The Troubles in Syria Spawned by French Divide and Rule, Middle East Policy Council, 8.4, http://www.mepc.org/journal/middle-east-policy-archives/troubles-syria-spawned-french-divide-and-rule (accessed December 2016)

57. Zonszein, M. Walled off: 12 Years of Israel's Separation Barrier, in Aljazeera, http://america.aljazeera.com/articles/2014/3/12/visual-activism-activestillsphotographsthebarrierwall.html (accessed July 2016)

58. Natan, Y. (2006) Moon-o-theism. Volume II. Create Space, 411. 
59. Watson Institute, (2015) Costs of War, Brown University, http://watson.brown.edu/costsofwar/costs/human/civilians/iraqi (accessed December 2016)

60. Sami Matar, Samimatar.com, http://samimatar.com/ (accessed December 2016)

61. Faham, Amr, "Comments to Omar Offendum’s \#SYRIA," Youtube, 2015, https://www.youtube.com/watch?v=TXjEWrhkb6g\&lc=z13fzdf45pzyyxkdw232tphagyanhzysb (accessed December 2016)

62. Offendum, Omar, “\#SYRIA,” Offendum Blogspot, 2012, http://offendum.blogspot.com/2012/03/syria.html (accessed December 2016)

63. Associate Press, (2011) Syrian Uprising Song Writer Meets Gruesome End, CBS News. http://www.cbsnews.com/news/syrian-uprising-songwriter-meets-gruesome-end/ (accessed July 2016)

64. The Desmond Tutu Peace Foundation Exhibitions, The Desmond Tutu Peace Foundation. http://www.tutufoundationusa.org/exhibitions.html (accessed July 2016)

65. Offendum, Omar, USA. Pdx.edu. Portland State University, http://www.pdx.edu/middle-east-studies/event/art-andnonviolent-resistance-syria-featuring-hip-hop-artist-omar-offendum?delta $=0$ (accessed July 2016)

66. Fleming, E. (2011) Hot, Loud, Angry and Political for Justice, Salem-news.com, http://www.salemnews.com/articles/february282011/political-jutice-ef.php (accessed July 2016)

67. qtd. in Davy, S. For Hip-hop Artist Omar Offendum, Apathy toward Syria Is Not an Option, Public Radio International, http://www.pri.org/stories/2015-05-04/hip-hop-artist-omar-offendum-apathy-toward-syria-not-option (accessed July 2016)

\section{ABOUT THE STUDENT AUTHORS}

Harry Olafsen is currently pursuing a Bachelor of Arts in History and English at Saint Francis University in Loretto, Pennsylvania. His emphasis on the plight of Syrian refugees and social responsibility has emerged from multiple research assignments about the Middle East and Islam, particularly with a focus on women's rights. His other work focuses on women's diaries (mainly housewives) from the American Civil War and how each woman's personal experience helped to perpetuate the war effort.

Mohammed Ali is pursuing a Bachelor's degree at Indiana University of Pennsylvania hoping to become a physician. His work on the Syrian crisis first began with a public presentation on the health issues children of Syrian refugees' encounter. His interest in social justice drives him to become engaged in local equity issues and thus a responsible citizen.

Mikayla McCord is currently pursuing a Bachelor of Business in International Business and Economics degree with a focus in Portuguese and Spanish at the University of South Carolina in Columbia, South Carolina. Her work on empowerment through music in this research project stemmed from both an interest in international affairs and social justice. Some of her other work has included research on the history of the conflict between Palestinians and Israelis.

\section{PRESS SUMMARY}

In this paper, we argue that Syrian-American educator, performer, poet, and musician Omar Offendum transforms his hip-hop music into an effective tool of political propaganda that can raise social consciousness to the needs of Syrians today and harbor social justice for Syria. Employing both English and Arabic, Offendum performs the authenticity of his hybrid identity and linguistically outlines a cultural space for a diverse audience to come together. Offendum does so because he feels the obligation and responsibility to fight for the rights of the often stereotyped and oppressed Middle Eastern individuals in both the East and the West, in order for all people to unite in the spirit of resistance and solidarity with one another. 
Print Edition ISSN 1536-4585

Online Edition ISSN 2375-8732 